Aus der Abteilung Gastroenteropathologie

(Prof. Dr. med. L. Füzesi)

Im Zentrum Pathologie

der Medizinischen Fakultät der Universität Göttingen

\begin{abstract}
Vergleich Gastrointestinaler Stromatumoren (GIST) mit
Exon-11-Punktmutationen und Exon-11-Deletionen

nach klinisch-pathologischen Parametern und Lokalisation
\end{abstract}

\author{
INAUGURAL-DISSERTATION \\ zur Erlangung des Doktorgrades \\ der Medizinischen Fakultät \\ der Georg-August-Universität zu Göttingen
}

vorgelegt von

\title{
Ruben Sengewein
}

aus

Bonn

Göttingen 2010 
Dekan: $\quad$ Prof. Dr. med. C. Frömmel

1. Berichterstatter: $\quad$ Priv.-Doz. Dr. med. F. Haller

2. Berichterstatter/in: Prof. Dr. med. Haase

3. Berichterstatter/in: Prof. dr. med., Dr. rer. nat. Crozier

Tag der mündlichen Prüfung: 02.03.2011 


\section{Inhalt}

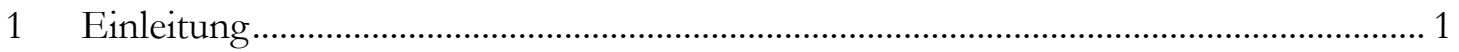

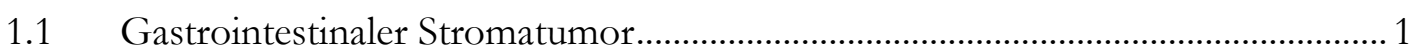

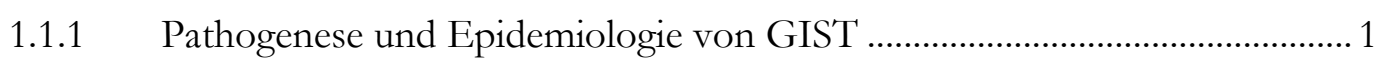

1.1.2 Klinisch-pathologische Parameter und Prognosefaktoren ............................... 4

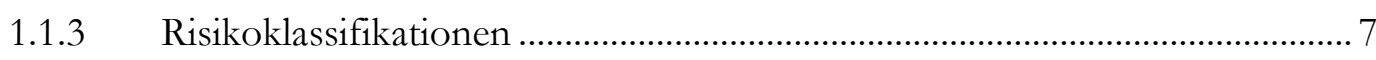

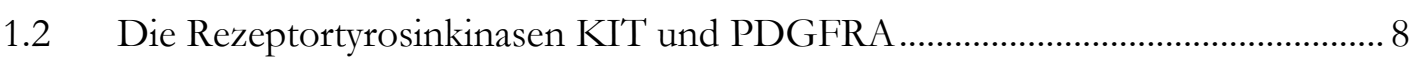

1.3 Mutationen des c-KIT und des PDGFRA-Gens bei GIST .................................... 9

1.3.1 KIT-Exon-11-Mutationen und ihre prognostische Bedeutung .................... 10

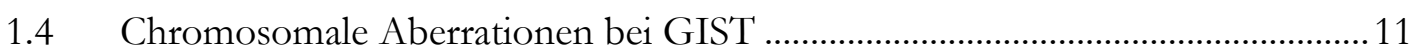

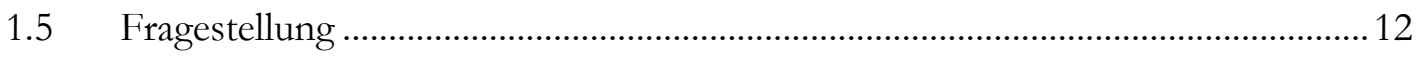

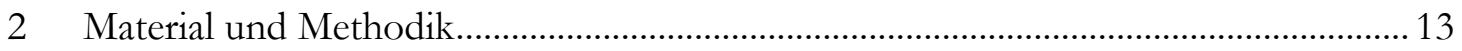

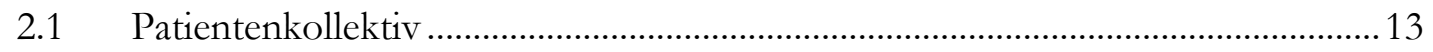

2.2 DNA-Isolierung aus formalinfixierten und paraffineingebetteten

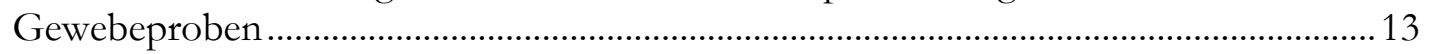

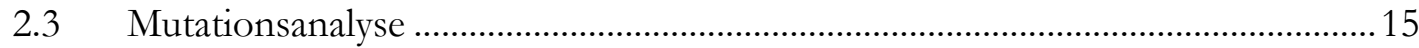

2.3.1 Amplifizierung der betrachteten DNA- Abschnitte für die Mutationsanalyse durch Polymerase-Kettenreaktion (PCR) .......................................... 15

2.3.2 Aufreinigung der PCR-Produkte ……………................................................. 18

2.3.3 Vorbereitung und Versenden der Proben zum Sequenzieren ........................ 19

2.3.4 Sequenzierung der amplifizierten Genabschnitte............................................ 19

2.3.5 Auswertung der DNA-Sequenzen................................................................... 20

2.4 Die Detektion von chromosomalen Veränderungen mittels CGH......................24

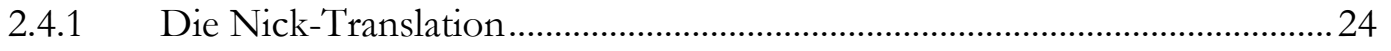

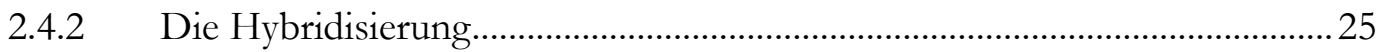

2.4.3 Aufreinigung, Blockung, Detektion .................................................................2 27

2.4.4 Auswertung und Beschreibung der Ergebnisse ...............................................2 28

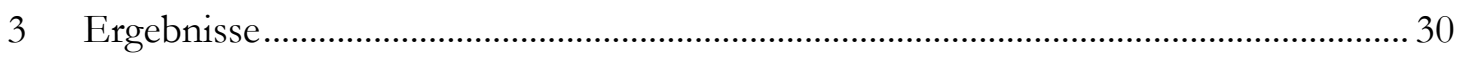

3.1 Darstellung der klinisch-pathologischen Parameter................................................. 30

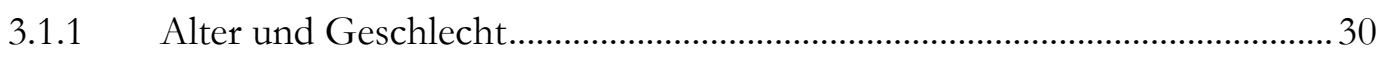

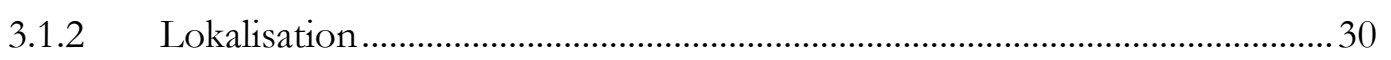

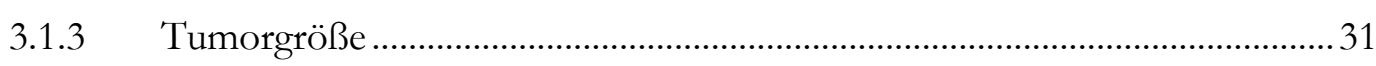

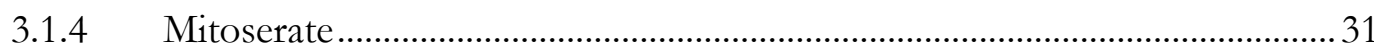


3.1.5 Risikoklassifikation nach Miettinen und Lasota (2006) ..................................32

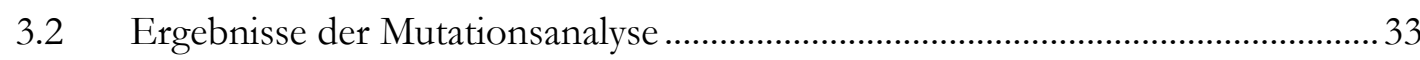

3.2.1 Beschreibung der Exon-11-Punktmutationen ...................................................33

3.2.2 Lokalisation der Punktmutationen bezogen auf KIT-Exon-11 .....................35

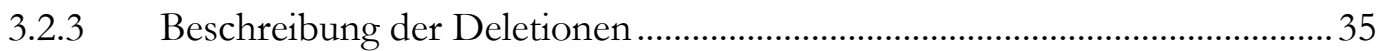

3.2.4 Lokalisation der Deletionen bezogen auf KIT-Exon-11 ……………...........38

3.3 Vergleich der Mutationstypen mit den klinisch-pathologischen Parametern......38

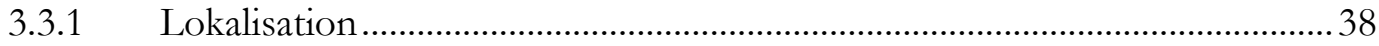

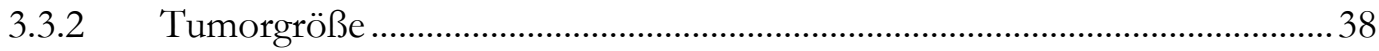

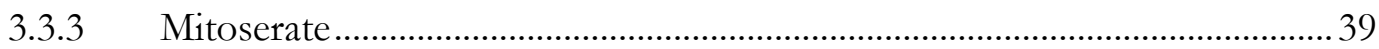

3.3.4 Risikoklassifikation nach Miettinen und Lasota (2006) ................................... 40

3.4 Vergleich der Mutationstypen mit den klinisch-pathologischen Parametern

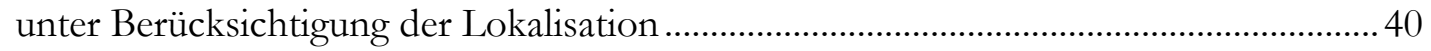

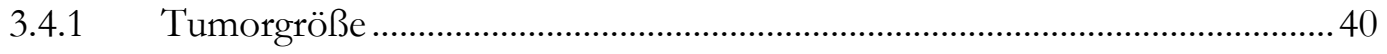

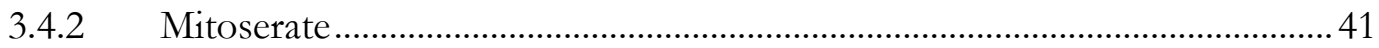

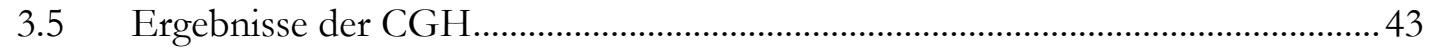

3.5.1 Vergleich der chromosomalen Aberrationen mit der Lokalisation .............. 43

3.6 Vergleich der Ergebnisse der Mutationsanalyse und der CGH.............................45

3.6.1 Häufigkeit chromosomaler Aberrationen im Vergleich von GIST mit einer KIT-Exon-11-Punktmutation bzw. Deletion................................................................. 45

3.6.2 Häufigkeit chromosomaler Aberrationen im Vergleich von GIST mit einer KIT-Exon-11-Punktmutation bzw. Deletion unter Berücksichtigung der

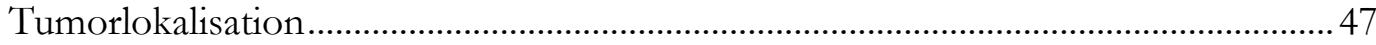

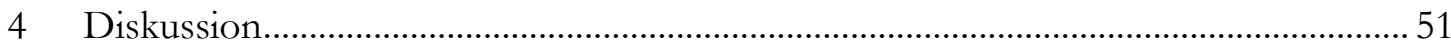

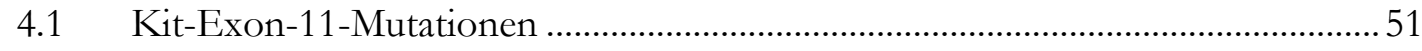

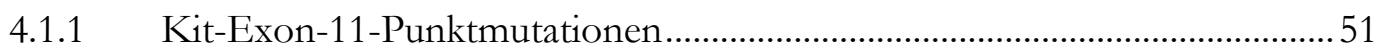

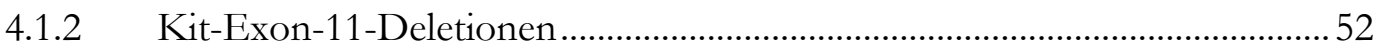

4.2 Korrelation zwischen GIST mit Exon-11-Punktmutation und Deletion und klinisch-pathologischen Parametern ............................................................................. 53

4.3 Beobachtete chromosomale Aberrationen bei den untersuchten GIST .............. 55

4.4 Korrelation zwischen proximal und distal gelegenen GIST hinsichtlich der

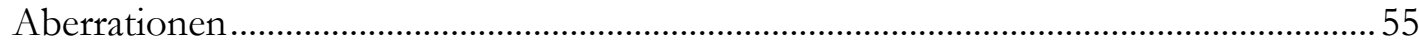

4.5 Korrelation zwischen Mutationstyp und Aberrationen ......................................... 57

4.6 Korrelation zwischen Punktmutation/Deletion und chromosomalen Aberrationen unter besonderer Berücksichtigung der Lokalisation 


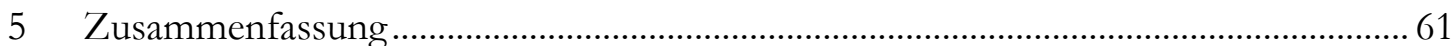

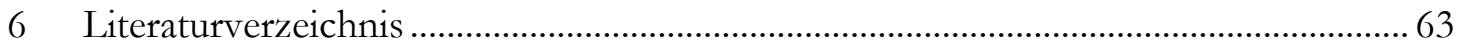




\section{Tabellenverzeichnis}

Tabelle 1-1: Immunhistochemische Differentialdiagnose für Spindelzelltumoren des Gastrointestinaltraktes aus Fletcher CD et al. (2002) S.461 ................................................... 3

Tabelle 1-2: Risikoklassifikation nach Fletcher CD et al. (2002), S.464 .................................. 7

Tabelle 1-3: Risikoklassifikation nach Miettinen und Lasota (2006), S.1474 ........................ 8

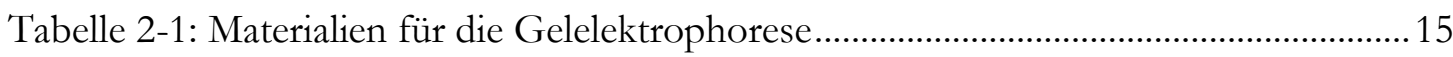

Tabelle 2-2: PCR-Primersequenzen zu den Genen KIT und PDGFRA ............................... 16

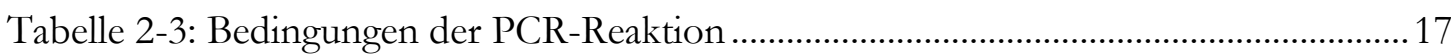

Tabelle 2-4: Sequenzierungs-Primersequenzen zu den Genen KIT und PDGFRA .......... 19

Tabelle 2-5: Auflistung der 20 primären Aminosäuren ......................................................... 21

Tabelle 2-6: Materialien zur Hybridisierung im Rahmen der CGH......................................2 26

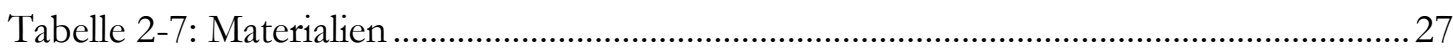

Tabelle 3-1: Vergleich von 63 proximal und 37 distal gelegenen GIST nach Größe und

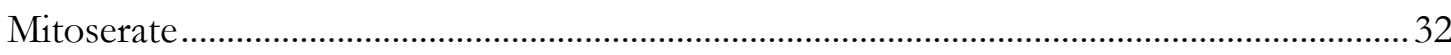

Tabelle 3-2: Beschreibung der 50 Exon-11-Punktmutationen auf DNA und Protein-

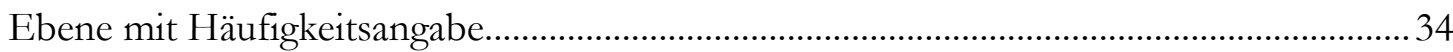

Tabelle 3-3: Beschreibung der Exon-11-Deletionen auf DNA und Protein-Ebene mit

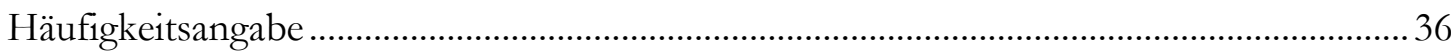

Tabelle 3-4: Vergleich der Tumorgröße und Mitoserate bei GIST mit Exon-11-

Punktmutation und Deletion.

Tabelle 3-5: Tumorgröße und Mitoserate bei GIST mit Exon-11-Punktmutation und Deletion nach Lokalisation

Tabelle 3-6: Statistischer Vergleich von Tumorgröße und Mitoserate von GIST mit Exon-11-Punktmutation und Deletion nach Lokalisation..................................................... 42 Tabelle 3-7: Vergleich der Chromosomalen Aberrationen nach Lokalisation; Anzahl der Fälle in Klammern; statistischer Vergleich von Verlusten und Zugewinnen mit Chi-

Square, von Aberrationen mit t-test für unverbundene Stichproben...................................... 44

Tabelle 3-8: Vergleich chromosomaler Aberrationen zwischen Exon-11-Punktmutationen

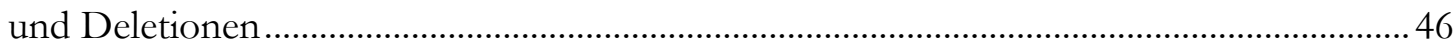

Tabelle 3-9: Vergleich chromosomaler Aberrationen bei GIST mit einer Exon-11-

Punktmutation, unterschieden nach der Lokalisation .48

Tabelle 3-10: Vergleich Chromosomaler Aberrationen bei GIST mit Exon-11-Deletionen nach der Lokalisation

Tabelle 3-11: Vergleich Chromosomaler Aberrationen bei proximal gelegenen GIST mit Exon-11-Punktmutation und Deletion 49

Tabelle 3-12: Vergleich Chromosomaler Aberrationen bei distal gelegenen GIST mit Exon-11-Punktmutation und Deletion 


\section{Abbildungsverzeichnis}

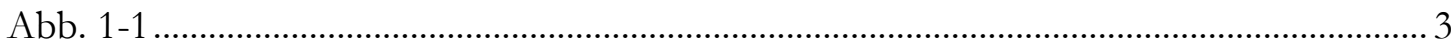

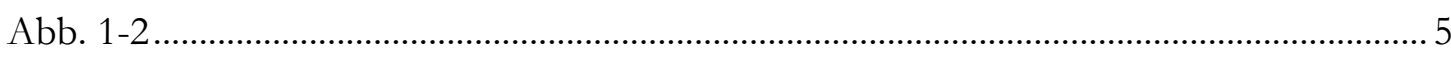

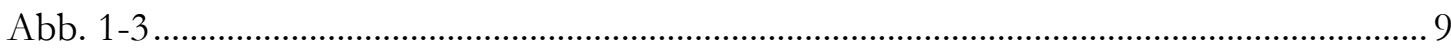

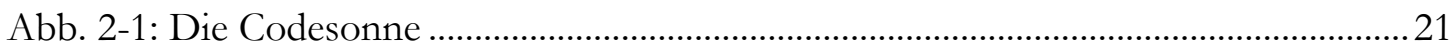

Abb. 2-2: Graphische Darstellung einer reinen Kit-Exon-11-Deletion aus dem eigenen

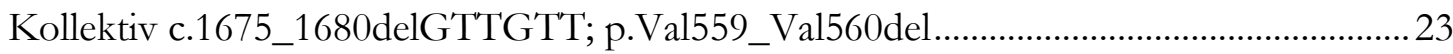

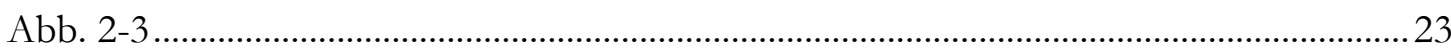

Abb. 3-1: Altersverteilung der 49 weiblichen und 51 männlichen Patienten mit GIST .... 30

Abb. 3-2: Größenverteilung von 63 proximalen und 37 distalen GIST ................................. 31

Abb. 3-3: Mitoserate/50HPFs nach 63 proximalen und 37 distalen GIST .......................... 32

Abb. 3-4: Risikogruppenverteilung von 100 GIST nach der Risikoklassifikation von

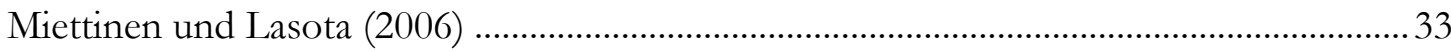

Abb. 3-5: Anzahl der Fälle mit Exon-11-Punktmutationen, bezogen auf das jeweils

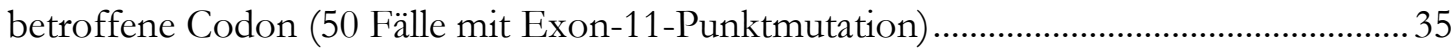

Abb. 3-6: Codonanzahl der Exon-11-Deletion mit Angabe ihrer Länge ............................... 37

Abb. 3-7: Anzahl der Fälle mit Deletionen, bezogen auf das jeweils betroffenen Codon

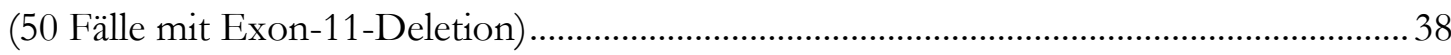

Abb. 3-8: Tumorgröße bei GIST mit Exon-11-Punktmutation und Deletion .......................39

Abb. 3-9: Mitoserate/50HPF bei GIST mit Exon-11-Punktmutation und Deletion......... 39

Abb. 3-10: Maximal Tumorgröße von 100 GIST nach Mutationstyp und Lokalisation... 41

Abb. 3-11: Mitoserate /50HPF von 100 GIST nach Mutationstyp und Lokalisation ...... 42

Abb. 3-12: Chromosomale Aberrationen von 100 GIST, Verluste wurden nach unten

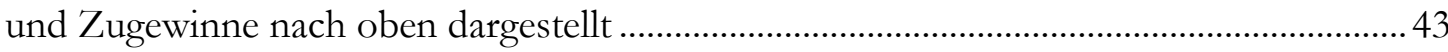

Abb. 3-13: Chromosomale Aberrationen bei 63 proximal gelegenen GIST.......................... 45

Abb. 3-14: Chromosomale Aberrationen bei 37 distal gelegenen GIST ............................... 45

Abb. 3-15: Chromosomale Verluste und Zugewinne von 50 GIST mit einer Exon-11-

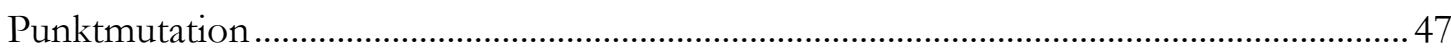

Abb. 3-16: Chromosomale Verluste und Zugewinne von 50 GIST mit einer Exon-11-

Deletion 


\section{Abkürzungsverzeichnis}

$\begin{array}{ll}\text { AFIP } & \text { Armed Forces Institute of Pathology } \\ \text { ATP } & \text { Adenosintriphosphat } \\ \text { bp } & \text { Basenpaar } \\ \text { CD } & \text { Cluster of Differentiation } \\ \text { CDK } & \text { Cyclin-dependent kinase } \\ \text { CGH } & \text { Chromosomale genomische Hybridisierung } \\ \text { ddNTP } & \text { Didesoxy-Nucleosid-Tri-Phosphat } \\ \text { del } & \text { Deletion } \\ \text { delins } & \text { Deletion/Insertion } \\ \text { DNA } & \text { Desoxyribonucleinsäure } \\ \text { dNTP } & \text { Desoxy-Nucleosid-Tri-Phosphat } \\ \text { E-Cup } & \text { Eppendorf-Cup } \\ \text { ED } & \text { Extrazelluläre Domäne } \\ \text { EDTA } & \text { Ethylendiamintetraacetat } \\ \text { enh } & \text { enhancement }\end{array}$

FNCLCC Fédération Nationale des Centres de Lutte Contre le Cancer

GIST Gastrointestinaler Stromatumor

HE Hämatoxylin-Eosin

HGVS Human Genome Variation Society

HPF High-Power-Field

Ins Insertion

ISCN International System for human Cytogenetic Nomenclature

Ish In-situ-Hybridisierung

JMD Juxtamembranäre Domäne

$\mathrm{Kb} \quad$ Kilobase/-n

$\mathrm{KCl} \quad$ Kaliumchlorid

KIT v-kit Hardy-Zuckerman 4 feline sarcoma viral oncogene homolog

$\mathrm{Mb} \quad$ Megabase/-n

mRNA Messenger Ribonukleinsäure

NCBI National Center for Biotechnology Information

PDGF Platelet-derived growth-factor

PDGFRA Platelet-derived-growth-factor-receptor alpha

PF Paraffin

PM Punktmutation

RB Retinoblastoma

rev reverse 
SCF Stammzellfaktor

SMA Smooth Muscle Antigen

SSC Strong Salt Concentration

STAT Signal transducer and activator of transcription

TBE Tris-Borat-EDTA

Ter terminal

TK1 Tyrosin-Kinase-Domäne 1

TK2 Tyrosin-Kinase-Domäne 2

WT Wildtyp 


\section{Einleitung}

\subsection{Gastrointestinaler Stromatumor}

\subsubsection{Pathogenese und Epidemiologie von GIST}

Der Gastrointestinale Stromatumor (GIST) ist mit 80\% der häufigste mesenchymale Tumor des Gastrointestinaltraktes (Hirota et al. 2001). Insgesamt sind GIST relativ selten mit einer jährlichen Inzidenz von ca. 0,68 - 1,45 Neuerkrankungen pro 100.000 Einwohner, und machen unter 1\% aller Tumoren des Gastrointestinaltraktes aus (Nilsson et al. 2005, Tran et al. 2005, Tryggvason et al. 2005). In Deutschland ergeben sich geschätzt ca. 600 - 1200 Neuerkrankungen an GIST pro Jahr.

Die Gruppe der mesenchymalen Tumoren des Gastrointestinaltraktes beinhaltet verschiedene Entitäten unterschiedlicher Dignität, die aus unterschiedlichen histologischen Geweben und Zelltypen entspringen bzw. solchen zugeordnet werden können. Mesenchymale Tumoren wurden schon 1941 von Golden und Stout beschrieben. Diese wurden allgemein als Tumoren mit glatter Muskulatur als Ursprung angesehen und uneinheitlich in Leiomyome, Leiomyosarkome, bizarre Leiomyome oder Leiomyoblastome unterteilt (Melnick 1932, Golden und Stout 1941, Stout 1962, Appelman 1986, Dei Tos 2003). Nach Einführung der Elektronenmikroskopie in den späten 60er Jahren beobachtete man in einigen dieser Tumoren neurogene Merkmale, die man bei glatten Muskelzellen nicht findet (Kay und Still 1969, Welsh 1969). Als Anfang der 80er Jahre erste immunhistochemische Antikörper zur Verfügung standen, fand man bei den Tumoren eine sehr heterogene Ausprägung von verschiedenen neurogenen (S100) und myogenen Markern (Aktin, Desmin), wodurch die Vermutung bestätigt wurde, dass es sich hierbei um eine sehr heterogene Gruppe von Tumoren mit unterschiedlicher Differenzierung handelt (Saul et al. 1987, Franquemont und Frierson 1992, Miettinen et al. 1995, Erlandson et al. 1996). 1983 wurde erstmals von Mazur und Clark der Begriff 'Gastrointestinaler Stromatumor` eingeführt (Mazur und Clark 1983). Dieses fand aufgrund noch nicht spezifisch nachweisbarer Oberflächenmarker zunächst wenig Beachtung. Man war sich einer genauen Klassifikation nicht sicher, und es bestand Uneinigkeit über die Einteilung. 1995 fand man heraus, dass GIST häufig das Oberflächenprotein CD34 exprimieren, womit die neue Entität relativ spezifisch abgegrenzt werden konnte (Miettinen et al. 1995). Allerdings blieben weitere ebenfalls CD34-positive Differenzialdiagnosen. Daher reichte CD 34 allein als ein nur relativ spezifischer Marker zunächst nicht aus.

Der Nachweis von neurogenen und myogenen Strukturen gab letztendlich den Hinweis auf die interstitiellen Zellen von Cajal, bei denen sich beide Strukturen finden lassen. Diese Zellen stellen einen Vermittler zwischen dem autonomen Nervensystem und den glatten 
Muskelzellen des Intestinaltraktes dar, und funktionieren in der muskulären Wandung des Gastrointestinaltraktes als sogenannte Schrittmacherzellen (Faussone-Pellegrini und Thuneberg 1999, Andersson et al. 2002). Die interstitiellen Zellen von Cajal wurden zum ersten Mal bereits im Jahre 1893 von Cajal beschrieben (Cajal 1893). In mehreren Studien wurde festgestellt, dass die interstitiellen Zellen von Cajal das Gen c-KIT (alternativ Antigen CD117) exprimieren (Maeda et al.1992, Huizinga et al. 1995, Isozaki et al. 1995, Sircar et al. 1999), wobei das c-KIT-Gen zur Familie der Typ-III-Rezeptor-Tyrosin-Kinasen gehört. Von Hirota et al. wurde 1998 die Expression des KIT-Genes bei GIST beobachtet, was letztendlich die Vermutung des Ursprungs von GIST aus den interstitiellen Zellen von Cajal oder einer gemeinsamen Vorläuferstammzelle nahelegte, weshalb nun GIST als eigene Tumorentität abgegrenzt werden konnte. Weitere Studien belegten die Expression des KITGenes bei GIST (Kindblom et al. 1998, Sarlomo-Rikala et al. 1998, Robinson et al. 2000).

In mehreren großen Studien an mesenchymalen Tumoren des Gastrointestinaltraktes unter der Verwendung der neuen Antikörper CD34 und c-KIT konnte festgestellt werden, dass die überwiegende Mehrzahl aller GIST positiv für c-KIT ist. Allerdings ist dabei anzumerken, dass Mutationen im KIT-Gen zwar die KIT-Funktion beeinflussen, nicht jedoch den Grund für die KIT-Expression in GISTs darstellen (Miettinen und Lasota 2006). Die Mutation von c-KIT führt zur Daueraktivierung der Typ-III-Rezeptor-Tyrosin-Kinase, wodurch es zu einer unkontrollierten Zellteilung kommt (Heinrich et al. 2003b, Miettinen et al. 2006). Insgesamt wird bei ca. 60- 70\% aller GIST eine Mutation des c-KIT-Gens mit anschließender Daueraktivierung des Rezeptors beobachtet (Lasota et al. 1999, Rubin et al. 2001, Heinrich et al. 2003b, Duensing et al. 2004, Andersson et al. 2006, Lasota und Miettinen 2008). Bei den verbleibenden GIST wird in ca. einem Drittel eine Mutation im PDGFRA-Gen (Platelet-derived-growth-factor Receptor Alpha) beobachtet (Heinrich et al. 2003a, Corless et al. 2005, Medeiros et al. 2004, Lasota und Miettinen 2008). Hierbei handelt es sich um einen dem c-KIT sehr ähnlichen Rezeptor. In einigen wenigen GIST wird weder im c-KIT noch im PDGFRA-Gen eine Mutation gefunden (Lasota und Miettinen 2008). Diese GIST werden als Wildtyp-GIST bezeichnet, und machen ca. 10\% aller GIST aus (Antonescu et al. 2005). 


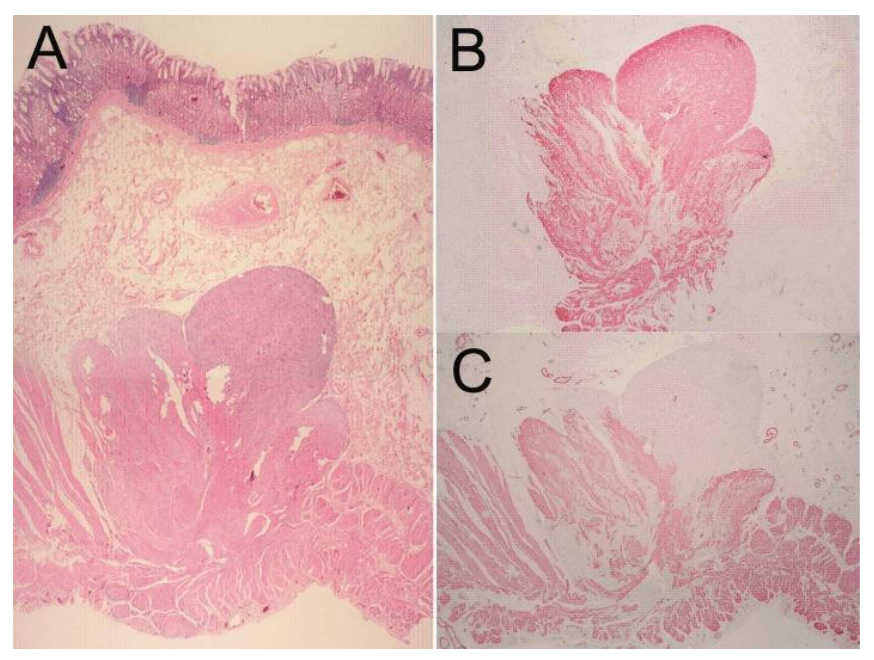

Abb. 1-1

0,5 cm großer GIST (Mikro-GIST) mit Ursprung in der muskulären Wandung des Magens, übernommen aus Haller (2008), S.2.

A: Querschnitt durch die Magenwand (H\&E x 20, oben Schleimhaut, unten muskuläre Wandung).

B: Immunhistochemische Färbung mit einem Antikörper gegen das CD117-Antigen markiert die Tumorzellen (CD117 x 20).

C: Immunhistochemische Färbung mit einem Antikörper gegen Aktin markiert die glatten Muskelzellen (Aktin x 20).

Tabelle 1-1: Immunhistochemische Differentialdiagnose für Spindelzelltumoren des Gastrointestinaltraktes aus Fletcher CD et al. (2002) S.461

\section{KIT}

(CD117)

\section{34}

SMA Desmin

GIST

$+\quad+$

$60-70 \%$

$+$

sehr selten $5 \%$

Tumor von den glatten

Muskelzellen ausgehend

$+10-15 \% \quad+\quad+$

selten

Schwannome

$+$

Fibromatosis

selten selten

$+\quad$ Selten

GIST treten im mittleren Erwachsenenalter (55-60 Jahre) auf. In seltenen Fällen werden GIST bei Kindern in der zweiten Lebensdekade beobachtet $(<1 \%)$ (Miettinen und Lasota 2006). Es gibt keine Geschlechtsbevorzugung (Nilsson et al. 2005), allerdings scheinen maligne GIST leicht vermehrt bei Männern vorzukommen (Miettinen und Lasota 2006). Zu ethnischen Unterschieden liegen bisher keine eindeutigen Studien vor (Lasota und Miettinen 2008). Familiäre Häufungen mit einer Keimbahnmutation von c-KIT wurden beschrieben 
(Lasota und Miettinen 2008). GIST bei Patienten mit Neurofibromatose Typ 1 (Andersson et al. 2005, Miettinen et al. 2006), Carney Trias (Carney 1983) und kindliche GIST (Miettinen et al. 2005, Prakash et al. 2005) weisen einen besonderen Phänotyp auf und zeigen in der Regel weder im KIT noch im PDGFRA-Gen eine Mutation (Lasota und Miettinen 2008).

\subsubsection{Klinisch-pathologische Parameter und Prognosefaktoren}

Makroskopisch erscheinen GIST als runde, scharf abgrenzbare, kapsellose Tumoren. Pseudokapseln können auftreten (Connolly et al. 2003). Ihre Schnittfläche präsentiert sich als fleischig und solide. Zentral können GIST zystische Degenerationen, Nekrosen oder Blutungen aufweisen. GIST treten meist uninodulär, seltener multinodulär auf. Mit zunehmender Größe können GIST entweder nach außen oder verdrängend ins Darmlumen wachsen. Dabei wird die Serosa vor sich hergeschoben und bleibt bei verstrichener Fältelung größtenteils erhalten. Es kann zu regressiven Veränderungen wie Ödembildung, Ulzerationen und Nekrosen kommen (Hillemanns und Hofler 2000, Sabah et al. 2004). GIST wachsen nicht invasiv und können auf Grund der oft erst späten und wenig spezifischen Symptome äußerst groß werden (bis $30 \mathrm{~cm}$ Durchmesser). Zu den ersten Symptomen zählen gastrointestinale Blutungen in Verbindung mit einer Anämie, Tumorruptionen bei akutem Abdomen oder Obstruktionen. Kleinere GIST werden eher zufällig bei endoskopischer Untersuchung oder intraoperativ gefunden. Zudem wurden in einer Studie bei vollständiger histologischer Aufarbeitung von Gastrektomie-Präparaten sogenannte Mikro-GIST mit einer Größe von $<0,5 \mathrm{~cm}$ in einer ungeahnt hohen Inzidenz gefunden (Kawanowa et al. 2006, Chetty 2008). Diese Mikro-GIST werden in den meisten Fällen als biologisch indolent eingestuft und sind klinisch wahrscheinlich nicht progredient (Chetty 2008). Zufällig endeckte GIST mit einer Größe von unter $1 \mathrm{~cm}$, sind häufig positiv für c-KIT (Corless et al. 2002). 

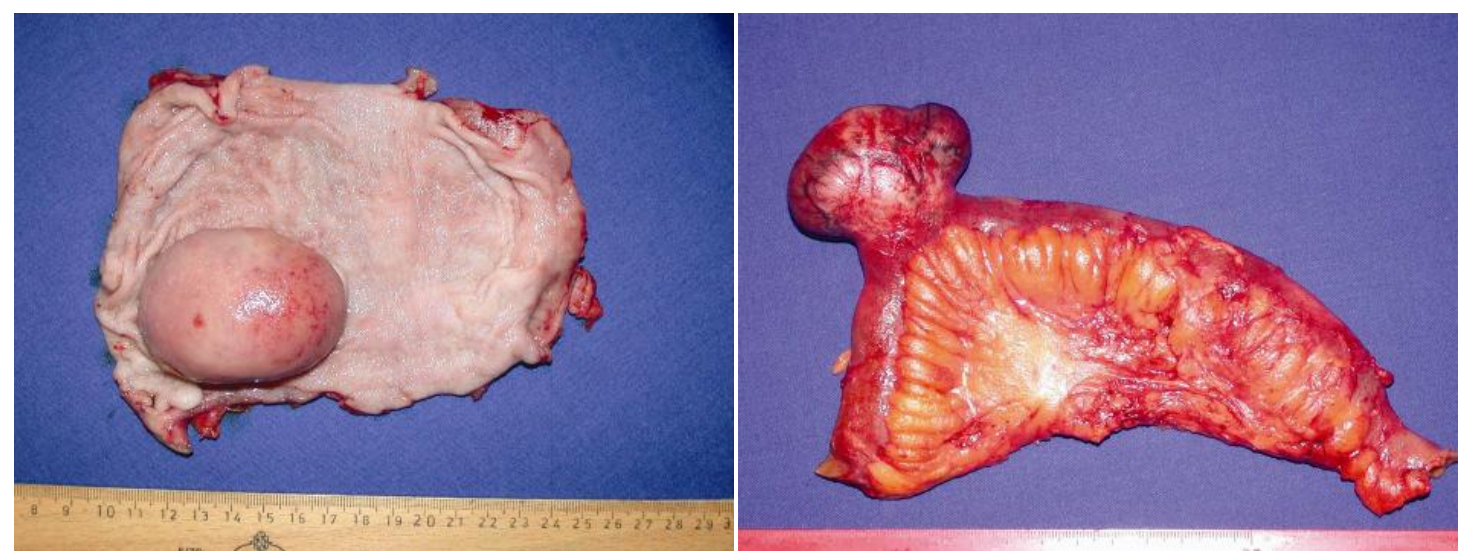

Abb. 1-2

Typische Wachstumsmuster von GIST. Links: Magenteilresektat mit einem nach innen gewachsenen $6,5 \mathrm{~cm}$ großen GIST mit darüber liegender, intakter Schleimhaut.

Rechts: Dünndarmteilresektat mit einem nach außen gewachsenen $5,5 \mathrm{~cm}$ großen GIST mit glattem Serosaüberzug, übernommen aus Haller (2008), S.5

Histologisch sind GIST zellreich und lassen sich in drei Hauptkategorien einteilen: spindelförmig (70\%), epitheloid (20\%) oder gemischtförmig (>10\%) (Füzesi 2003, Mechtersheimer et al. 2003, Corless et al. 2004, Miettinen et al. 2006). Es wurden bisher noch weitere, seltener auftretende Variationen mit einem auffälligen myxoiden Stroma, Gangliom oder Carcinoid-ähnlich wachsendem Erscheinungsbild, oder sehr selten ein pleomorphen Wachstumsmuster beschrieben (Fletcher CD et al. 2002).

Die Zytomorphologie lässt keinen sicheren Rückschluss auf die Prognose zu und eignet sich nur sehr bedingt für die Einschätzung der Dignität (Fletcher CD et al. 2002).

$\mathrm{Da}$ auch sehr kleine und mitotisch wenig aktive GIST metastasieren können, ist eine sichere Einteilung der Tumoren in benigne und maligne nicht möglich. Diese Beobachtung führte zu der Bezeichnung „Tumoren mit unsicherem malignen Potential“ (Miettinen et al. 2002, Miettinen et al. 2006).

Ca. $20-25 \%$ der GIST im Magen und ca. 40-50\% der intestinalen GIST sind maligne (Miettinen et al. 2006). 20-50\% aller klinisch auffälligen GIST metastasieren oder führen zum Lokalrezidiv nach der chirurgischen Resektion. GIST metastasiert am häufigsten in die Leber und am zweithäufigsten in die Abdominalhöhle (DeMatteo et al. 2000, Nilsson et al. 2005, Tran et al. 2005, Tryggvason et al. 2005, DeMatteo et al. 2008). Sehr selten treten Metastasen in Knochen, weichem Bindegewebe oder in der Haut auf. Im fortgeschrittenen Tumorstadium nach ausgedehnter Lebermetastasierung werden auch Lymphknoten- oder Lungenmetastasen gefunden. Spätmetastasen können auch noch 10 bis 15 Jahre nach chirurgischer Entfernung auftreten (Miettinen und Lasota 2006). Patienten mit bereits metastasierten Tumoren hatten vor Einführung der Therapie mit dem Tyrosinkinase-Inhibitor Ima- 
tinib eine verkürzte Überlebensdauer (Ng et al. 1992, DeMatteo et al. 2000, Fletcher JA und Rubin 2007).

Für die Abschätzung der Malignität wurde 2002 eine Risikoklassifikation erstellt, bei der das Malignitätsrisiko nach Größe und Mitosezahl eingeschätzt wird (Fletcher CD et al. 2002). Miettinen und Lasota (2006) beziehen zudem die Lokalisation mit ein. Auf Grund des dennoch unsicheren biologischen Potentials empfiehlt es sich bei allen GIST-Patienten, zeitlich nicht begrenzte klinische Kontrolluntersuchungen durchzuführen (Miettinen et al. 2002, Miettinen et al. 2006).

\section{Tumorgröße}

GIST sind durchschnittlich ca. $5 \mathrm{~cm}$ groß, wobei die Tumorgröße zwischen $0,1 \mathrm{~cm}$ und $33 \mathrm{~cm}$ variieren kann. Die Tumorgröße ist ein gut reproduzierbarer Faktor der nahezu in allen Untersuchungen signifikant mit dem klinischen Verhalten von GIST korreliert (Appelman 1986, Franquemont und Frierson 1992, Rudolph et al. 1998b, DeMatteo et al. 2000, Miettienen et al. 2005, Nilsson et al. 2005, Tran et al. 2005, Tryggvason et al. 2005, Miettienen et al. 2006, Rutkowski et al. 2007, DeMatteo et al. 2008). So finden sich bei kleinen GIST mit einer Größe von unter $2 \mathrm{~cm}$ sehr selten Metastasen, wohingegen GIST mit einer Größe von über $10 \mathrm{~cm}$ häufiger metastasieren.

\section{Mitosenanzahl}

Die Mitosenzahl wird vom Pathologen unter dem Lichtmikroskop ausgezählt, ist ein Maß für die Zellteilungsaktivität und korreliert somit mit der Wachstumsgeschwindigkeit des Tumors. Angegeben wird die Mitosenanzahl in 50 hochauflösenden Gesichtsfeldern bzw. High-Power-Fields (HPFs). Dabei entspricht dies einer Fläche von $10 \mathrm{~mm}^{2}$. Generell ist die Mitosenanzahl ein guter Parameter für die Beurteilung der Dignität von Weichteiltumoren, der in der gängigen Klassifikation der FNCLCC (Fédération Nationale des Centres de Lutte Contre le Cancer) Verwendung findet (Coindre et al. 1996). GIST weisen im Gegensatz zu anderen Sarkomen wesentlich weniger Mitosen auf (Rudolph et al. 1998a) und können auch bei niedriger Mitoserate metastasieren (Appelman 1986, Franquemont und Frierson 1992, Rudolph et al. 1998b, DeMatteo et al. 2000, Singer et al. 2002, Miettienen et al. 2005, Nilsson et al. 2005, Tran et al. 2005, Tryggvason et al. 2005, Miettienen et al. 2006c, Rutkowski et al. 2007, DeMatteo et al. 2008).

\section{Anatomische Lokalisation}

Generell können GIST im gesamten Gastrointestinaltrakt vom unteren Ösophagus bis hin zum Rektum auftreten. Am häufigsten findet sich GIST im Magen (50 - 60\%), gefolgt von 
Dünndarm (20 - 30\%), Dickdarm (10\%), Ösophagus (5\%) und seltener $(<5 \%)$ an anderen Stellen der Abdominalhöhle (Fletcher CD et al. 2002). Bereits 1986 erkannte man die Bedeutung der anatomischen Lokalisation hinsichtlich des klinischen Verlaufs (Appelman et al. 1986). In mehreren großen Studien ließ sich zeigen, dass gastrale GIST einen günstigeren klinischen Verlauf als GIST des Dick- oder Dünndarms haben (Miettinen et al. 2005a, Miettinen et al. 2006a, Miettinen et al. 2006c, DeMatteo et al. 2008).

\subsubsection{Risikoklassifikationen}

Nach Fletcher CD et al. (2002) wurde eine Risikostratifizierung zur Prognoseeinschätzung erstellt. Die Tumoren werden nach maximaler Größe in cm und Mitoserate/50 HPF in Risikogruppen eingeteilt. Die Risikoklassifikation beinhaltet folgende vier Gruppen: GIST mit sehr niedrigem Risiko, mit niedrigem Risiko, mit mittlerem Risiko und zuletzt GIST der Hochrisikogruppe (Tabelle 1-2).

Tabelle 1-2: Risikoklassifikation nach Fletcher CD et al. (2002), S.464

Tumorgröße

\begin{tabular}{lll}
\hline sehr niedrig & $<2 \mathrm{~cm}$ & $\leq 5$ Mitosen/50 HPF* \\
niedrig & 2 bis $5 \mathrm{~cm}$ & $\leq 5$ Mitosen/50 HPF* \\
mittel & $<5 \mathrm{~cm}$ & 6 bis 10 Mitosen $/ 50 \mathrm{HPF}^{*}$ \\
& $5 \mathrm{bis} 10 \mathrm{~cm}$ & $\leq 5 \mathrm{Mitosen} / 50 \mathrm{HPF}^{*}$ \\
hoch & $>5 \mathrm{~cm}$ & $>5 \mathrm{Mitosen} / 50 \mathrm{HPF}^{*}$ \\
& $>10 \mathrm{~cm}$ & Jede Mitoserate \\
& Jede Größe & $>10$ Mitosen $/ 50 \mathrm{HPF}^{*}$ \\
\hline
\end{tabular}

Zur gleichen Zeit wurde am AFIP (Armed Forces Institute of Pathology) in den USA eine zweite Risiko-Klassifikation erarbeitet, die zusätzlich zu den beiden Parametern Tumorgröße und Mitosenanzahl die anatomische Lokalisation miteinbezieht (Miettinen et al. 2002). Es werden ebenfalls vier Gruppen unterteilt. 2006 wurde die Risikoklassifikation weiter spezifiziert. GIST im Magen haben danach - bei gleicher Mitoserate und Tumorgröße - ein geringeres malignes Potential als GIST im Dünndarm (Miettinen und Lasota 2006). Die Gründe für das aggressivere biologische Verhalten von GIST im Dünndarm sind bisher nicht genau bekannt (Miettinen und Lasota 2006). Intestinaler GIST tendiert zum Zeitpunkt der Diagnosestellung größer als gastraler GIST zu sein (Miettinen et al. 2006). Die Kriterien sind in Tabelle 1-3 zusammengefasst. 
Tabelle 1-3: Risikoklassifikation nach Miettinen und Lasota (2006), S.1474

\begin{tabular}{llll} 
& & Größe in cm & Mitoserate $/ \mathbf{5 0 H P F}$ \\
\hline Sehr niedrig & Gastral & $\leq 2$ & $\leq 5$ \\
& Intestinal & $\leq 2$ & $\leq 5$ \\
Niedrig & Gastral & $>2$ bis $\leq 10$ & $\leq 5$ \\
& & $\leq 2$ & $>5$ \\
Intermediär & Intestinal & $>2$ bis $\leq 5$ & $\leq 5$ \\
& Gastral & $>10$ & $\leq 5$ \\
& & $>2$ bis $\leq 5$ & $>5$ \\
Maligne & Intestinal & $>5$ bis $\leq 10$ & $\leq 5$ \\
& Gastral & $>5$ & $>5$ \\
& Intestinal & egal & $>5$ \\
& & $>10$ & egal
\end{tabular}

\subsection{Die Rezeptortyrosinkinasen KIT und PDGFRA}

Die Gene KIT und PDGFRA sind auf dem Chromosom 4q12 lokalisiert, scheinen von einem gemeinsamen Ursprungsgen abzustammen und besitzen untereinander eine große Ähnlichkeit (Heinrich et al. 2003a, Corless et al 2005, Lasota und Miettinen 2008). Der c-KITRezeptor ist identisch mit der Typ-III-Rezeptor-Tyrosin-Kinase v-kit Hardy- Zuckerman 4 feline sarcoma viral oncogene homolog (KIT). Der c-KIT Rezeptor besteht aus einer extrazellulären Domäne, einem transmembranären Segment, einer juxtamembranären Domäne und einer Proteinkinase-Domäne (Roskoski 2005a, Roskoski 2005b). Die juxtramembranäre Domäne inhibiert in Abwesenheit vom c-KIT Ligand SCF die Rezeptoraktivität (Mol et al. 2004).

Normalerweise werden KIT und PDGFRA durch ihre Liganden SCF (Stammzellfaktor) bzw. PDGF aktiviert. Bindet SCF an den Rezeptor, führt dies zu Dimerisation und einer anschließenden Phosphorylierung verschiedener Signalmoleküle im Zytoplasma (Roskoski et al. 2005a). Die physiologische Aktivierung der Tyrosinkinase beinhaltet die Regulierung wichtiger Zellfunktionen, wie Proliferation, Apoptose, Chemotaxis und ist entscheidend für die Differenzierung verschiedener Zellen, sowohl in der Embryogenese als auch postnatal (Lennartsson et al. 2005, Roskoski et al. 2005a). Die Überaktivierung kann beim Menschen zu verschieden Neoplasmen wie GIST, Leukämien, Mastocytomen und Lymphomen führen. 
1998 konnte in einer Arbeit gezeigt werden, dass in GIST aktivierende Mutationen des KIT-Gens zu einer ligandenunabhängigen, dauerhaften Aktivierung der TyrosinkinaseAktivität und damit zu einer unkontrollierten intrazellulären Signalweitergabe und nachfolgend übermäßigen Zellproliferation führen (Hirota et al. 1998).

\subsection{Mutationen des c-KIT und des PDGFRA-Gens bei GIST}

Insgesamt zeigen ca. 60 - 70\% aller GIST aktivierende Mutation des KIT-Gens (Lasota et al. 1999, Rubin et al. 2001, Heinrich et al. 2003b, Duensing et al. 2004, Andersson et al. 2006, Lasota und Miettinen. 2008). Von den übrigen GIST weist die Mehrzahl aktivierende Mutationen des PDGFRA-Rezeptors (platelet-derived-growth-factor receptor alpha) auf (Heinrich et al. 2003a, Corless et al. 2005, Lasota und Miettinen 2008). Die Entdeckung von weltweit mittlerweile ca. 15 Familien mit Keimbahnmutationen von KIT bzw. PDGFR $A$ und entsprechend früher Entstehung von multiplen GIST, sowie die Generierung von drei Mausmodellen mit KIT-Mutation und Ausbildung eines spezifischen Phänotyps mit multiplen GIST bestätigen die höchstwahrscheinlich initial tumorauslösende Bedeutung der KIT bzw. PDGFRA-Mutationen für GIST (Tran et al. 2005, Antonescu 2006).

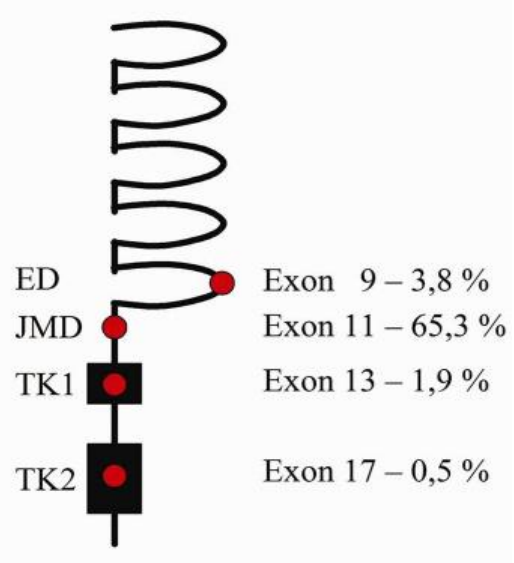

KIT

Abb. 1-3

Schematische Übersicht des KIT-Rezeptors mit der Zuordnung der Mutationen zu den Exonen und den durch sie kodierten Proteindomänen. Die Häufigkeiten beziehen sich auf 208 in Göttingen untersuchte primäre GIST. ED: Extrazelluläre Domäne; JMD: Juxtamembranäre Domäne; TK1: TyrosinKinase-Domäne 1; TK2: Tyrosin-Kinase-Domäne, übernommen aus Haller (2008), S.12

Mutationen im KIT oder PDGFRA-Gen führen zur konsekutiven Phosphorylierung der entsprechenden Rezeptortyrosinkinase. Es gibt vier unterschiedliche Lokalisationen für Mu- 
tationen. Die extrazelluläre Domäne (ED) und die juxtamembranäre Domäne (JMD) werden auch als Regulatordomäne zusammengefasst. Die Tyrosin-Kinase-Domänen 1 und 2 (TK1; TK2) zählen zur Enzymdomäne. Am häufigsten finden KIT Mutationen in der juxtamembranären Domäne, die dem Exon 11 entspricht, statt. Am zweithäufigsten, allerdings wesentlich seltener als Exon-11-Mutationen finden sich Mutationen in der extrazellulären Domäne, die dem Exon 9 entspricht. Mutationen in TK1 (Exon 13) und TK2 (Exon 17) finden wesentlich seltener statt (Wardelmann et al. 2007, Lasota und Miettinen 2008).

Exon-11-Mutationen führen zur Störung der Autoregulierung und damit zur spontanen Aktivierung (Ma et al. 1999, Chan et al. 2003). Exon-9-Mutationen führen durch Störung der Didimerisierung zur spontanen Homodimerisierung und damit zur Daueraktivierung der Tyrosinkinase (Heinrich et al. 2003b). Mutationen auf Exon 13 oder 17 sind mit unter 1\% eher selten. Der Mechanismus, der zur Funktionsstörung der Tyrosinkinase führt, ist noch nicht bekannt.

\subsubsection{KIT-Exon-11-Mutationen und ihre prognostische Bedeutung}

Im Exon 11 finden sich drei große Hauptgruppen von Mutationen, wobei verschiedene Exon-11-Mutationstypen unterschieden werden können. Am häufigsten finden sich Deletionen gefolgt von Punktmutationen und Duplikationen. Ungefähr 60-70\% der KIT-Exon11-Mutationen sind In-Frame-Deletionen von einem oder mehreren Codons (Miettinen et al. 2006). Die meisten Deletionen befinden sind im proximalen Anteil des Codons zwischen Codon 550 und 561. Die häufigsten Einzeldeletionen betreffen die Codons Trp557 und Lys558.

Die zweithäufigsten Mutationen im Exon 11 sind mit 20-30\% Punktmutationen. Es sind fast ausschließlich folgende vier Codons betroffen: Trp557, Val559, Val 560 und Leu 576 (Miettinen et al. 2006, Lasota und Miettinen 2008). Interne Tandem-Duplikationen von einem bis zu 20 Codons treten im distalen Teil von Exon 11 auf und sind relativ selten, besitzen eine bessere Prognose und werden fast ausschließlich in gastralen GIST gefunden (Andersson et al. 2006).

Die Position der Deletion spielt womöglich eine Rolle für den klinischen Verlauf. So scheinen Deletionen im Codon 557 und Codon 558 mit einer früheren Metastasierung und damit mit einem malignen klinischen Verlauf assoziiert zu sein (Wardelmann et al. 2003, Martin et al. 2005). Generell ließ sich beobachten, dass GIST mit Exon-11-Deletionen eine höhere Proliferationszahl, eine höhere Mitosenanzahl, sowie eine kürzere, krankheitsfreie Überlebenszeit aufweisen als GIST mit Exon-11-Punktmutation (Wardelmann et al. 2003, Martin et al. 2005, Andersson et al. 2006, Haller et al. 2008). Der genaue Mechanismus für die höhere Malignität bei GIST mit Exon-11-Deletionen ist bisher noch nicht bekannt. Es gibt mehrere Ansätze, warum GIST mit Exon-11-Deletionen eine größere Malignität aufweisen könnten. Die höheren Mitosezahlen bei den Exon-11-Deletionen lässt eine höhere 
Stimulation der Zellproliferation vermuten. Bei Exon-11-Deletionen finden sich eine höhere Expression von Cyclin D, was wahrscheinlich für die höhere Malignität von Exon-11Deletionen mitverantwortlich ist (Haller et al. 2008). Deletionen hemmen, vermutlich durch den Verlust mehrerer Aminosäuren, die autoinhibitorische Funktion der juxtaglomulären Domäne effektiver als einfache Punktmutationen zumal die Exon-11-Deletionen besonders am 5'Ende vom Exon lokalisiert sind (Andersson et al. 2006, Haller et al. 2008).

Die längere, krankheitsfreie Überlebenszeit von GIST mit Exon-11-Punktmutationen gegenüber Exon-11-Deletionen lässt sich allerdings nur bei proximal gelegenen GIST beobachten, nicht jedoch bei distalen GIST (Haller et al. 2008, Miettinen et al. 2006).

\subsection{Chromosomale Aberrationen bei GIST}

Bei GIST werden spezifische chromosomale Aberrationen beobachtet, die sich nach Häufigkeit und Zeitpunkt des Auftretens während der Tumorprogression in primäre, sekundäre und tertiäre Ereignisse einteilen lassen.

Primäre Ereignisse treten früh in der Tumorgenese auf und finden sich in der Mehrzahl der GIST. Der Verlust von 14q, 1p und 15q sind die frühen Ereignisse in GIST (El-Rifai et al. 1996, Sarlomo-Rikala et al. 1998, Heinrich et al. 2002, Meza-Zapeda et al. 2006, Ässämäki et al. 2007, Gunawan et al. 2007, Wozniak et al. 2007). Die wichtigsten sekundären Ereignisse sind vor allem $-22 q,-9 p$ und $+8 q$, die jeweils mit einem ungünstigen klinischen Verlauf assoziiert sind (El-Rifai et al. 2000, Kim et al. 2000, Gunawan et al. 2004, Lasota et al. 2005, Gunawan et al. 2007). Als tertiäre Ereignisse werden späte, wenig spezifische Veränderungen bezeichnet, die auch bei anderen Tumorentitäten gefunden werden können.

Die Anzahl der Gesamtaberrationen korreliert mit einem höheren Risiko für eine malignen klinischen Verlauf von GIST (El-Rifai et al. 2000, Wozniak et al. 2007). El-Rifai et al. (2000) konnten zeigen, dass bei benignen GIST weniger chromosomale Aberrationen auftreten, als bei malignen GIST. Verluste treten eher bei der Entstehung von GIST auf, während Zugewinne eine Rolle bei der Malignen Transformation sowie Metastasierung spielen, wobei besonders der Zugewinn auf Chromosom 8 in metastasierten oder primär malignen GIST gefunden wird. Distaler GIST zeigt in der frühen Phase eine höhere Anzahl von Verlusten. Dies ist eventuell für die höhere Malignität der distalen GIST mitverantwortlich (Wozniak et al. 2007).

Die häufigste beobachtete chromosomale Aberration bei GIST ist der Verlust von $14 \mathrm{q}$ der in fast 70\% von GIST gefunden wird, gefolgt von 22q, 1p und 15q (El-Rifai et al. 1996, Sarlomo-Rikala et al. 1998, Heinrich et al. 2002, Meza-Zapeda et al. 2006, Ässämäki et al. 2007, Gunawan et al. 2007, Wozniak et al. 2007).

Aberrationen einzelner Chromosomen korrelieren unter anderem mit der anatomischen Lokalisation. Dabei kommen Verluste von $14 \mathrm{q}$ eher in proximalen und Verluste von 1q, 
$15 q$ und 22q eher in distalen GIST vor, wobei in der Mehrheit der gemeinsame Verlust von 1p und 15q beobachtet wird (Chen et al. 2004, Gunawan et al. 2007, Wozniak et al. 2007).

\subsection{Fragestellung}

In der vorliegenden Arbeit soll untersucht werden, inwiefern GIST mit Exon-11- Punktmutation bzw. Deletion sich unter Berücksichtigung des Mutationstyp und der Lokalisation in ihrer Größe und Mitosezahl und damit in ihrer Prognoseabschätzung nach Miettinen et al. 2006 unterscheiden. Im zweiten Teil soll untersucht werden, ob es Unterschiede hinsichtlich chromosomaler Aberrationen zum einen in Bezug auf die Lokalisation und zum anderen in Bezug auf den Mutationstyp bei GIST gibt.

Folgende Fragen lassen sich formulieren:

1. Welche Punktmutationen und Deletionen im Exon-11 können gefunden werden?

2. Gibt es Unterschiede zwischen proximal und distal gelegenen GIST bezüglich der klinisch-pathologischen Parameter Tumorgröße, Mitoseanzahl, Lokalisation und Risikoklassifikation?

3. Gibt es Unterschiede zwischen GIST mit Exon-11-Punktmutation und Deletion bezüglich der klinisch-pathologischen Parameter Tumorgröße, Mitoseanzahl, Lokalisation und Risikoklassifikation?

4. Gibt es Unterschiede zwischen GIST mit einer Exon-11-Deletion bzw. Punktmutation bezüglich der klinisch-pathologischen Parameter Tumorgröße, Mitoseanzahl und Risikoklassifikation unter Einbeziehung der anatomischen Lokalisation?

5. Gibt es Unterschiede zwischen proximalen und distalen GIST bezüglich der chromosomalen Aberrationen?

6. Gibt es Unterschiede zwischen GIST mit einer Exon-11-Punktmutation und Deletion bezüglich der chromosomalen Aberrationen?

7. Gibt es Unterschiede zwischen GIST mit einer Exon-11-Deletion bzw. Punktmutation bezüglich der chromosomalen Aberrationen unter Einbeziehung der anatomischen Lokalisation? 


\section{Material und Methodik}

\subsection{Patientenkollektiv}

In der vorliegenden Dissertation wurden 100 primäre GIST untersucht. Bei den Proben handelt es sich um Gewebeproben, die in den drei Instituten Aachen (damaliger Leiter: Prof. Dr. med. C. Mittermayer), Braunschweig (Leiter: Prof. Dr. med. K. Donhuijsen) und dem Universitätsklinikum Göttingen in den Jahren 1992 bis 2007 gesammelt und in Formalin fixiert wurden. Zunächst wurden alle vorhandenen GIST nach c-Kit-Mutationen auf den Exons 9,11,13 und 17 und PDGFRA-Mutationen auf den Exons 12 und 18 untersucht. Für die vorliegende Arbeit wurden primäre GIST mit Exon-11-Punktmutation oder Deletion ausgewählt. Die Untersuchungen an dem zu diagnostischen Zwecken asservierten Patientenmaterial wurden von der Ethikkommission der Universitätsmedizin Göttingen bewilligt (Ethikvotum Nr. 14/1/05).

\subsection{DNA-Isolierung aus formalinfixierten und paraffineinge- betteten Gewebeproben}

Sowohl für die Mutationsanalyse, als auch für die CGH wird aufgereinigte Tumor-DNA benötigt. Um von den Formalin-fixierten und Paraffin-eingebetteten Gewebeproben ausreichend Material für die DNA-Isolierung zu erhalten, wurden auf den jeweils zugehörigen HE-Schnitten die Tumorzellen enthaltenden Bereiche markiert und die Blöcke anschließend mit einem Skalpell so bearbeitet, dass die folgenden mit dem Mikrotom (Reichert-Jung (Leica Microsystems AG); Wetzlar, Deutschland) hergestellten Schnitte möglichst kein tumorfreies Gewebe enthielten. Hierbei wurden je nach Größe der Probe (Gewebestück oder Stanze) 10-20 Paraffinschnitte mit einer Dicke von $10 \mu \mathrm{m}$ angefertigt, die dann in gekennzeichnete Eppendorf-Cups (1,5 ml; Eppendorf; Hamburg, Germany) gegeben wurden.

Um die Proben zu entparaffinieren, wurden vier Waschgänge durchgeführt. Bei den ersten beiden wurden je $1000 \mu \mathrm{l}$ Xylol (Merck; Darmstadt, Deutschland) in die E-Cups pipettiert, diese dann gevortext und schließlich für 10 Minuten bei Raumtemperatur inkubiert. Danach wurden die E-Cups kurz anzentrifugiert und der Überstand vorsichtig abpipettiert. Der dritte und vierte Schritt waren identisch, jedoch wurde hier statt des Xylols Ethanol verwendet. Nach dem vierten Durchgang wurde möglichst aller Ethanol entfernt und das Gewebe in den offenen Cups bei ca. $60^{\circ} \mathrm{C}$ im Brutschrank getrocknet.

Es folgte der Proteinase-K-Verdau des Gewebes und damit die Ablösung der DNA: Hierzu wurden $200 \mu \mathrm{l}$ DNA-Isolierungspuffer und $40 \mu \mathrm{l}$ Proteinase K (aus dem Qiagen-Kit) 
zum Gewebe hinzugefügt, dieses gut gevortext und dann über Nacht bei $55^{\circ} \mathrm{C}$ und $850 \mathrm{rpm}$ auf den Thermomixer gestellt.

Am nächsten Tag erfolgte die Inaktivierung der Proteinase über acht Minuten bei $95{ }^{\circ} \mathrm{C}$ im Thermomixer. Im Anschluss wurde für 10 Minuten bei $13500 \mathrm{rpm}$ zentrifugiert und der die DNA enthaltende Überstand in neue E-Cups gegeben. Dadurch wurde eine Restkontamination mit Paraffin und Geweberesten vermieden.

Die anschließende Aufreinigung der Proben erfolgte mit Hilfe des DNA-Isolierungs-Kits (Qiagen; Hilden, Germany): Hierfür wurden als erstes $200 \mu \mathrm{l}$ AL-Puffer in die Cups gegeben, diese kurz gevortext und die Proben anschließend für 10 Minuten bei $70{ }^{\circ} \mathrm{C}$ und 1400 rpm auf den Thermomixer gestellt. Danach wurden $240 \mu \mathrm{l}$ 100\%iges Ethanol hinzugefügt und fünf Minuten bei Raumtemperatur inkubiert. Der komplette Inhalt (ca. $650 \mu \mathrm{l}$ ) wurde daraufhin auf einen Filter gegeben, der in einer beschrifteten Säule steckte und zwei Minuten bei $10000 \mathrm{rpm}$ und Raumtemperatur zentrifugiert. War danach noch Flüssigkeit auf dem Filter, so zentrifugierte man erneut mit max. 12000 rpm. Nun wurde die erste Säule verworfen und der Filter auf eine neue Säule gesetzt. Nach Zugabe von $500 \mu l$ AW1-Puffer auf den Filter und zwei Minuten Zentrifugieren bei $10000 \mathrm{rpm}$ wechselte man ebenfalls die Säule, bevor man nach Zugabe von $500 \mu$ l AW2-Puffer und drei Minuten Zentrifugieren bei 14000 rpm schließlich den Filter auf das fertig beschriftete E-Cup (Probennummer, Datum, $\mathrm{PF}=$ Paraffin) setzte. Um die sich immer noch im Filter befindende DNA herauszulösen, wurde abschließend $50 \mu \mathrm{l}$ AE-Puffer hinzugegeben, zwei Minuten gewartet und dann zwei Minuten bei $10000 \mathrm{rpm}$ zentrifugiert. Nach Wiederholung dieser letzten drei Schritte erhielt man $100 \mu \mathrm{l}$ DNA als Endvolumen.

Um im Anschluss die Molekülgröße der fragmentierten DNA zu bestimmen, wurde eine Gelelektrophorese durchgeführt. Hierfür benötigte man ein 1,5\%iges Agarosegel, für das $0,75 \mathrm{~g}$ Agarose und $50 \mathrm{ml}$ 1xTBE (45 $\mathrm{ml}$ Aqua bidest. $+5 \mathrm{ml}$ 10xTBE) in einen Kolben gegeben und dieser dann für 4x 30 Sekunden in der Mikrowelle erhitzt wurde. Nach Zugabe von 7,5 $\mu$ l Ethidiumbromid wurde das Gel in die vorbereitete Kammer gegossen, wo es in 20- 30 Minuten fest wurde.

Für die Gelproben wurden je $5 \mu l$ der aufgereinigten DNA mit $3 \mu l$ Loading Dye Solution (MBI-Fermentas; St. Leon-Rot, Deutschland) in die Kammern einer Mikrotiterplatte gegeben. Der Zusatz von Bromphenolblau im Loading-Dye (Tabelle 2-1) ermöglicht hierbei, den Lauf der DNA während der Elektrophorese optisch verfolgen zu können. Als Längenstandard dienten 1,5 $\mu$ l Lambda-Marker (MBI-Fermentas; St. Leon-Rot, Deutschland), (s. Tabelle 2-1), der ebenfalls mit $5 \mu$ l Aqua ad iniectabilia (DeltaSelect GmbH; Dreieich, Deutschland) und $3 \mu$ l Loading Solution parallel zu den DNA-Proben in eine Geltasche pipettiert wurde. Im Anschluss erfolgte die Auftrennung der DNA bei 90 Volt für 45 Minuten. Danach wurde ein Foto des Gels unter UV-Licht (312 nm) angefertigt, auf dem das in die DNA interkalierte Ethidiumbromid durch Fluoreszenz die Lage der DNA-Banden anzeigte. 
Die Länge der einzelnen Fragmente für die CGH sollte zwischen 600 bis 2000 bp liegen (Kallioniemi et al. 1994).

Tabelle 2-1: Materialien für die Gelelektrophorese

\begin{tabular}{ll}
\hline Name & Zusammensetzung \\
\hline Loading Dye Solution & $10 \mathrm{mM}$ Tris- $\mathrm{HCl}(\mathrm{pH} 7,6), 0,03 \%$ bromophenol blue, \\
& $0,03 \%$ xylene cyanol FF, 60\% glycerol, $60 \mathrm{mM}$ EDTA \\
Lambda-Marker & $0,5 \mu \mathrm{g} / \mu \mathrm{l}$, Fragmentlänge: $21-0,56 \mathrm{~kb}$ \\
\hline
\end{tabular}

Parallel hierzu erfolgte die photometrische Messung der Proben, die der Überprüfung der Konzentration und Reinheit der DNA diente. Dafür wurden jeweils $5 \mu l$ mit $95 \mu l$ Aqua ad iniectabilia verdünnt, diese kurz gevortext und auf $10000 \mathrm{rpm}$ anzentrifugiert. Anschließend wurde die Extinktion, die nach dem Lambert-Beer`schen Gesetz proportional dem molaren Extinktionskoeffizienten, der Konzentration des gelösten Stoffes und der durchstrahlten Schichtdicke ist, bei 260 und $280 \mathrm{~nm}$ im Photometer (Eppendorf; Hamburg, Germany) gemessen; als Leerwert diente Aqua ad iniectabilia. Durch Messung bei $260 \mathrm{~nm}$ wurde die Konzentration der doppelsträngigen DNA im Photometer bestimmt. Bei einer Wellenlänge von $280 \mathrm{~nm}$ (Absorptionsmaximum von Proteinen) ließ sich ein Quotient bilden, der es zuließ, eine Aussage über die Reinheit der DNA zu machen. Als optimal galten hierbei Ratio-Werte zwischen 1,8 und 1,9.

\subsection{Mutationsanalyse}

Die Mutationsanalyse wurde für alle 100 Fälle durchgeführt

\subsubsection{Amplifizierung der betrachteten DNA- Abschnitte für die Mutationsanalyse durch Polymerase-Kettenreaktion (PCR)}

In der Vorbereitung wurden Pipetten, Pipettenspitzen, Eppendorf-Cups (1,5 ml), SoftTubes $(0,2 \mathrm{ml})$ und aliquotiertes Wasser für 20-30 Minuten in einer hierfür vorgesehenen Arbeitshaube mit UV-Licht bestrahlt, um eine mögliche Kontamination von Mastermix und Proben zu vermeiden. Des Weiteren wurde der PCR-Puffer, $\mathrm{MgCl}_{2}$ und die zu verwendenden Primer (s. Tabelle 2-2) aufgetaut und zusammen mit den Proben und den Desoxynukleotiden (dNTPs) auf Eis gestellt. Nach dem Beschriften der Eppendorf-Cups für den Mastermix (Exon-Nummer) und der Softtubes für die PCR-Proben (1 bis n) wurde damit begonnen, den Mastermix herzustellen. Hierfür wurden pro Probe 37,0 $\mu$ l aliquotiertes Wasser, 
5,0 $\mu$ l 10x PCR-Puffer, 1,5 $\mu \mathrm{l} \mathrm{MgCl}_{2}$, je 2,0 $\mu \mathrm{l}$ forward und reverse primer (je $10 \mathrm{pmol} / \mathrm{l}$ ), 1,0 $\mu \mathrm{l}$ dNTPs und 0,2 $\mu \mathrm{l}$ Platinum Taq-Polymerase $(5 \mathrm{U} / \mu \mathrm{l})$ in ein E-Cup pipettiert.

Tabelle 2-2: PCR-Primersequenzen zu den Genen KIT und PDGFRA

\begin{tabular}{|c|c|c|c|}
\hline Gen & Exon & Primer & Primersequenzen \\
\hline \multirow[t]{8}{*}{ KIT } & \multirow[t]{2}{*}{9} & forward & 5'- CAG - GGC - T'TT - TGT - T'TT - CTT - CC \\
\hline & & reverse & 5'- ATC - ATG - ACT - GAT - ATG - GTA - GAC - AGA - GC \\
\hline & \multirow[t]{2}{*}{11} & forward & 5'- GTG - CTC - TAA - TGA - CTG - AGA - C \\
\hline & & reverse & $5^{\prime}-\mathrm{TAC}-\mathrm{CCA}-\mathrm{AAA}-\mathrm{AGG}-\mathrm{TGA}-\mathrm{CAT}-\mathrm{GG}$ \\
\hline & \multirow[t]{2}{*}{13} & forward & $5^{\prime}-\mathrm{GCT}-\mathrm{TGA}-\mathrm{CAT}-\mathrm{CAG}-\mathrm{T}^{\top} \mathrm{T} \mathrm{T}-\mathrm{GCC}-\mathrm{AG}$ \\
\hline & & reverse & 5'- ATA - ACC - TGA - CAG - ACA - ATA - AAA - GG \\
\hline & \multirow[t]{2}{*}{17} & forward & 5'- AAG - TTA - GTT - TTC - ACT - CTT - TAC - AAG \\
\hline & & reverse & 5'- TTG - AAA - CTA - AAA - ATC - CTT - TGC - AGG - AC \\
\hline \multirow[t]{6}{*}{ PDGFRA } & \multirow[t]{2}{*}{12} & forward & $5^{\prime}-\mathrm{TCC}-\mathrm{AGT}-\mathrm{CAC}-\mathrm{TGT}-\mathrm{GCT}-\mathrm{GCT}-\mathrm{TC}$ \\
\hline & & reverse & 5'- GCA - AGG - GAA - AAG - GGA - GTC - TT \\
\hline & \multirow[t]{2}{*}{14} & forward & 5'- TGG - TAG - CTC - AGC - TGG - ACT - GAT \\
\hline & & reverse & 5'-GGG - ATG - GAG - AGT - GGA - GGA - TT \\
\hline & \multirow[t]{2}{*}{18} & forward & $5^{\prime}-\mathrm{CAG}-\mathrm{CTA}-\mathrm{CAG}-\mathrm{ATG}-\mathrm{GCT}-\mathrm{TGA}-\mathrm{TC}$ \\
\hline & & reverse & 5'- GAA - GGA - GGA - TGA - GCC - TGA - C \\
\hline
\end{tabular}

Dabei musste beachtet werden, dass der Mastermix für die Probenanzahl $n+2$ hergestellt wurde, da bei den Versuchen jeweils eine Negativkontrolle (Mastermix ohne DNA) und eine Positivkontrolle (Patienten-DNA aus Frischgewebe) mitgeführt wurde. Erstere diente der Detektierung von eventuellen Verunreinigungen der PCR, mit letzterer wurde die Qualität der PCR überprüft. Im Folgenden wurden die E-Cups kurz anzentrifugiert, gut gevortext und je $49 \mu \mathrm{l}$ in die $200 \mu \mathrm{l}$-Softtubes überführt, in die danach je $1 \mu$ l Proben-DNA hinein pipettiert wurde. Nach kurzem Anzentrifugieren der Softtubes wurden diese in den Thermocycler (Labcycler von Sensoquest) gestellt, der auf die entsprechende Anzahl von Zyklen programmiert wurde. Für die PCR hatte sich bei den KIT-Exonen 9, 11, 13, 17 und dem PDGFRA-Exon 12 die Menge von $1 \mu \mathrm{l}$ DNA und die Anzahl von 45 Zyklen (Dauer ca. 2:09h) als optimal herausgestellt. Bei Exon 18 des PDGFRA-Gens wurden auf Grund einer effizienteren PCR nur 40 Zyklen durchlaufen. Im Falle einer nicht ausreichenden Menge amplifizierten Materials konnte sowohl die DNA-Menge als auch die Zyklenzahl variiert werden.

Der PCR-Prozess bestand aus einer bestimmten Anzahl von Zyklen, die in einem Thermocycler durchlaufen wurden. Jeder Zyklus setzte sich dabei aus drei Schritten zusammen: der Denaturierung, der Primerhybridisierung (Annealing) und der Elongation (s. Tabelle 2-3): 
Tabelle 2-3: Bedingungen der PCR-Reaktion

\begin{tabular}{|c|c|c|c|c|c|}
\hline Gen & Exon & PCR-Schritte & Zeit & Temperatur & Zykluszahl \\
\hline \multirow[t]{5}{*}{ KIT } & $9,11,13,17$ & Erste Denaturierung & $5 \min$ & $95^{\circ} \mathrm{C}$ & \multirow{5}{*}{$45 \mathrm{x}$} \\
\hline & & Denaturierung & 40 sek & $95^{\circ} \mathrm{C}$ & \\
\hline & & Annealing & 40 sek & $57^{\circ} \mathrm{C}$ & \\
\hline & & Extension & 35 sek & $72^{\circ} \mathrm{C}$ & \\
\hline & & Finale Extension & $5 \mathrm{~min}$ & $72{ }^{\circ} \mathrm{C}$ & \\
\hline \multirow[t]{10}{*}{ PDGFRA } & 12,14 & Erste Denaturierung & $5 \min$ & $95^{\circ} \mathrm{C}$ & \multirow{5}{*}{$45 \mathrm{x}$} \\
\hline & & Denaturierung & 40 sek & $95^{\circ} \mathrm{C}$ & \\
\hline & & Annealing & 40 sek & $57^{\circ} \mathrm{C}$ & \\
\hline & & Extension & 35 sek & $72{ }^{\circ} \mathrm{C}$ & \\
\hline & & Finale Extension & $5 \mathrm{~min}$ & $72{ }^{\circ} \mathrm{C}$ & \\
\hline & \multirow[t]{5}{*}{18} & Erste Denaturierung & $5 \mathrm{~min}$ & $95^{\circ} \mathrm{C}$ & \multirow{5}{*}{$40 \mathrm{x}$} \\
\hline & & Denaturierung & 40 sek & $95^{\circ} \mathrm{C}$ & \\
\hline & & Annealing & 40 sek & $57^{\circ} \mathrm{C}$ & \\
\hline & & Extension & 35 sek & $72^{\circ} \mathrm{C}$ & \\
\hline & & Finale Extension & $5 \mathrm{~min}$ & $72{ }^{\circ} \mathrm{C}$ & \\
\hline
\end{tabular}

Denaturierung - Zunächst wurde die doppelsträngige DNA auf $95{ }^{\circ} \mathrm{C}$ erhitzt, um die Wasserstoffbrückenbindungen aufzubrechen und die beiden Stränge zu trennen. Dabei war die erste Denaturierungsphase besonders lang, um sicherzustellen, dass sowohl die AusgangsDNA als auch die Primer nur noch in Einzelsträngen vorlagen.

Primerbybridisierung - Im Folgenden wurde die Temperatur 40 Sekunden lang auf einem für die Primer optimalen Niveau gehalten, das eine spezifische Anlagerung der Primer an die DNA erlaubte. Würde die Temperatur zu niedrig gewählt werden, könnten sich die Primer unter Umständen auch an nicht-100\%-komplementäre Sequenzen anlagern und so zu unspezifischen Produkten führen. Würde die Temperatur zu hoch gewählt werden, wäre die thermische Bewegung der Primer unter Umständen so groß, dass sie sich gar nicht richtig anheften könnten.

Die Temperatur, welche die beiden oben genannten Effekte weitgehend ausschloss, lag bei $57^{\circ} \mathrm{C}\left(2-3{ }^{\circ} \mathrm{C}\right.$ unter dem Schmelzpunkt der Primersequenzen).

Elongation - Schließlich füllte die DNA-Polymerase ausgehend vom 3'-Ende des Primers die fehlenden Stränge mit freien Nukleotiden auf und bildete so einen neuen Einzelstrang. Das Temperaturoptimum der verwendeten DNA-Polymerase lag bei $72{ }^{\circ} \mathrm{C}$, der Schritt dauerte 
35 Sekunden. Nach Vollendung aller Zyklen kühlte der Thermocycler die Reaktionsansätze auf $4-8{ }^{\circ} \mathrm{C}$ ab.

Zur Überprüfung wurde eine Gelelektrophorese durchgeführt. Diese erfolgte analog der Gelelektrophorese bei der DNA-Isolierung (siehe Kapitel 2.2). Abweichend wurde ein 2\%iges Gel hergestellt, sowie jeweils $10 \mu \mathrm{l}$ der einzelnen Proben eingesetzt. Außerdem erfolgte die Verwendung des Längenstandards pUC19 (Fragmentlängen: 501-67 bp; MBI Fermentas; St. Leon-Rot, Deutschland).

Auf dem angefertigten Foto des Gels musste darauf geachtet werden, dass bei der Negativkontrolle keine Bande vorhanden war und die Banden der Proben den Exon-spezifischen Banden des Standards entsprachen. Bei misslungener PCR, d.h. wenn bei einigen der Proben im Agarosegel keine Banden zu sehen waren, konnte man versuchen, durch Erhöhung der eingesetzten DNA-Menge $(>1 \mu \mathrm{l})$ oder durch Erhöhung der Anzahl der Zyklen $(>45)$ in einem erneuten Versuch ein positives Ergebnis zu erzielen. Eine erneute PCR war ebenfalls angezeigt bei einer positiven Negativkontrolle, die auf Verunreinigungen im Laufe des Arbeitsprozesses hinwies.

\subsubsection{Aufreinigung der PCR-Produkte}

Zu Beginn der Aufreinigung wurden $300 \mu \mathrm{l}$ Membran Binding Solution in die E-Cups vorgegeben, das PCR-Produkt (ca. $50 \mu \mathrm{l}$ ) hinzugefügt, gut gevortext und die Proben anschlieBend kurz anzentrifugiert. Danach wurde alles auf einen, sich auf einer Säule befindenden Filter gegeben, zwei Minuten gewartet und anschließend eine Minute bei 13000 rpm zentrifugiert. Als nächster Schritt wurde der Filter auf eine neue Säule gesetzt und die alte verworfen.

Es folgten zwei Waschvorgänge, bei denen man jeweils $600 \mu$ l Waschpuffer auf den Filter gab, eine Minute bei $13000 \mathrm{rpm}$ zentrifugierte und wiederum den Filter auf eine neue Säule setzte. Hierauf wurde zwei weitere Minuten trocken-zentrifugiert und endlich der Filter auf ein neues, mit Probenname und entsprechendem Exon beschriftetes, E-Cup gesetzt. Die sich im Filter befindende DNA wurde mit 30 $\mu$ l Nuclease-free-water abeluiert, d.h. aus dem Filter gelöst. Um das Lösen sicherzustellen, wartete man fünf Minuten ab, zentrifugierte erneut eine Minute bei 13000 rpm und verwarf dann den Filter. Für den Gel-Check wurde, wie im Rahmen der PCR beschrieben (s. Kapitel 2.3.1), ebenfalls ein 2\%iges Agarosegel hergestellt. Von den Proben wurden jeweils $3 \mu$ l eingesetzt, als Standard diente erneut pUC19 (Fragmentlängen: 501-67 bp; MBI Fermentas; St. Leon-Rot, Deutschland). Auf dem Foto des Gels war wiederum darauf zu achten, dass bei allen Proben die geforderten Banden auftraten. 


\subsubsection{Vorbereitung und Versenden der Proben zum Sequenzieren}

Vor dem Sequenzieren wurden je $3 \mu$ der PCR-Produkte zusammen mit 2,5 $\mu$ l aliquotiertem Wasser und 1,5 $\mu$ l Primer (forward oder reverse) (Tabelle 2-4) in 0,2 $\mathrm{ml}$ Softtubes gegeben.

Tabelle 2-4: Sequenzierungs-Primersequenzen zu den Genen KIT und PDGFRA

\begin{tabular}{|c|c|c|c|}
\hline Gen & Exon & Primer & Primersequenzen \\
\hline \multirow[t]{8}{*}{ KIT } & \multirow[t]{2}{*}{9} & forward & 5'- AGG - GCT - T'T'T - GT'T - TTC - TTC - CC \\
\hline & & reverse & 5'- CCT - AAA - CAT - CCC - CTT - AAA - TTG - G \\
\hline & \multirow[t]{2}{*}{11} & forward & $5^{\prime}-\mathrm{TGC}-\mathrm{TCT}-\mathrm{AAT}-\mathrm{GAC}-\mathrm{TGA}-\mathrm{GAC}-\mathrm{AAT}$ \\
\hline & & reverse & 5'- AAA - AAG - GTG - ACA - TGG - AAA - GCC \\
\hline & \multirow[t]{2}{*}{13} & forward & $5^{\prime}-\mathrm{CAT}-\mathrm{CAG}-\mathrm{TTT}^{\prime} \mathrm{T}-\mathrm{GCC}-\mathrm{AGT}-\mathrm{TGT}-\mathrm{GC}$ \\
\hline & & reverse & $5^{\prime}-\mathrm{AAC}-\mathrm{CTG}-\mathrm{ACA}-\mathrm{GAC}-\mathrm{AAT}-\mathrm{AAA}-\mathrm{AGG}-\mathrm{C}$ \\
\hline & \multirow[t]{2}{*}{17} & forward & $\begin{array}{l}5^{\prime}-\mathrm{GTT}^{\prime}-\mathrm{TTC}-\mathrm{ACT}-\mathrm{CTT}-\mathrm{TAC}-\mathrm{AAG}-\mathrm{TTA}-\mathrm{AAA}- \\
\text { TG }\end{array}$ \\
\hline & & reverse & $5^{\prime}-\mathrm{AAA}-\mathrm{ATC}-\mathrm{CTT}-\mathrm{TGC}-\mathrm{AGG}-\mathrm{ACT}-\mathrm{G}$ \\
\hline \multirow[t]{6}{*}{ PDGFRA } & \multirow[t]{2}{*}{12} & forward & 5'- TGG - TGC - ACT - GGG - ACT - TTG \\
\hline & & reverse & 5'-AAG - GGA - AAA - GGG - AGT - CT'T \\
\hline & \multirow[t]{2}{*}{14} & forward & $5^{\prime}-\mathrm{TGG}-\mathrm{TAG}-\mathrm{CTC}-\mathrm{AGC}-\mathrm{TGG}-\mathrm{ACT}-\mathrm{GAT}$ \\
\hline & & reverse & 5'- GGG - ATG - GAG - AGT - GGA - GGA - T' \\
\hline & \multirow[t]{2}{*}{18} & forward & $5^{\prime}-\mathrm{CAG}-\mathrm{ATG}-\mathrm{GCT}-\mathrm{TGA}-\mathrm{TCC}-\mathrm{TGA}-\mathrm{G}$ \\
\hline & & reverse & $5^{\prime}-\mathrm{AGG}-\mathrm{ATG}-\mathrm{AGC}-\mathrm{CTG}-\mathrm{ACC}-\mathrm{AGT}-\mathrm{G}$ \\
\hline
\end{tabular}

Die weitere Amplifizierung des PCR-Produktes und die Sequenzierung wurden von einem externen Labor (Sequence Laboratories GmbH/SeqLab, Göttingen, Deutschland) vorgenommen.

\subsubsection{Sequenzierung der amplifizierten Genabschnitte}

Für die Sequenzierung der amplifizierten Genabschnitte wurde das Kettenabbruchverfahren nach Sanger verwendet: Bei diesem wird zunächst die DNA-Doppelhelix durch Erwärmung denaturiert, woraufhin die DNA-Einzelstränge für das weitere Vorgehen zur Verfügung stehen. Ausgehend von dem, an den Einzelstrang bindenden Primer, wird durch das Enzym DNA-Polymerase einer der beiden komplementären DNA-Stränge verlängert. Dabei werden in den neusynthetisierten Strang mit unterschiedlichen Fluoreszenz-Farbstoffen markierte Didesoxy-Nukleosid-Triphosphate (ddNTPs) eingebaut, die keine 3'-Hydroxygruppe besitzen. Dies führt zu einem Kettenabbruch, da die OH-Gruppe am 3'-C-Atom für die Verknüpfung mit der Phosphatgruppe des nächsten Nukleotids fehlt. In der Folge entstehen 
DNA-Fragmente unterschiedlicher Länge, die in jedem Ansatz stets mit dem gleichen ddNTP enden. Die entstehenden Abbruchprodukte werden mittels Kapillarelektrophorese aufgetrennt und mit Hilfe eines Lasers zur Fluoreszenz angeregt. Die ddNTPs am Ende jedes DNA-Fragmentes zeigen dadurch Fluoreszenz unterschiedlicher Farbe und können so von einem Detektor erkannt werden. Das Chromatogramm (die Abfolge der Farbsignale, die am Detektor erscheinen) gibt direkt die Sequenz der Basen des sequenzierten DNA-Stranges wieder.

\subsubsection{Auswertung der DNA-Sequenzen}

Nach erfolgreicher DNA-Sequenzierung der Proben erfolgte die Auswertung der Sequenzen. Diese wurden nacheinander mit den entsprechenden Wildtyp-/Original-Sequenzen verglichen und die vorliegenden Veränderungen in der Basenabfolge beschrieben. Dabei diente die reverse-Sequenz des Falls stets als Kontrolle bzw. Beweis dessen, was man in der forward-Sequenz beschrieben hatte.

\section{Der genetische Code}

Bei der Auswertung der DNA-Sequenzen, die aus einer bestimmten Abfolge der vier Basen Adenin („A“) und Thymin/Uracil (,T/U“) ( $\rightarrow$ Pyrimidinbasen), sowie Guanin (,,G“) und Cytosin („C“) ( $\rightarrow$ Purinbasen) bestehen, war es wichtig, den genetischen Code zu kennen. Nach diesem codieren die im DNA-Einzelstrang 3'-wärts des Translations-initiierenden ATGs liegenden Kombinationen aus jeweils drei aufeinander folgenden Basen für jeweils eine der 20 primären Aminosäuren. Da es jedoch bei vier zur Verfügung stehenden Basen 128 Kombinationsmöglichkeiten gibt, werden neben den Aminosäuren, die nur durch eine bestimmte Dreier-Kombination codiert werden (z.B. TGG $\rightarrow$ Tryptophan (Trp/W)), andere durch bis zu sechs verschiedene Kombinationen codiert (z.B. AGC, AGT, TCA, TCC, TCG, TCT $\rightarrow$ Serin (Ser/S)). Daraus resultiert als wichtiges Faktum, dass es auch bei Mutationen, bei denen alle drei Basen eines Codons verändert sind (z.B. AGC>TCT), noch nicht zwingend zu einer veränderten Aminosäure kommen muss (Serin $>$ Serin), während bei anderen Mutationen eine veränderte Base reicht (z.B. TGG>TGC), um zum Austausch der Aminosäure zu führen (Tryptophan>Cystein (Cys/C)). Abb. 2-1 zeigt die Code-Sonne, die alle möglichen Dreier-Basen-Kombinationen (Codons), sowie die durch sie codierten Aminosäuren zeigt. Dabei wird die Reihenfolge der Basen eines Codons jeweils von innen nach außen gelesen. 


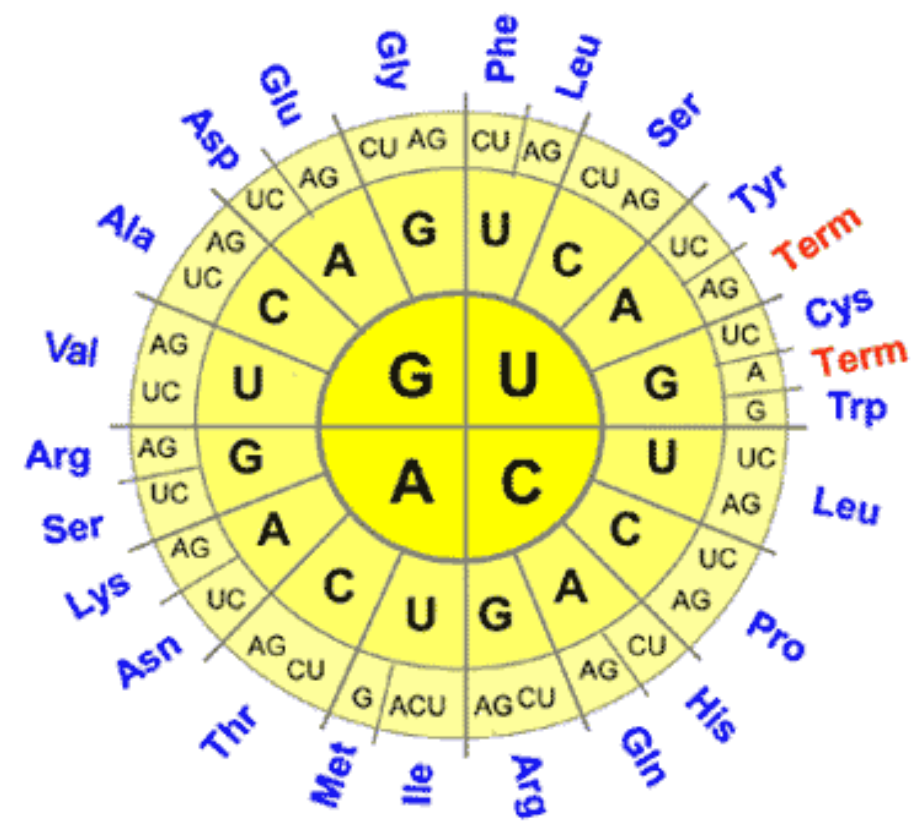

Abb. 2-1: Die Codesonne

Darstellung aller möglichen Dreier-Kombinationen der vier Basen Adenin („A“), Cytosin $\left(, C^{\prime}\right)$, Guanin („G“) und Thymin/Uracil (,T/U“), sowie der durch sie codierten Aminosäuren.

Zur übersichtlicheren Darstellung bei der Mutations-Beschreibung gibt es für jede der primären Aminosäuren sowohl einen Drei- als auch einen Ein-Buchstaben-Code. Eine Übersicht über die 20 primären Aminosäuren, sowie diese erwähnten Codes zeigt Tabelle 2-5. Es sind jeweils der Name, sowie der Drei- bzw. der Ein-Buchstaben-Code aufgeführt.

Tabelle 2-5: Auflistung der 20 primären Aminosäuren

\begin{tabular}{llllll}
\hline Aminosäure & & \multicolumn{5}{l}{ Aminosäure } \\
\hline Alanin & Ala & A & Leucin & Leu & L \\
Arginin & Arg & R & Lysin & Lys & K \\
Asparagin & Asn & N & Methionin & Met & M \\
Aspartat & Asp & D & Phenylalanin & Phe & F \\
Cystein & Cys & C & Prolin & Pro & P \\
Glutamin & Gln & Q & Serin & Ser & S \\
Glutamat & Glu & E & Threonin & Thr & T \\
Glycin & Gly & G & Tryptophan & Trp & W \\
Histidin & His & H & Tyrosin & Tyr & Y \\
Isoleucin & Ile & I & Valin & Val & V \\
\hline
\end{tabular}




\section{Beschreibungen der Mutationen auf DNA- und Proteinebene}

Die Beschreibung der Mutationen erfolgte nach der aktuellen Empfehlung der „Human Genome Variation Society“ zur Beschreibung von Mutationen auf DNA und Proteinebene (http://www.hgvs.org/mutnomen/index.html). Die Wildtyp- bzw. OriginalBasensequenzen der einzelnen Gene (DNA-Ebene; aktuelle Version für cKIT: $\{$ NM_000222.2\}) und die daraus resultierenden Aminosäureabfolgen (Protein-Ebene; aktuelle Version für KIT: \{NP_000213.1\}) waren von der Human Genome Reference DNA Sequence des National Centers for Biotechnology Information (NCBI; www.ncbi.nlm.nih.gov) vorgegeben.

Dabei wurden alle beobachteten Mutationen zunächst auf DNA-Ebene beschrieben. Die Mutationen auf DNA-Ebene wurden mit einem „c.“ für „coding DNA“ gekennzeichnet. Punktmutationen wurden durch das Zeichen „, “ indiziert. Als Beispiel sei die Punktmutation c.1676T $>$ A erwähnt, wobei an der Basenstelle 1676 „T“ durch „A“ substituiert wird. Deletionen werden durch „del“ nach der Angabe des ersten und letzten deletierten Nekleotids beschrieben. Als Beispiel diene die Deletion c.1669_1671delTGG, wobei die Nukleotide „TGG“ an Stelle 1669 bis 1671 deletiert werden. Deletions/Insertionen wurden durch „delins“ gekennzeichnet. Die Deletions/Insertion c.1674_1677delinsT beschreibt die Deletion der Nucleotide 1674 bis 1677, und die Insertion von „T“ an dieser Stelle. Die Nucleotide 1674 bis 1677 werden quasi durch „,T“ ersetzt.

Im Weiteren folgte die Beschreibung der Mutation auf der Proteinebene. Dies wurde zunächst durch das Kürzel „p.“ für Proteinebene gekennzeichnet. Punktmutationen werden unterteilt in „Missense-“, „Stille-“ und „Nonsense-Mutationen“. Folgt der Punktmutation auf dann-Ebene ein Aminsosäureaustausch auf Proteinebene, spricht man von einer Missense-Mutation. Als Beispiel dient die Punktmutation p.Val559Asp. Die Aminosäure Valin wird beim Codon 559 durch Asparagin ersetzt. Lässt sich auf DNA-Ebene eine Punktmutation nachweisen, welche allerdings auf Proteinebene zu keinem Aminosäuretausch führt, so werden diese Punktmutationen als stille Mutationen bezeichnet. Der Begriff NonsenseMutationen beschreibt den Austausch einer ursprünglichen Aminosäure durch ein Stopcodon.

Deletionen können in reine Deletionen und kombinierte Deletionen/Insertionen unterteilt werden. Reine Deletionen führen auf Proteinebene zu dem Verlust von einer oder mehreren Aminosäuren. Bei den kombinierten Deletions/Insertionen findet auf DNA Ebene eine 3 Nucleotid-Deletion statt, die zwei unterschiedliche für Aminosäuren kodierenden Codons betrifft, wobei sich ein neues Codon bildet, welches für eine andere Aminosäure kodiert. Als Beispiel diene folgende Abbildung: 

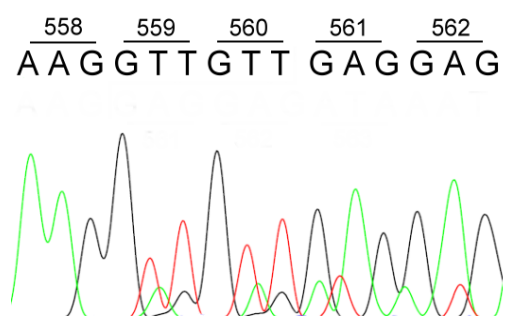

$\frac{558}{A A G G T T G T T} \frac{559}{\frac{560}{G A G}} \frac{562}{G A G}$

A A G G G G A A A A A T

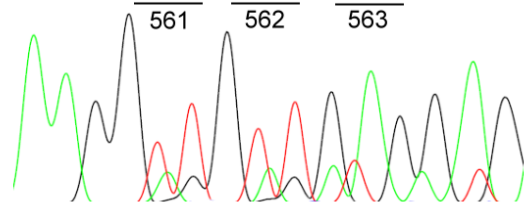

Abb. 2-2: Graphische Darstellung einer reinen Kit-Exon-11-Deletion aus dem eigenen Kollektiv c.1675_1680delGTTGTT; p.Val559_Val560del

\begin{tabular}{|c|c|c|c|c|c|c|c|c|}
\hline Gln & Trp & Lys & Val & Val & Glu & Ile & Asn & Gly \\
\hline 556 & 557 & 558 & 559 & 560 & 561 & 562 & 563 & 564 \\
\hline$C A G$ & T G G & $A A G$ & $\mathrm{G} \mathrm{T} \mathrm{T}$ & $G \eta^{T}$ & $G A G$ & $\mathrm{GAG}$ & $A T A$ & $A A A T$ \\
\hline
\end{tabular}

Gln Cys Glu lle Asn Gly

Abb. 2-3

Systematische Darstellung der Deletion/Insertion c.1671_1679delGAAGGTTGT;

p.Trp557_Va1560delinsCys. Zur klareren Darstellung wurde die graphische Darstellung der Mutation weggelassen

Dies ist exemplarisch für einen GIST mit einer Deletion/Insertion der Basen von Position 1670 bis 1679 dargestellt auf Exon-11. Aufgrund der nicht vollständigen Beteiligung der beiden Basentripletts 557 und 560 bildeten die Basen „T“ und „G“ an Position 1668 und 1669 mit der Base „T“ an Position 1680 ein neues Codon, welches auf Protein-Ebene für die neue Aminosäure Cystein kodiert. Auf DNA-Ebene wurde dieser Fall als reine Deletion mit c.1670_1679delGAAGGTTGT beschrieben. Auf der Protein-Ebene wurden die vier Aminosäuren „Trp“, „Lys“, „Val“ und „Val“ deletiert und durch „Cys“ ersetzt. Die Beschreibung auf Protein-Ebene lautete daher korrekt: p.Trp557_Val560delinsCys (Abb. 2-3). 


\subsection{Die Detektion von chromosomalen Veränderungen mittels CGH}

Die CGH-Analyse wurde für alle 100 Fälle des Kollektivs durchgeführt. Die CGH setzt sich neben der DNA-Isolierung (s. Kapitel 2.2) aus weiteren Schritten zusammen: Zuerst erfolgt die Markierung der Tumor- und Referenz-DNA mit unterschiedlichen Fluoreszenzfarbstoffen durch die Nick-Translation, dann die Hybridisierung der markierten Tumor- und Referenz-DNA mit Metaphase-Chromosomen, und abschließend die Auswertung der CGH mit dem Mikroskop/Computer.

\subsubsection{Die Nick-Translation}

Die für die Nick-Translation, welche ein standardisiertes Verfahren im Rahmen der CGH ist, benötigten Substanzen wurden zügig auf Eis in vorbereitete und beschriftete EppendorfCups pipettiert. Dabei wurden zuerst pro Ansatz $3 \mu \mathrm{g}$ Tumor- bzw. Referenz-DNA vorgelegt, wobei die $\mu$ l-Menge der Tumor-DNA anhand der Konzentrationswerte (1000:DNAKonzentration $(\mu \mathrm{g} / \mathrm{ml}) \mathrm{x}$ ), die nach der DNA-Isolierung per photometrischer Messung ermittelt worden waren, errechnet wurden. Dementsprechend konnten die eingesetzten $\mu 1$ Mengen variieren. Des Weiteren wurden $10 \mu$ l DNA-Puffer (10x konzentriert; MBI Fermentas; St. Leon-Rot, Deutschland), je $2 \mu \mathrm{l}$ dATP, dCTP, dGTP (Pharmacia Biotech; Freiburg, Deutschland) und $1 \mu \mathrm{l}$ dTTP (Pharmacia Biotech; Freiburg, Deutschland) hinzugefügt, sowie $1 \mu \mathrm{l} 1 \mathrm{mM}$ Biotin-16-dUTP zur Tumor-DNA und $1 \mu \mathrm{l} 1 \mathrm{mM}$ Digoxigenin-11-dUTP (Roche; Mannheim, Deutschland) zur Referenz-DNA gegeben. Die bei $-20{ }^{\circ} \mathrm{C}$ gelagerten Nukleotide wurden vorher langsam auf Eis erwärmt. Außerdem wurden noch $2 \mu$ DNAPolymerase I (MBI Fermentas; St. Leon-Rot, Deutschland) und 1,2 $\mu$ l DNAse I - 1:50 verdünnt (98 $\mu$ l TRIS-HCl, 100 mM, ph 7,5 + $2 \mu$ DNAse; Boehringer; Mannheim, Deutschland) hinzugegeben. Abschließend wurden die Ansätze je nach vorgelegtem Volumen mit Aqua ad iniectabilia (DeltaSelect GmbH; Dreieich, Deutschland) auf $100 \mu l$ aufgefüllt.

Die Eppendorf-Cups wurden anschließend kurz gevortext, anzentrifugiert und dann bei $15{ }^{\circ} \mathrm{C}$ für $50 \mathrm{~min}$ (Tumor-DNA) bzw. $60 \mathrm{~min}$ (Referenz-DNA) auf dem Thermomixer inkubiert.

Während der Nick-Translation werden durch die DNAse I Einzelstrangsbrüche in die DNA geschnitten (“nicks"), die dann durch die DNA-Polymerase I unter Einbau von Biotin bzw. Digoxigenin wieder aufgefüllt werden (Der Einbau von dTTP und Biotin/Digoxigenin erfolgt jeweils zu gleichen Teilen). Dabei dient Biotin-16-dUTP (grün) der Markierung von Tumor-DNA und Digoxigenin-11-dUTP (rot) der Markierung der Referenz-DNA. Anschließend sollten die markierten Fragmente eine Länge von ca. 100 - 700 Basenpaaren aufweisen. Zum Abstoppen der Reaktion wurden die Proben im Anschluss bei $-20{ }^{\circ} \mathrm{C}$ eingefroren. 
Zur Überprüfung wurde eine Gelelektrophorese durchgeführt. Diese erfolgte analog der Gelelektrophorese bei der DNA-Isolierung (siehe Kapitel 2.2). Als Längenstandard wurde abweichend pUC19 (Fragmentlängen: 501-67 bp; MBI Fermentas; St. Leon-Rot, Deutschland) verwendet.

\subsubsection{Die Hybridisierung}

Auf die Nick-Translation folgte die Hybridisierung der markierten Tumor- und ReferenzDNA auf die vorgefertigten, auf $37^{\circ} \mathrm{C}$ erwärmten Objektträger mit den MetaphaseChromosomen (CGH Target Slides; Vysis Inc.; Downers Grove, USA). Die verwendeten Metaphasenfelder waren zuvor auf der Rückseite der Objektträger mit einem Diamant-Stift markiert worden.

Zum Abstoppen der DNAse und der Polymerase wurden die Nick-TranslationsProdukte, die im gewünschten Längenbereich lagen, mit $5 \mu$ EDTA ( $\mathrm{pH}$ 8, 0,5 M; Serva, Heidelberg, Deutschland) versetzt und für $5 \mathrm{~min}$ bei $37^{\circ} \mathrm{C}$ und $1400 \mathrm{rpm}$ im Thermomixer aufgetaut. Im Falle zu langer DNA-Fragmente wurde eine zweite Inkubationszeit für 5 - 10 min bei $15^{\circ} \mathrm{C}$ auf dem Thermomixer angeschlossen.

Danach wurden je $67 \mu$ l Tumor- und Referenz-DNA (entspricht jeweils $2 \mu \mathrm{g}$ ), sowie $80 \mu \mathrm{l}$ humane Cot-1-DNA ( $1 \mu \mathrm{g} / \mu$; Boehringer; Mannheim, Deutschland) in vorbereiteten Eppendorf-Cups zusammengeführt. Im Falle eines schlechten Kontroll-Gels wurden statt $67 \mu \mathrm{l}$ $100 \mu \mathrm{l}(95 \mu \mathrm{l}$ Tumor-DNA + $5 \mu \mathrm{l}$ EDTA) eingesetzt. Des Weiteren wurden $12 \mu \mathrm{l} 3 \mathrm{M}$ Natriumacetatlösung pH 4,8 (Merck; Darmstadt, Deutschland) sowie $580 \mu \mathrm{l}$ 100\% Ethanol (bei $100 \mu \mathrm{l}$ Tumor-DNA $670 \mu 1$ Ethanol) hinzugegeben und die DNA dann nach kurzem Vortexen für mindestens $30 \mathrm{~min}$ bei $-80^{\circ} \mathrm{C}$ präzipitiert. - Aufgrund der, im Mengenvergleich zur Tumor- und Referenz-DNA, im absoluten Überschuss vorliegenden Cot-1-DNA, blockiert diese bei der Hybridisierung die repetitiven Sequenzen, die vor allem um das Zentromer und in Bereichen der Chromosomen mit einem hohen Anteil von Heterochromatin liegen.

Nach dem Fällen der DNA wurden die Ansätze wieder aufgetaut und 45 min bei $4{ }^{\circ} \mathrm{C}$ und $14000 \mathrm{rpm}$ zentrifugiert. Im Folgenden wurde der Überstand abpipettiert, zum verbleibenden DNA-haltigen Pellet $800 \mu 170 \%$ Ethanol gegeben, was dem Herauslösen der Salze dient und anschließend $30 \mathrm{~min}$ bei $45{ }^{\circ} \mathrm{C}$ sowie $1400 \mathrm{rpm}$ im Thermomixer inkubiert. Danach wurde erneut für 5 min bei $4{ }^{\circ} \mathrm{C}$ mit $14000 \mathrm{rpm}$ zentrifugiert, der flüssige Überstand verworfen und das Pellet für 30 min bei Raumtemperatur unter dem Abzug getrocknet.

Das getrocknete Pellet wurde dann mit $6 \mu$ l deionisiertem Formamid (Fluka Biochemika; Buchs, Schweiz), das die Schmelztemperatur der DNA bei der folgenden Denaturierung senkt, resuspendiert und im Thermomixer bei $37^{\circ} \mathrm{C}$ und $1400 \mathrm{rpm}$ für 60 min inkubiert.

Da auf den Objektträgern die noch vorhandenen Proteinrückstände des Zellkerns die spätere Auswertung aufgrund unspezifischer Hybridisierung beeinflussen könnten, wurden die Objektträger im Vorfeld einer proteolytischen Pepsin-Behandlung unterzogen. Dazu wurde 
eine Glasküvette mit $70 \mathrm{ml}$ Aqua dest. im Wasserbad auf $37^{\circ} \mathrm{C}$ erwärmt, dann $20 \mu \mathrm{l}$ Pepsin (100 mg/ml; Sigma; St. Louis, USA) und $700 \mu l 1$ N HCl (Merck; Darmstadt, Deutschland) hinzugegeben und die Objektträger für $5 \mathrm{~min}$ in die Glasküvette gestellt. Zum Abstoppen der Reaktion folgte dann eine Inkubation der Objektträger für 5 min in einer Küvette mit 2x SSC-Lösung pH 7,0 (Tabelle 2-6) und anschließend die Dehydrierung in einer aufsteigender Alkoholreihe mit $70 \%, 85 \%$ und $100 \%-20{ }^{\circ} \mathrm{C}$ kaltem Ethanol für je 5 min. Danach wurden die Objektträger für 30 min bei Raumtemperatur getrocknet.

Zur Hybridisierung des Ansatzes an DNA-Einzelstränge musste die in den Chromosomen bisher noch vorliegende Doppelhelix aufgetrennt (denaturiert) werden. Dazu wurde die Denaturierungslösung, die nach vorliegendem Schema zusammenpipettiert wurde (Tabelle 2-6), in einer Glasküvette im Wasserbad auf $69^{\circ} \mathrm{C}$ erwärmt und jeweils 2 Objektträger aus der feuchten Kammer (Hybrite) genommen und für exakt 2 min bei $69{ }^{\circ} \mathrm{C}$ in der Lösung belassen. Die anschließende Dehydrierung erfolgte nun in einer Küvette mit aufsteigender Alkoholreihe für jeweils 5 min mit 70\%, 85\% und $100 \%-20^{\circ} \mathrm{C}$ kaltem Ethanol. Bei Raumtemperatur wurden die Objektträger erneut getrocknet und bei $37{ }^{\circ} \mathrm{C}$ wiederum auf die Wärmeplatte der feuchten Kammer gelegt.

Tabelle 2-6: Materialien zur Hybridisierung im Rahmen der CGH

\begin{tabular}{ll}
\hline Name & Zusammensetzung \\
\hline 20x SSC (Strong Salt & $175,5 \mathrm{~g}$ Natriumchlorid (Merck; Darmstadt, Deutschland) \\
Concentration) pH 7,0 & $88,29 \mathrm{~g}$ Natriumcitratdihydrat (Merck; Darmstadt, Deutsch- \\
& land) \\
& $1000 \mathrm{ml}$ Aqua bidest. \\
& $5 \mathrm{ml}$ 20xSSC, pH 7,0 \\
& $5 \mathrm{ml} 0,5 \mathrm{M} \mathrm{NaH2PO} 4, \mathrm{pH} 7,0$ (Merck; Darmstadt, Deutsch- \\
Denaturierungslösung & land) \\
& $5 \mathrm{ml}$ Aqua bidest. \\
& $35 \mathrm{ml}$ deionisiertes Formamid (Merck; Darmstadt, Deutsch- \\
& land) \\
& $30 \%$ Dextransulfat (Merck; Darmstadt, Deutschland) \\
\hline
\end{tabular}

Zu den Proben in den Eppendorf-Cups wurden $7 \mu$ l Master Mix (s.Tabelle 2.4.2/1) zur Stabilisierung der DNA hinzugefügt und diese im Anschluss für 6 min bei $78{ }^{\circ} \mathrm{C}$ im Thermomixer denaturiert. Nach Zentrifugation bei $37^{\circ} \mathrm{C}$ für 30 min wurden je $13 \mu$ des DNA-Mix zur Hybridisierung auf die Objekträger pipettiert (jeweils zwei Proben auf einen Objektträger), diese mit Deckgläsern (15 x 15 mm) luftblasenfrei eingedeckelt, mit Fixogum (Marabu; Tamm, Deutschland) verschlossen und für 72 Stunden in der feuchten Kammer belassen. 
In dieser Zeit findet die Hybridiserungsreaktion statt, bei der die Tumor- und die Referenz-DNA um die Bindungsstellen auf den Metaphase-Chromosomen konkurrieren. Beim Überwiegen von Tumor-DNA (Zugewinn) bindet diese statistisch häufiger an den Chromosomen als die Referenz-DNA ( $\rightarrow$ grüne Fluoreszenz), bei einem Verlust innerhalb des Tumor-Genoms überwiegt die Referenz-DNA ( $\rightarrow$ rote Fluoreszenz). Durch quantitative Messung des roten und grünen Fluoreszens-Signals über die Längsachse eines jeden Chromosoms lässt sich später eine Aussage über Verluste, Zugewinne und Amplifikationen der Tumor- DNA treffen.

\subsubsection{Aufreinigung, Blockung, Detektion}

Nach 72 Stunden wurden die fertig hybridisierten Objektträger zur Entfernung von Rückständen und unspezifisch gebundener DNA einigen Waschvorgängen unterzogen (zur Zusammensetzung der verschiedenen Lösungen siehe auch Tabelle 2-7). Dafür wurden zuerst die mit Fixogum fixierten Deckgläschen nach zweiminütigem Einweichen der Objektträger in einer Küvette mit Waschlösung B vorsichtig abgenommen. Danach erfolgte nach gleichem Schema ein dreimaliger, jeweils fünfminütiger Waschvorgang im Schüttelbad bei $42{ }^{\circ} \mathrm{C}$ in einer Küvette mit Waschlösung A ( $\rightarrow$ Entfernung unspezifisch gebundener DNA), sowie Waschlösung B ( $\rightarrow$ Abwaschen von Lösung A). Hierbei wurde zur Vergrößerung des Wascheffekts für jeden Waschvorgang eine neue Küvette gewählt.

Tabelle 2-7: Materialien

\begin{tabular}{|c|c|}
\hline Lösung & Bestandteile \\
\hline Waschlösung A: & $\begin{array}{l}70 \% \text { Formamid }+2 \mathrm{x} \text { SSC } \mathrm{pH} 7 \\
(75 \mathrm{ml} \text { nicht deionisiertes Formamid, } 15 \mathrm{ml} 20 \mathrm{x} \text { SSC, } 60 \mathrm{ml} \text { Aqua bi- } \\
\text { dest.) }\end{array}$ \\
\hline Waschlösung B: & $\begin{array}{l}\text { 2x SSC pH } 7 \\
(40 \mathrm{ml} 20 \mathrm{x} \text { SSC, } 360 \mathrm{ml} \text { Aqua bidest.) }\end{array}$ \\
\hline Waschlösung C: & $\begin{array}{l}0,1 \% \text { Tween } 20+4 x \text { SSC pH } 7 \\
(60 \mathrm{ml} 20 x \text { SSC, } 240 \mathrm{ml} \text { Aqua bidest., } 300 \mu \mathrm{l} \text { Tween } 20)\end{array}$ \\
\hline Blockinglösung: & $\begin{array}{l}\text { 0,15 g bovines Serumalbumin (BSA; SIGMA; St. Louis, USA) + } \\
5 \mathrm{ml} \text { Lösung C } \rightarrow \text { 3\% Blockinglösung }\end{array}$ \\
\hline Detektionslösung: & $1 \mathrm{ml} \mathrm{3 \%}$ Blockinglösung $+2 \mathrm{ml}$ Lösung $\mathrm{C} \rightarrow$ 1\% Detektionslösung \\
\hline
\end{tabular}

Nach Zugabe von $300 \mu$ l Blockinglösung (s. Tabelle 2-7) auf die Objektträger, wurden diese für 30 min bei $37^{\circ} \mathrm{C}$ in einer feuchten Kammer inkubiert. In dieser Zeit wurden durch die Blockinglösung bestimmte Bindungsplätze abblockt und so später unspezifische Bindungen durch die Fluoreszenz-Antikörper verhindert. 
Während der Inkubationszeit wurden an einem abgedunkelten Arbeitsplatz zu $1000 \mu \mathrm{l}$ der hergestellten Detektionslösung (s. Tabelle 2-7) $15 \mu$ l Fluoresceiniso-thiocyanat-Avidin (Vector; Burlingame, USA) und $5 \mu \mathrm{l}$ anti-Digoxiginin-Rhodamin (Roche; Mannheim, Deutschland) gegeben, die die lichtempfindlichen fluoreszierenden Antikörper gegen Biotin und Digoxigenin in gleicher Konzentration enthielten. Dieser Ansatz musste eventuell in mehreren Ausführungen hergestellt werden, da pro Objektträger $300 \mu \mathrm{l}$ fertige Detektionslösung (mit Antikörpern) benötigt wurden und demnach ein Ansatz für jeweils drei Objektträger ausreichte.

Die fertigen Ansätze wurden dann $10 \mathrm{~min}$ bei $37^{\circ} \mathrm{C}$ und $1000 \mathrm{rpm}$ auf den Thermomixer gestellt und anschließend $3 \mathrm{~min}$ bei $8000 \mathrm{rpm}$ zentrifugiert, um mögliche AntikörperKomplexe aus dem Überstand zu entfernen. Der Überstand (860- $900 \mu \mathrm{l})$, den man in ein neues, lichtgeschütztes E-Cup pipettierte, enthielt dann nur noch einzelne Antikörper.

Schließlich wurden lichtgeschützt $300 \mu \mathrm{l}$ der fertigen Detektionslösung (mit AK) auf die Objekträger pipettiert, von denen vorher Reste der Blockinglösung mit $2 \mathrm{ml}$ der Waschlösung C (s. Tabelle 2-7) entfernt worden waren und diese mit Deckgläsern (24 x 60) erneut für 60 min bei $37^{\circ} \mathrm{C}$ in der feuchten Kammer inkubiert. Um die nicht-gebundenen Antikörper zu entfernen, schloss sich ein dreimaliger jeweils fünfminütiger Waschvorgang mit Waschlösung $\mathrm{C}$ im Schüttelbad bei $42^{\circ} \mathrm{C}$ an.

Als letzter Schritt wurden die Präparate/Objektträger dann mit je $20 \mu \mathrm{l}$ bzw. je einem Tropfen/Feld DAPI-Eindeckelungsmedium (1 $\mu$ l Diamino-2-phenylindol (SIGMA; St. Louis, USA) + $50 \mu$ l Actinomycin (SIGMA; St. Louis, USA) $+1 \mathrm{ml}$ Vectorshield (Vector Laboratories; Burlingame, USA) erneut $1: 4$ verdünnt mit Vectorshield) versehen. Hierbei diente DAPI der Übersichtsfärbung/Anfärbung der Chromosomenbänderung für die spätere Sortierung und Vectorshield als Anti-Bleichmittel bzw. zum Fluoreszenzschutz. Da das langsame Ausbleichen der Fluochrome die Fluoreszenzaufnahme trotzdem auf ca. 14 Tage beschränkte, sollten die Präparate, die solange bei $4^{\circ} \mathrm{C}$ lichtgeschützt gelagert wurden, in dieser Zeit fotografiert werden.

\subsubsection{Auswertung und Beschreibung der Ergebnisse}

Die Auswertung der Metaphasen erfolgte nach Aufnahme monochromer Bilder mit dem Programm SmartCapture2 (Vysis Inc.; Downers Grove, USA) durch eine computergekoppelte CCD-Kamera (Sensys Photometrics; München, Deutschland) bei 880-facher VergröBerung und 8bit-Farbtiefe (256 Graustufen) mittels der Software Quips Karyotyping/CGH (Vysis Inc.; Downers Grove, USA). Als Mikroskop wurde ein Axioskop 2 (ZEISS; Göttingen, Deutschland) mit 10er, 20er und 63er Objektiv (10x, 20x, 63x Ölimmersion; ZEISS; Göttingen, Deutschland) verwendet.

Die Ausleuchtung erfolgte durch eine Quecksilberdampflampe (HBO mit selbstjustierender Ausleuchtung; ZEISS; Göttingen, Deutschland), deren Licht durch ein softwareseitig 
gesteuertes Filterrad (Ludl-Filterrad; Ludl; Hawthorne, USA) mit einem anti-DigoxigininRhodamin (FITC)-Filter, einem Fluoresceinisothiocyanat (TR CGH)-Filter und einem DAPI-Filter geschickt wurde.

Nach dem automatischen Scannen des Objektträgers wurden für jeden Fall 20 Metaphasen fotografiert, gespeichert und die Chromosomen zu einem Karyogramm geordnet, das man manuell mit Hilfe der verschiedenen Filter auf Farben, Größe und Banden der Chromosomenpaare überprüfte. Anschließend erfolgte die Speicherung der fertigen Karyogramme. Die Auswertung von 20 Metaphasen pro Fall erfolgte, da im einzelnen Karyogramm auf Grund von gelöschten sich überlagernden bzw. nicht zuzuordnenden Chromosomen nicht immer alle Chromosomen vorhanden waren.

Aus den durchschnittlich 15-20 CGH-Profilideogrammen wurde dann mittels der CGHSoftware ein Summeninterpreter generiert und dadurch unerwünschte Rauscheffekte minimiert. Als nächstes erfolgte die Festlegung der Schwellenwerte für Verluste (losses) und Gewinne (gains), die individuell für Gewinne zwischen 1,15 bis 1,20 und für Verluste zwischen 0,80 bis 0,85 angepasst wurden (Normalwert eines unveränderten Chromosoms: 1,0). Von einer Amplifikation, also einer vielfachen Vermehrung eines bestimmten Abschnittes, wurde ab einem Wert von 1,5 gesprochen. In Einzelfällen wurden diese Schwellenwerte verändert, wenn anhand des Interpreters ein deutlicher Trend zu beobachten war, der durch die Werte des 95\%-Konfidenzintervalls als signifikant angezeigt wurde.

Die Beschreibung der Veränderungen erfolgte entsprechend der ISCN (1995)Nomenklatur für humane Chromosomen für in-situ-Hybridisierung (Mitelman 1995): Zuerst wurde der festgelegte Schwellenwert aufgeführt (z.B. „0,2:“). Es folgten die Buchstaben „rev ish" für reverse in situ-Hybridisierung und dann nacheinander die Beschreibung der Zugewinne (Abkürzung „enh“ für enhancement), der Verluste („dim“ für dimition), sowie zuletzt möglicher Trend-Zugewinne/Verluste (,trend enh“ bzw. „trend dim“) oder vorliegender Amplifikationen (,amp“).

Dabei wurden die Zugewinne und Verluste sowohl auf dem p-Arm, als auch auf dem qArm des Chromosoms immer vom Zentromer aus beschrieben. War dass gesamte Chromosom betroffen, wurde es einzeln, ohne Erwähnung des p- bzw. q-Arms aufgeführt (z.B. „14“) Waren beide Arme, aber nicht das ganze Chromosom betroffen, erfolgte die Beschreibung vom p-Arm (über das Zentromer) zum q-Arm (z.B. „14p10q20“). War beispielsweise Chromosom 14 von Abschnitt q12 bis zum Ende des q-Arms betroffen, lautete die Beschreibung „14q12qter“ („,ter“ für terminal). 


\section{Ergebnisse}

\subsection{Darstellung der klinisch-pathologischen Parameter}

\subsubsection{Alter und Geschlecht}

49 der insgesamt 100 Patienten waren weiblich, und 51 waren männlich, das Geschlechtsverhältnis von Frauen zu Männern betrug somit 1 : 1,04. Das Alter der insgesamt 100 Patienten zum Zeitpunkt der Operation/Biopsie lag zwischen 42 und 90 Jahren, und betrug im Mittel 68,5 ( $\pm 10,4)$ Jahre. Bei den Frauen lag das Alter im Mittel bei 71,1 $( \pm 10,8)$ Jahren, während es bei den Männern im Mittel bei 66,1 ( $\pm 10,4)$ Jahren lag (Abb. 3-1). Damit bestand ein signifikanter Unterschied im Alter zum Zeitpunkt der Operation bei Männern und Frauen ( $t$-Test für unverbundene Stichproben: $p=0,02$ ).

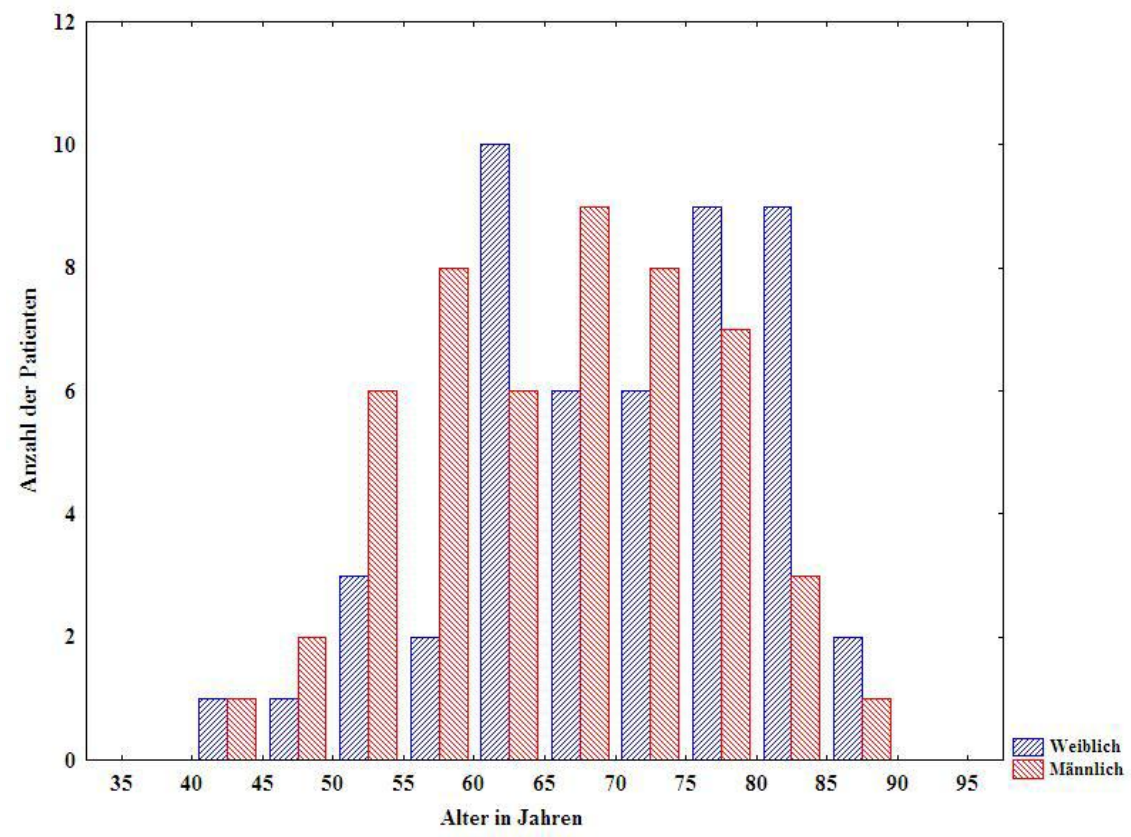

Abb. 3-1: Altersverteilung der 49 weiblichen und 51 männlichen Patienten mit GIST

\subsubsection{Lokalisation}

Bei der Tumorlokalisation wurde proximal von distal unterschieden, wobei die GIST aus dem Magen als proximale GIST, und die GIST aus dem Dünndarm und Dickdarm als distale GIST bezeichnet wurden. Insgesamt waren 63 der GIST proximal und 37 distal lokalisiert. 


\subsubsection{Tumorgröße}

Die maximale Tumorgröße lag zwischen $0,5 \mathrm{~cm}$ und $20 \mathrm{~cm}$. Im Durchschnitt waren die untersuchten Fälle 5,6 cm $( \pm 4,3 \mathrm{~cm})$ groß. Die graphische Darstellung der Tumorgröße erfolgte als Histogramm, wobei die GIST entsprechend der später vorgestellten Risikoklassifikation in 4 Gruppen mit den Grenzen $<2 \mathrm{~cm}, 2-5 \mathrm{~cm}, 5-10 \mathrm{~cm}$, und $>10 \mathrm{~cm}$ eingeteilt wurden (Abb. 3-2).

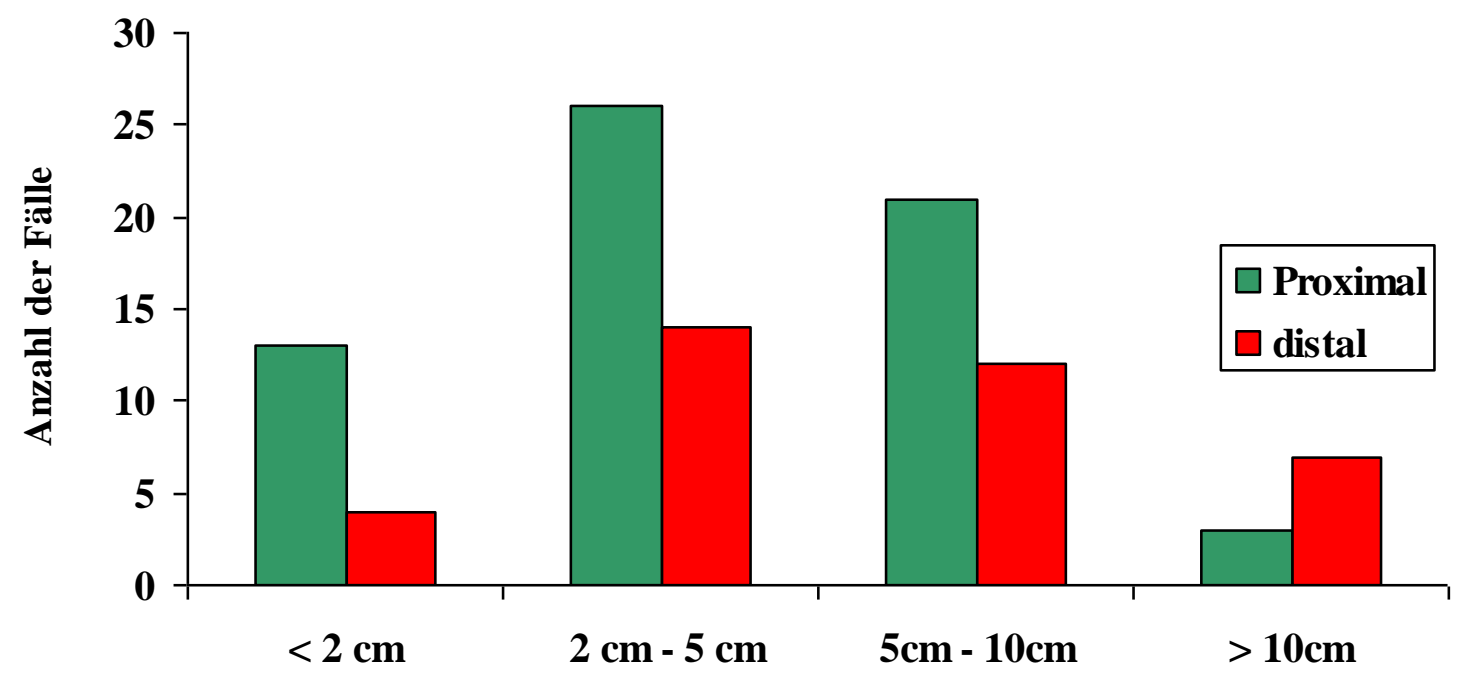

Abb. 3-2: Größenverteilung von 63 proximalen und 37 distalen GIST

Die proximalen GIST waren durchschnittlich $5 \mathrm{~cm}( \pm 3,8 \mathrm{~cm})$ groß, distale GIST waren hingegen im Mittel 6,7 cm $( \pm 4,8 \mathrm{~cm})$ groß (Tabelle 3-1). Damit waren distale GIST signifikant größer als proximale GIST (t-Test für unverbundene Stichproben: $\mathrm{p}=0,048)$.

\subsubsection{Mitoserate}

Im Durchschnitt betrug die Mitoserate 8,5 ( \pm 20) Mitosen auf 50 High-Power-Fields (HPFs). Proximale GIST hatten im Durchschnitt eine Mitoserate von 5,2 ( \pm 11$) / 50 \mathrm{HPFs}$, und distale GIST im Durchschnitt von 11,4 ( \pm 29,1)/50 HPFs (Tabelle 3-1). Damit wiesen distal gelegene GIST eine signifikant höhere Mitoserate auf als proximale GIST (t-Test für unverbundene Stichproben: $\mathrm{p}=0,025)$. 


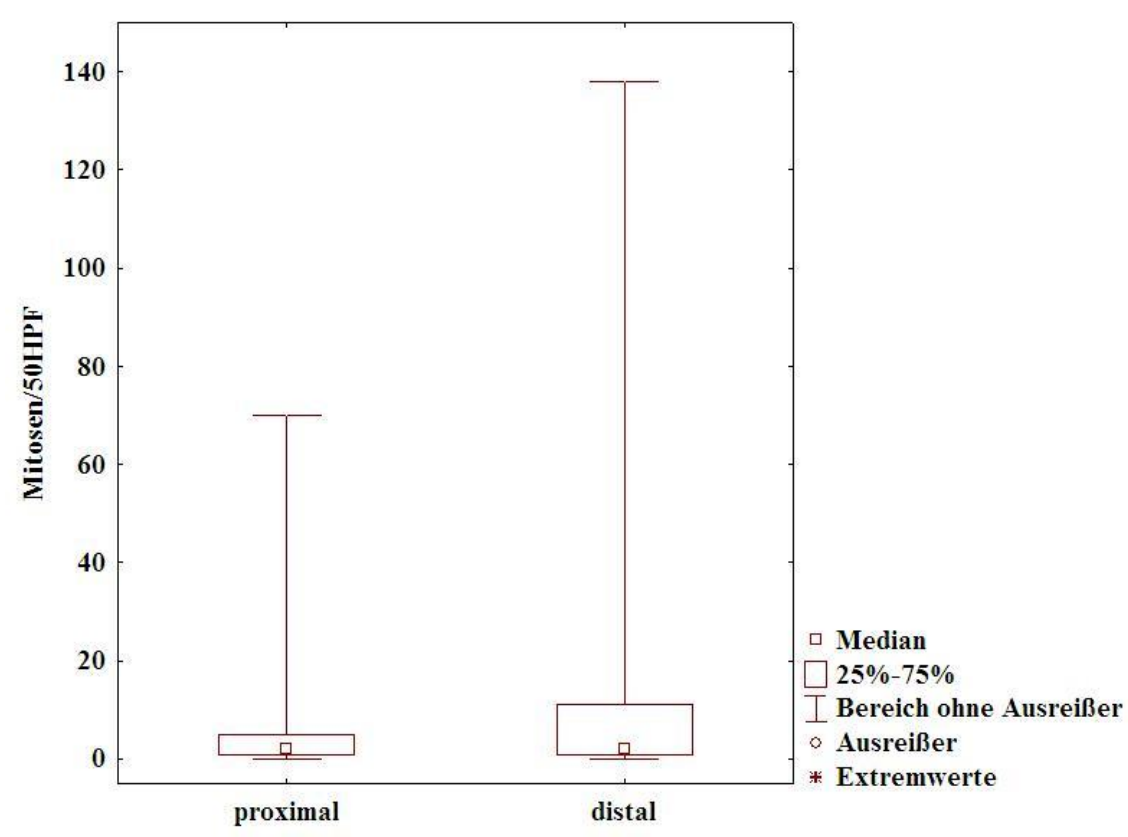

Abb. 3-3: Mitoserate/50HPFs nach 63 proximalen und 37 distalen GIST

Tabelle 3-1: Vergleich von 63 proximal und 37 distal gelegenen GIST nach Größe und Mitoserate

\begin{tabular}{|l|l|lll|}
\hline Lokalisation & Gesamtkollektiv & Proximal & Distal & t-test \\
\hline Tumorgröße in cm & $5,6( \pm 4,3)$ & $4,97( \pm 3,8)$ & $6,7( \pm 4,8)$ & $\mathbf{p}=\mathbf{0 , 0 4 8}$ \\
Mitoserate/50HPF & $8,6( \pm 20,1)$ & $5,2( \pm 11)$ & $14,4( \pm 29,1)$ & $\mathbf{p}=\mathbf{0 , 0 2 5}$ \\
\hline
\end{tabular}

\subsubsection{Risikoklassifikation nach Miettinen und Lasota (2006)}

Nach Miettinen und Lasota (2006) ließen sich vier Gruppen zur Abschätzung der Malignität bilden, wobei die Mitoserate, die Tumorgröße und die Tumorlokalisation berücksichtigt wurden. Bei 19 Patienten ergab sich eine sehr niedriges Risiko für malignes Verhalten, in 49 Fällen ein niedriges Risiko, in 8 Fällen ein intermediäres Risiko, und in 24 Fällen hatten die GIST ein sehr hohes Risiko (Abb. 3-4). 


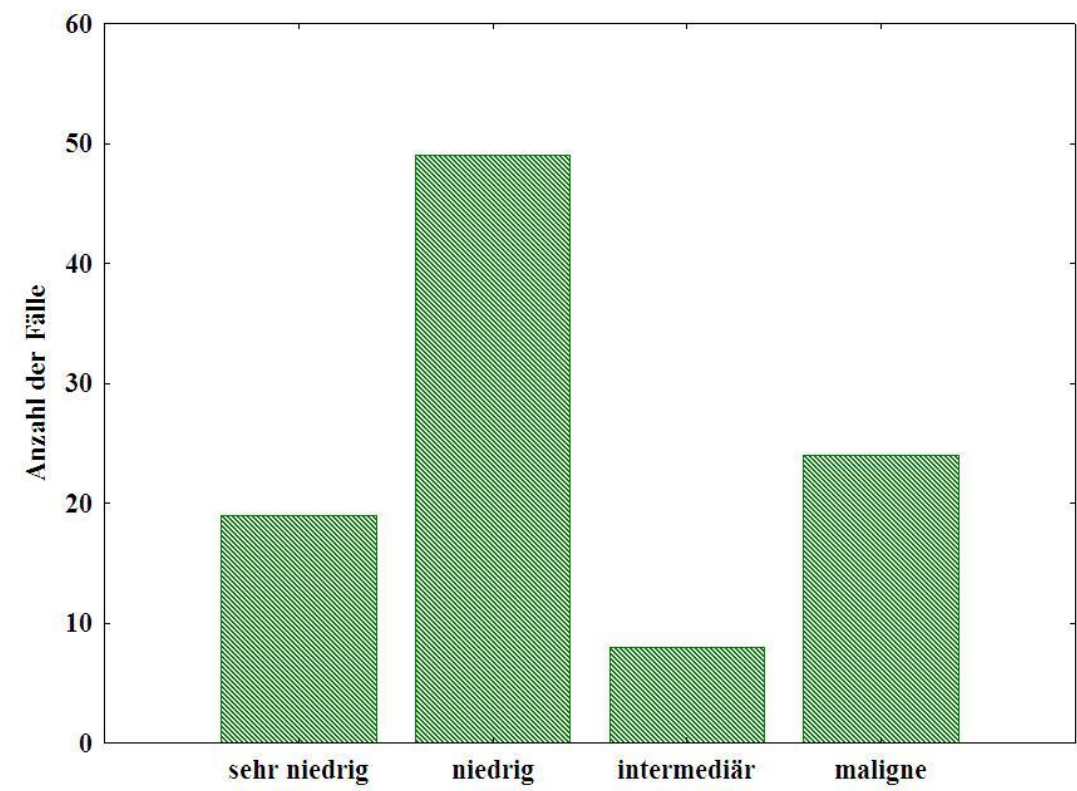

Abb. 3-4: Risikogruppenverteilung von 100 GIST nach der Risikoklassifikation von Miettinen und Lasota (2006)

\subsection{Ergebnisse der Mutationsanalyse}

50 Fälle wiesen eine Exon-11-Punktmutation auf, und 50 Fälle eine Exon-11-Deletion. Die Mutationen wurden zuerst auf der Ebene der DNA beschrieben, dann auf der Ebene des Proteins. Für die Auswertung und den Vergleich mit den klinisch-pathologischen Parametern und der CGH wurde die Beurteilung auf Protein-Ebene herangezogen.

\subsubsection{Beschreibung der Exon-11-Punktmutationen}

In insgesamt 10 Fällen fand ein Basenaustausch der Base Thymin (T) an Position 1669 statt. Von diesen 10 Fällen wurde in 5 Fällen die Base Cytosin (C) substituiert, in 4 Fällen Guanin $(\mathrm{G})$, und in einem Fall Adenin (A). Auf Protein-Ebene führte dies zum Austausch der Aminosäure Tryptophan, welche durch das Codon 557 kodiert wird. Je nach Substitution des Nukleotids auf der DNA-Ebene kam es dabei zur unterschiedlichen Substitution auf Protein-Ebene. Die Substitution durch ein „C“ auf DNA-Ebene führte auf Protein-Ebene zur Substitution durch die Aminosäure Arginin, bei Substitution durch „G“ oder „A“ auf DNAEbene kam es zur Substitution durch Lysin auf Protein-Ebene. In einem Fall wurde zusätzlich auf DNA-Ebene ein weiterer Austausch von „G“ zu „A“ an Position 1684 festgestellt, welcher auf Protein-Ebene zu einer Substitution von Glutamin am Codon $562 \mathrm{zu}$ Lysin führte. In insgesamt 23 Fällen fand ein Basentausch der Base Thymidin (T) an Position 1676 statt. In 11 Fällen wurde die Base Adenin (A) substituiert, in 7 Fällen die Base Guanin (G) und in 5 Fällen Cytosin (C). Auf Protein-Ebene führte dies zum Austausch von Valin, wel- 
ches für das Codon 559 kodiert. Je nach Substitution des Nucleotids auf DNA-Ebene kam es dabei zu unterschiedlichen Substitutionen auf Protein-Ebene. Die Substitution durch ein „A“ auf DNA-Ebene führte auf Protein-Ebene zur Substitution durch die Aminosäure Asparagin , bei Substitution durch, ,G“ auf DNA-Ebene kam es zur Substitution durch Glycin auf Protein-Ebene und bei Substitution durch „C“ auf DNA-Ebene kam es auf ProteinEbene zur Substitution von Alanin. In 9 Fällen fand ein Basentausch der Base „T“ $\mathrm{zu}$ „A“ an Position 1679 statt. Auf Protein-Ebene führte dies zum Austausch von Valin, welches durch das Codon 560 kodiert wird. An dieser Position wurde die Aminosäure Asparagin substituiert. In 3 Fällen fand neben dem beschriebenen Basenaustausch an Position 1679 ein weiterer Basentausch von „T“ $\mathrm{zu}$ „G“ an Position 1670 statt. Auf Protein-Ebene führte dies zum Austausch von Valin zu Glutamin. Auf DNA-Ebene wurde der Fall als Deletion/Insertion beschrieben, auf Protein-Ebene als Punktmutation. Da die Einteilung der Punktmutationen und Deletionen auf Protein-Ebene vorgenommen wurde, und es sich zugleich um eine typische Lokalisation der der Punkmutationen handelte, wurden diese Fälle zu der Gruppe der Punktmutationen gezählt. In 5 Fällen wurde auf DNA-Ebene die Base „T“ durch „C“ an Position 1727 ausgetauscht. Auf Protein-Ebene führte dies zum Austausch von Leucin, welches durch das Codon 576 kodiert wird, zu Prolin. In einem Fall wurde zusätzlich auf DNA-Ebene ein weiterer Austausch von „A“ zu „T“ an Position 1733 festgestellt, welcher auf Protein-Ebene zu einer Substitution von Tryptophan am Codon 578 zu Phenylalanin führte. In einem dieser Fälle wurde neben dieser Mutation noch eine weiter Basentausch von „A“ $\mathrm{zu}$ „T“ an Position 1733 gefunden. Dies führte auf Protein-Ebene zu einem Aminosäuretausch von Tryptophan zu Phenylalanin auf Codon 578.

Tabelle 3-2: Beschreibung der 50 Exon-11-Punktmutationen auf DNA und Protein-Ebene mit Häufigkeitsangabe

\begin{tabular}{|c|c|c|}
\hline DNA KIT\{NM_000222.2\} & Protein KIT $\{$ NP_000213.1\} & Anzahl \\
\hline c.1669T $>\mathrm{G}$ & p. Trp557Gly & 4 \\
\hline c.1669T $>C$ & p. Trp557Arg & 4 \\
\hline c. $[1669 \mathrm{~T}>\mathrm{C}(+) 1684 \mathrm{G}>\mathrm{A}]$ & p. [Trp557Arg (+) Glu562Lys] & 1 \\
\hline c. $1669 \mathrm{~T}>\mathrm{A}$ & p. Trp557Arg & 1 \\
\hline c. $1676 \mathrm{~T}>\mathrm{A}$ & p. Val559Asp & 11 \\
\hline c. $1676 \mathrm{~T}>\mathrm{G}$ & p. Val559Gly & 7 \\
\hline c. $1676 \mathrm{~T}>\mathrm{C}$ & p. Val559Ala & 5 \\
\hline c. $1679 \mathrm{~T}>\mathrm{A}$ & p. Val560Asp & 9 \\
\hline c.1679_1670delinsAG & p. Val560Glu & 3 \\
\hline c. $1727 \mathrm{~T}>\mathrm{C}$ & p. Leu576Pro & 4 \\
\hline c. $[1727 \mathrm{~T}>\mathrm{C}(+) 1733 \mathrm{~A}>\mathrm{T}]$ & p. [Leu576Pro (+) Tyr578Phe] & 1 \\
\hline
\end{tabular}




\subsubsection{Lokalisation der Punktmutationen bezogen auf KIT-Exon-11}

Bezogen auf die Lokalisation im Exon-11 des KIT-Gens waren von den Punktmutationen ausschließlich vier Codons betroffen (Abb. 3-5): in 20\% der Fälle handelte es sich um Codon 557, in 44\% der Fälle um Codon 559, in 24\% um Codon 560, und in 10\% um Codon 576. Bei 2 Fällen lag zusätzlich noch eine zweite Mutation vor, die dann das Codon 563 bzw. das Codon 578 betraf.

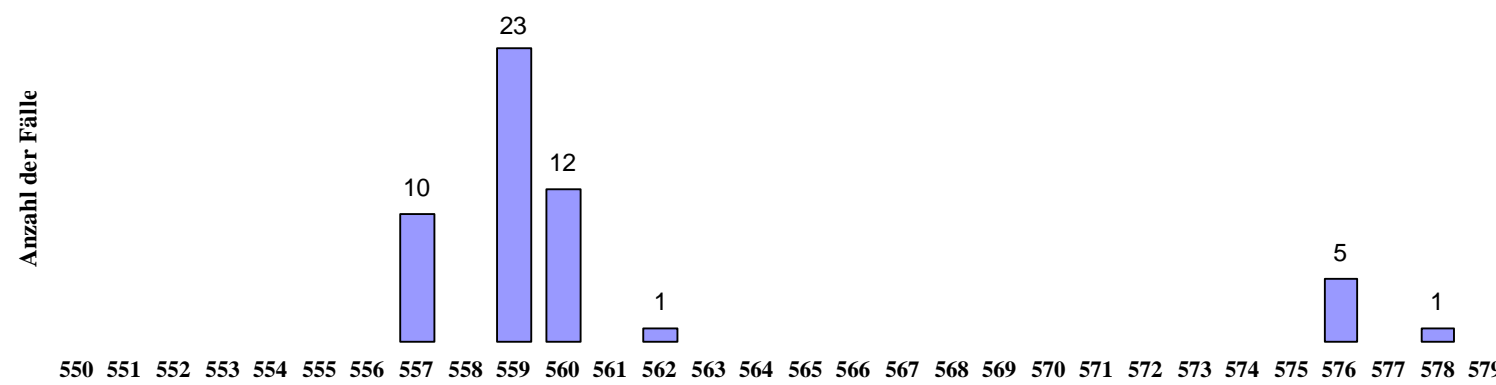

Abb. 3-5: Anzahl der Fälle mit Exon-11-Punktmutationen, bezogen auf das jeweils betroffene Codon (50 Fälle mit Exon-11-Punktmutation)

\subsubsection{Beschreibung der Deletionen}

\section{Reine Deletionen}

Bei 23 Fällen lag auf der DNA-Ebene eine reine Deletion vor, die jeweils 3 bis 24 Basen betraf. Diese Deletionen führten auf Proteinebene zum Verlust von 1 bis 8 aufeinander folgenden Aminosäuren. Die Deletion c.1669_1674delTGGAAG führte zum Beispiel auf Proteinebene zu einem Verlust der beiden Aminosäuren Tryptophan und Lysin an den Codons 557 und 558. Diese Deletion wurde auf Protein-Ebene als p.Trp557_Lys558del beschrieben, und war mit 7 Fällen die häufigste Deletion. Bei vier Fällen mit einer reinen Deletion auf DNA-Ebene, die nicht genau im Leseraster lag, führte diese Mutation auf Protein-Ebene zu einer Deletion/Insertion, wobei die deletierten Aminosäuren durch eine neue Aminosäure ersetzt wurden. In einem Fall wurde neben einer reinen Deletion noch eine weitere Substitution in einem nicht angrenzenden Codon gefunden. (c. $[1667 \mathrm{~A}>\mathrm{C} \quad(+)$ 1672_1689delAAGGTTGTTGAGGAGATA]; p. [Glu556Pro (+) Lys558_Ile563del]) Dieser Fall wurde zu den Deletionen eingeteilt. Bei einem weiteren Fall mit einer Deletion auf DNA-Ebene stellte sich eine Besonderheit dar. Hier begann die Deletion bereits 4 Basenpaare vor Beginn des Exons 11 im Intron 10, und betraf weitere 15 Basenpaare im Exon 11. Für die verlorenen Basen wurde „GCTAG“ inseriert. Die Basen „AG“ dienen dabei wahrscheinlich als Spliceakzeptor. Dieser Fall wurde auf DNA-Ebene als Deletion c.16484A_1672delinsGCT (mit AG als wahrscheinlichem Spliceakzeptor) beschrieben, welche auf Protein-Ebene wahrscheinlich zu einer reinen Deletion von 9 Aminosäuren führte. 


\section{Kombinierte Deletionen/Insertionen}

In 12 Fällen wurde auf DNA-Ebene eine Deletion/Insertion gefunden. Hierbei handelte es sich um Deletionen, bei denen es im Zuge der DNA-Reparatur zum Einbau einer neuen Base gekommen war. Korrekt beschrieben wurden diese Fälle daher auf DNA-Ebene als eine Deletion von mehreren Basen mit Insertion einer oder mehreren neuen Basen. Auf Protein-Ebene folgte daraus eine Deletion von mehreren Aminosäuren mit Insertion einer neuen Aminosäure. In einem besonderen Fall fand eine Inversion der vier aufeinander folgenden Basen 1670 bis 1673 statt. Die Beschreibung auf DNA-Ebene lautete c.1669_1673delinv. Auf Protein-Ebene wurden die beiden betroffenen Aminosäuren Tryptophan und Lysin auf Codon 557 und 558 zu Phenylalanin und Prolin ausgetauscht. Dies wurde als Deletion/Insertion mit p.557_558delinsPhePro beschrieben. Dieser Fall wurde zu den Deletionen gezählt.

Tabelle 3-3: Beschreibung der Exon-11-Deletionen auf DNA und Protein-Ebene mit Häufigkeitsangabe

\begin{tabular}{|c|c|c|}
\hline DNA KIT $\{$ NM_000222.2\} & Protein KIT\{NP_000213.1\} & Anzahl \\
\hline c. [1667A>C (+) 1672_1689delAAGGTTGTTGAGGAGATA] & p. [Glu556Pro (+) Lys558_Ile563del] & 1 \\
\hline c.1648_1653delAAACCC & p.Lys550_Pro551del & 1 \\
\hline c.1654_1665delATGTATGAAGTA & p.Met552_Val555del & 1 \\
\hline c.1657_1674delTATGAAGTACAGTGGAAG & p.Val553_Lys558del & 1 \\
\hline c.1661_1675delAAGTACAGTGGAAGG & p.Glu554_Lys558del & 1 \\
\hline c.1663_1668delGTACAG & p.Val555_Gln556del & 1 \\
\hline c.1666_1683delCAGTGGAAGGTTGTTGAG & p.Gln556_Glu561del & 1 \\
\hline c.1669_1671delTGG & p.Trp557del & 1 \\
\hline c.1669_1674delTGGAAG & p.Trp557_Lys558del & 7 \\
\hline c.1669_1680delTGGAAGGTTGTT & p.Trp557_Val560del & 1 \\
\hline c.1669_1683delTGGAAGGTTGTTGAG & p.Trp557_Glu561del & 4 \\
\hline c.1672_1686delAAGGTTGTTGAGGAG & p.Lys558_Glu562del & 1 \\
\hline c.1675_1683delGTTGTTGAG & p.Val559_Glu561del & 1 \\
\hline c.1678_1680delGTT & p.Val560del & 4 \\
\hline c.1705_1728delGTTTACATAGACCCAACACAACTT & p.Val569_Leu576del & 1 \\
\hline c.1708_1728delTACATAGACCCAACACAACTT & p.Tyr570_Leu576del & 1 \\
\hline c.1735_1737delGAT & p.Asp579del & 4 \\
\hline c.1650_1667delACCCATGTATGAAGTACA & p.Lys550_Gln556delinsLys & 1 \\
\hline c.1671_1676delGAAGGT & p.Trp557_Val559delinsCys & 1 \\
\hline
\end{tabular}


c.1671_1679delGAAGGTTGT

c.1679_1681delTTG

c.1677_1680delins'T

c.1648_1668delins'TTG

c.1648_1670delins'T'T'TCG

c.1649_1668delins'TA

c.1649_1774delinsCTGTACT'TCAG

c.1654_1662delinsCAA

c.1668_1674delinsAGGG

c.1673_1692delinsAG

c.1674_1677delins'T

c.1674_1677delinsT

c.1701_1716delinsC

c.1720_1728delins'T'TT

c.1648-4A_1672delinsGCTAG mit AG als wahrscheinlicher Spliceakzeptorstelle

c.1669_1673delinv
p.Trp557_Val560delinsCys 1

p.Val560_Glu561delinsGlu 1

p.Val559delinsAsn 1

p.Lys550_Gln556delinsLeu 1

p.Lys550_Trp557delinsPheLeu 1

p.Lys550_Glu554delinsIle 1

p.Met552_Lys558delins'ThrValLeuGln 1

p.Met552_Glu554delinsGlu 1

p.Trp557_Lys558delinsGly 1

p.Lys558_Asn564delinsArg 1

p.Val559delinsAsn 1

p.Lys558_Val559delinsAsn 1

p.Asn567_Asp572delinsAsn 1

p. Thr574_Leu576delinsPhe 1

p. Lys550_Lys558del 1

p. Trp557_Lys558delinsPhePro 1

Auf Protein-Ebene reichten die Deletionen vom Verlust eines einzelnen Codons bis hin zu Deletionen mit einem Verlust von 9 Codons, und waren im Mittel 3 bis 4 Codons lang (Abb. 3-6).

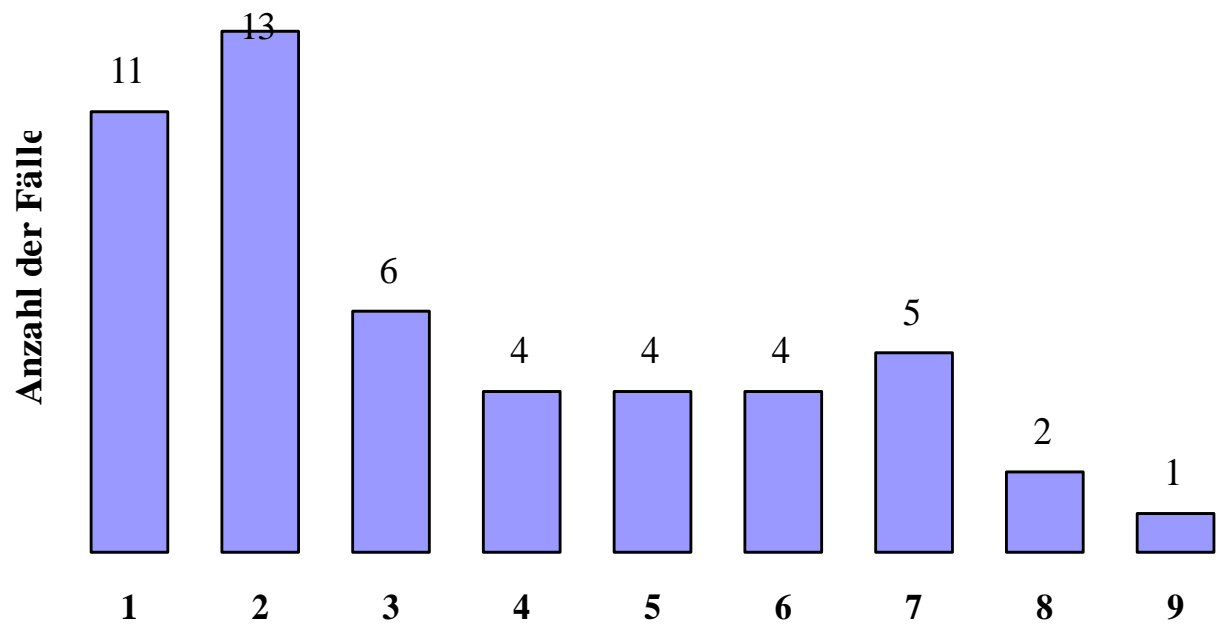

Abb. 3-6: Codonanzahl der Exon-11-Deletion mit Angabe ihrer Länge 


\subsubsection{Lokalisation der Deletionen bezogen auf KIT-Exon-11}

Die meisten Deletionen (42 Fälle) fanden sich zwischen Codon 550 und Codon 564. (Abb. 3-7). Weitere 4 GIST wiesen Deletionen von mehreren Codons im Bereich von Codon 567 bis Codon 576 auf, 4 Einzeldeletionen fanden sich an Codon 579.

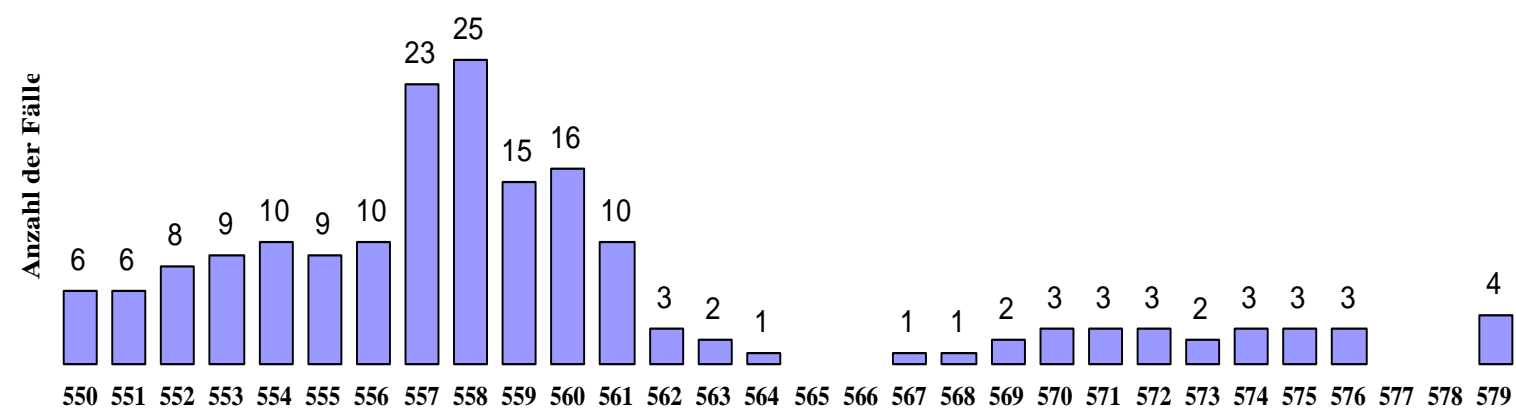

Abb. 3-7: Anzahl der Fälle mit Deletionen, bezogen auf das jeweils betroffenen Codon (50 Fälle mit Exon-11-Deletion)

\subsection{Vergleich der Mutationstypen mit den klinisch- pathologischen Parametern}

\subsubsection{Lokalisation}

$33(\%)$ GIST mit einer Exon-11-Punktmutation lagen proximal, und 17 (\%) lagen distal. 30 $(\%)$ GIST mit einer Exon-11-Deletion lagen proximal, 20 (\%) lagen distal. Die Verteilung der Lokalisation von GIST mit einer Exon-11-Punktmutation bzw. einer Deletion war nicht signifikant unterschiedlich (Chi-Square: $\mathrm{p}=0,5)$.

\subsubsection{Tumorgröße}

Die maximale Tumorgröße der GIST mit einer Exon-11-Punktmutation lag zwischen 0,5 und $19 \mathrm{~cm}$, und betrug damit im Durchschnitt 5,7 cm $( \pm 4,2 \mathrm{~cm})$.Die maximale Tumorgröße der GIST mit einer Exon-11-Deletion lag zwischen $1 \mathrm{~cm}$ und $20 \mathrm{~cm}$, und betrug im Mittel 5,5 cm ( $\pm 4,4 \mathrm{~cm})$ (Abb. 3-8). GIST mit einer Exon-11-Punktmutation bzw. einer Deletion unterschieden sich damit nicht signifikant in ihrer Größe (t-test für unverbundene Stichproben: $p=0,8)$ (Tabelle 3-4). 


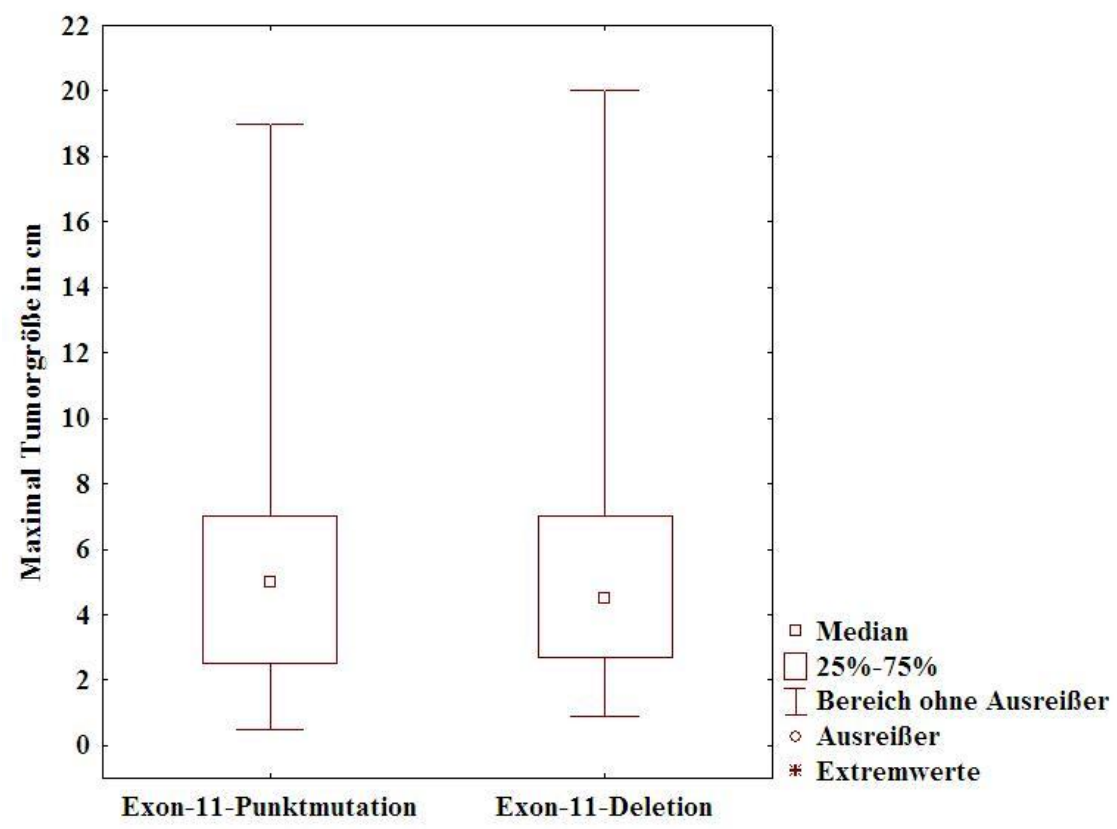

Abb. 3-8: Tumorgröße bei GIST mit Exon-11-Punktmutation und Deletion

\subsubsection{Mitoserate}

GIST mit einer Exon-11-Punktmutation hatten im Durchschnitt eine Mitoserate von 4,6 ( \pm 10,7) Mitosen /50HPF. GIST mit einer Exon-11-Deletion hatten im Durchschnitt 12,6 ( \pm 25,8) Mitosen /50HPF (Abb. 3-9). GIST mit einer Exon-11-Deletion hatten damit eine statistisch signifikant höhere Mitoserate als GIST mit einer Exon-11-Punktmutation (t-test für unverbundene Stichprobe: $\mathrm{p}=0,047$ ) (Tabelle 3-4).

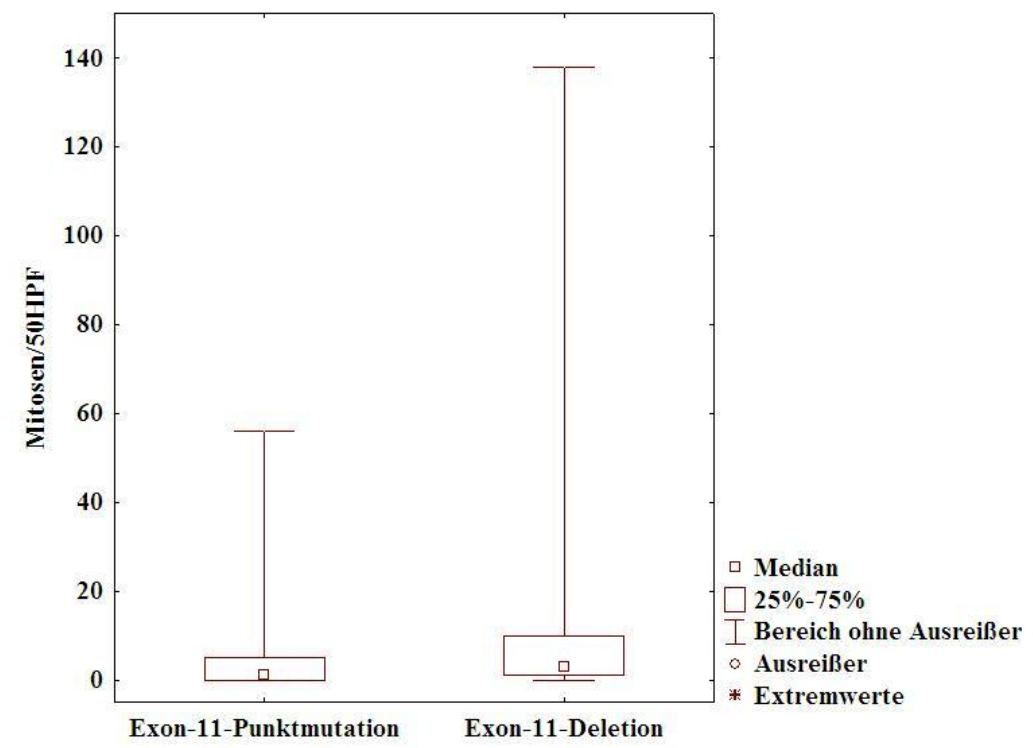


Tabelle 3-4: Vergleich der Tumorgröße und Mitoserate bei GIST mit Exon-11-Punktmutation und Deletion

\begin{tabular}{|l|lll|}
\hline Mutationen & Punktmutation & Deletion & t-test \\
\hline \multirow{2}{*}{$\begin{array}{l}\text { Tumorgröße } \\
\text { Mitoserate }\end{array}$} & $5,7(4,2)$ & $5,5(4,4)$ & $\mathrm{P}=0,83$ \\
\cline { 2 - 4 } & $4,6(10,7)$ & $12,6(25,8)$ & $\mathbf{P}=\mathbf{0 , 0 4 7}$ \\
\hline
\end{tabular}

\subsubsection{Risikoklassifikation nach Miettinen und Lasota (2006)}

Nach der Risikoeinteilung nach Miettinen und Lasota (2006) wurden bei den GIST mit den Exon-11-Punktmutationen 8 Fälle als GIST mit einem sehr niedrigen Risiko, 30 Fälle mit niedrigem, 3 mit intermediärem und 8 mit hohem Risiko eingestuft. Bei den GIST mit den Exon-11-Deletionen wurden 9 Fälle mit sehr niedrigem Risiko, 20 mit niedrigem, 7 mit intermediärem Risiko und 15 als GIST mit hohem Risiko eingestuft. Die Gruppe mit sehr niedrigem und niedrigem Risiko, sowie die Gruppen mit intermediärem und hohem Risiko wurden jeweils zu einer Gruppe zusammengefasst. Es gab eine Tendenz zum höheren Risiko bei den GIST mit einer Exon-11-Deletion, diese war jedoch nicht signifikant (Chi-Square Test: $\mathrm{p}=0,086)$

\subsection{Vergleich der Mutationstypen mit den klinisch- pathologischen Parametern unter Berücksichtigung der Lokali- sation}

\subsubsection{Tumorgröße}

Proximal gelegene GIST mit einer Exon-11-Punktmutation hatten eine durchschnittliche Größe von 4,6 ( $\pm 2,6) \mathrm{cm}$, während distal gelegene GIST mit einer Exon-11-Punktmutation eine durchschnittliche Größe von 7,9 ( $\pm 5,6) \mathrm{cm}$ aufwiesen (Abb. 3-10). Damit waren bei den GIST mit einer Exon-11-Punktmutation die distal gelegenen GIST signifikant größer als die proximal gelegenen ( $\mathrm{t}$-Test für unverbundene Stichproben $\mathrm{p}=0,006$ ). Proximal gelegene GIST mit einer Exon-11-Deletion hatten eine durchschnittliche Größe von 5,4 $( \pm 4,9) \mathrm{cm}$, und distal gelegene GIST mit einer Exon-11-Deletion eine Größe von 5,7 $( \pm 3,7) \mathrm{cm}$. Proximal und distal gelegene GIST mit einer Exon-11-Deletion wiesen damit keinen signifikanten Unterschied in der Größe auf (t-test für unverbundene Stichproben: $\mathrm{p}=0,8$ ). 


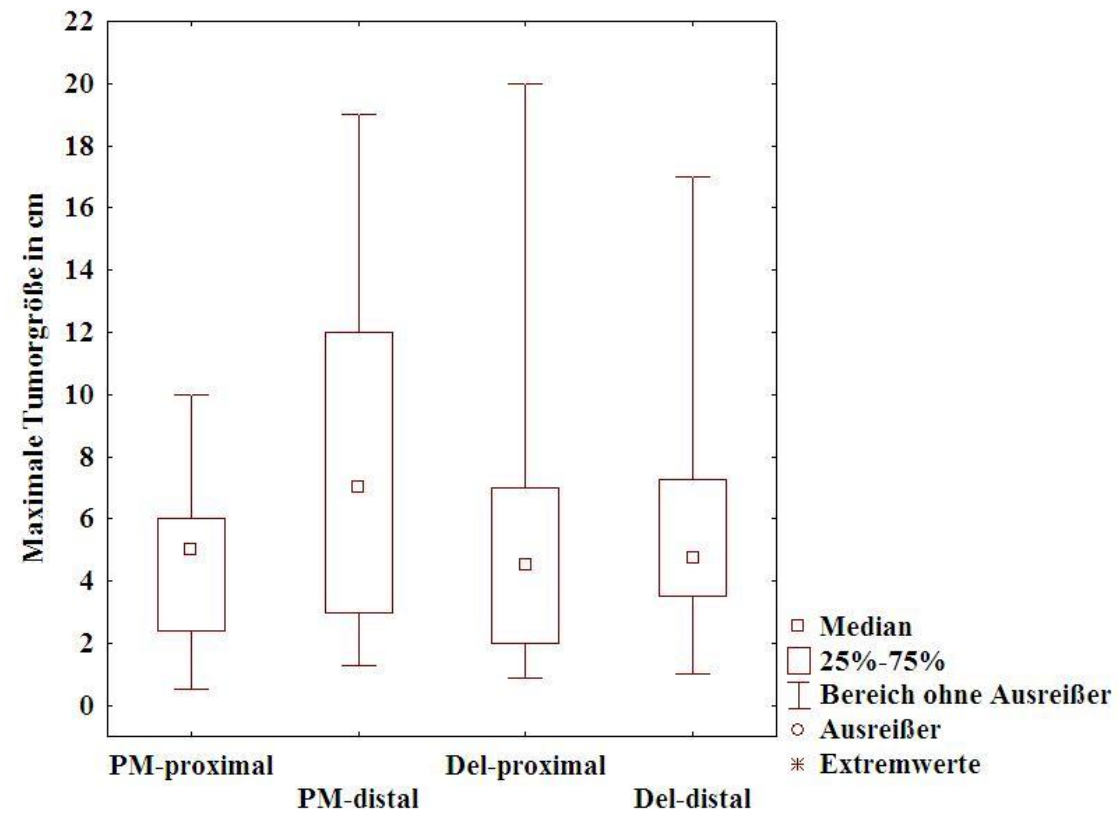

Abb. 3-10: Maximal Tumorgröße von 100 GIST nach Mutationstyp und Lokalisation

Proximal gelegene GIST mit einer Exon-11-Deletion unterschieden sich in ihrer Größe nicht signifikant von den proximal gelegenen GIST mit einer Exon-11-Punktmutation (t-test für unverbundene Stichproben: $\mathrm{p}=0,4)$. Distal gelegene GIST mit einer Exon-11-Deletion unterschieden sich in ihrer Größe ebenfalls nicht signifikant von den distalen GIST mit einer Exon-11-Punktmutation (t-test für unverbundene Stichproben: $\mathrm{p}=0,17$ ) (Tabelle 3-5 und Tabelle 3-6).

\subsubsection{Mitoserate}

Proximal gelegene GIST mit einer Exon-11-Punktmutation hatten im Mittel eine Mitoserate von 2,1 ( \pm 2,5) /50HPF, distal gelegene GIST mit einer Exon-11-Punktmutation eine Mitoserate von durchschnittlich 9,4 ( \pm 17,3) /50HPF (Abb. 3-11). Damit hatten bei den GIST mit einer Exon-11-Punktmutation die proximal gelegenen eine signifikant niedrigere Mitoserate als die distal gelegenen ( $t-$ Test für unverbundene Stichproben: $p=0,02$ ). Bei den GIST mit Exon-11-Deletionen hatten die proximal gelegenen GIST eine durchschnittliche Mitoserate von 8,5 $( \pm 15,1) / 50 \mathrm{HPFs}$, und die distal gelegenen GIST eine durchschnittliche Mitoserate von 18,7 ( \pm 36,2) /50HPFs, damit bestand kein statistisch signifikanter Unterschied ( $\mathrm{t}$-Test für unverbundene Stichproben: $\mathrm{p}=0,18$ ). Die proximal gelegenen GIST mit einer Exon-11-Punktmutation hatten im Mittel 2,1 $( \pm 2,5)$ Mitosen/50HPFs, während proximale GIST mit einer Exon-11-Deletion im Mittel 8,5 $( \pm 15,1)$ Mitosen/50HPF aufwiesen. Damit hatten proximal gelegene GIST mit einer Exon-11-Deletion eine signifikant höhere Mitoserate als proximale GIST mit einer Exon-11-Punktmutation (t-Test für unverbundene Stich- 
proben: $\mathrm{p}=0,02)$. Demgegenüber unterschieden sich distale GIST mit Exon-11Punktmutation oder Deletion nicht signifikant in ihrer Mitoserate (t-Test für unverbundene Stichproben: $\mathrm{p}=$ 0,2) (Tabelle 3-5 und Tabelle 3-6).

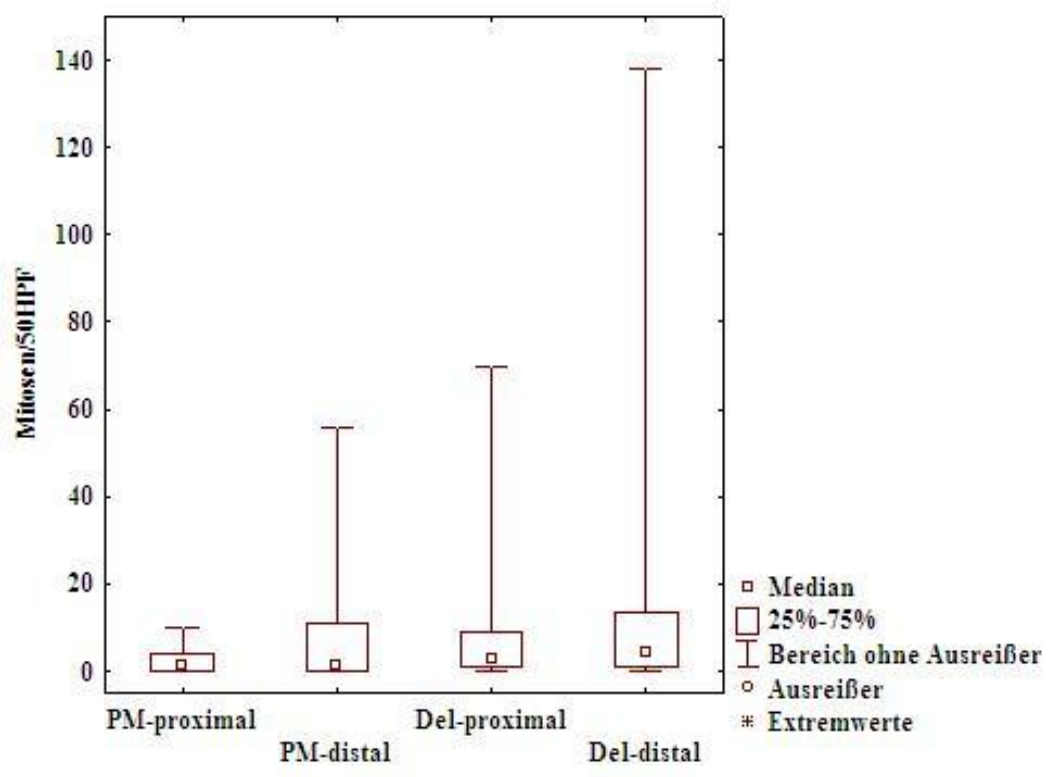

Abb. 3-11: Mitoserate /50HPF von 100 GIST nach Mutationstyp und Lokalisation

Tabelle 3-5: Tumorgröße und Mitoserate bei GIST mit Exon-11-Punktmutation und Deletion nach Lokalisation

\begin{tabular}{|ll|ll|}
\hline & & Punktmutation & Deletion \\
\hline Tumorgröße in cm & Proximal & $4,6(2,6)$ & $5,4(4,9)$ \\
& Distal & $7,9(5,6)$ & $5,7(3,7)$ \\
\hline Mitoserate/50HPF & Proximal & $2,1(2,5)$ & $8,5(15,1)$ \\
& Distal & $9,4(17,3)$ & $18,7(36,2)$ \\
\hline
\end{tabular}

Tabelle 3-6: Statistischer Vergleich von Tumorgröße und Mitoserate von GIST mit Exon-11Punktmutation und Deletion nach Lokalisation

\begin{tabular}{|l|ll|l|}
\hline \multicolumn{3}{|c|}{ t-test } \\
\hline Tumorgröße in cm & PM-Prox & PM-Dist & $\mathbf{p}=\mathbf{o , 0 0 6}$ \\
& Del-Prox & Del-Dist & $\mathrm{p}=0,8$ \\
& PM-Prox & Del-Prox & $\mathrm{p}=0,4$ \\
& PM-Dist & Del-Dist & $\mathrm{p}=0,2$ \\
\hline Mitoserate/50HPF & PM-Prox & PM-Dist & $\mathbf{p}=\mathbf{0 , 0 2}$ \\
& Del-Prox & Del-Dist & $\mathrm{p}=0,2$ \\
& PM-Prox & Del-Prox & $\mathbf{p}=\mathbf{0 , 0 2}$ \\
& PM-Dist & Del-Dist & $\mathrm{p}=0,03$ \\
\hline
\end{tabular}




\subsection{Ergebnisse der CGH}

Insgesamt kamen bei den 100 GIST 433 chromosomale Aberrationen vor, darunter 295 (69\%) Verluste und 138 (30\%) Zugewinne waren. In 2 Fällen lag eine Amplifikation vor, in einem Fall 2 Amplifikationen. Die Amplifikationen wurden zu den Zugewinnen gerechnet. Im Durchschnitt hatten die GIST 4,4 $( \pm 4,1)$ Aberrationen, davon im Durchschnitt $3( \pm 2,5)$ Verluste und 1,4 $( \pm 2,7)$ Zugewinne. Die meisten Verluste im Gesamtkollektiv fanden sich auf den Chromosomen 14q (77\%), 1p (43\%), 15q (33\%) und 22q (43\%). Der Verlust von $13 \mathrm{q}$ wurde in $8 \%$ gefunden. Die meisten Zugewinne wurden auf den Chromosomen $5 \mathrm{p}$ $(16 \%)$ und $5 q(13 \%)$, auf $8 p(8 \%)$ und $8 q(11 \%), 4 p(7 \%)$ und $4 q(8 \%)$, sowie auf $7 p(7 \%)$ und $7 \mathrm{q}(7 \%)$ gefunden.

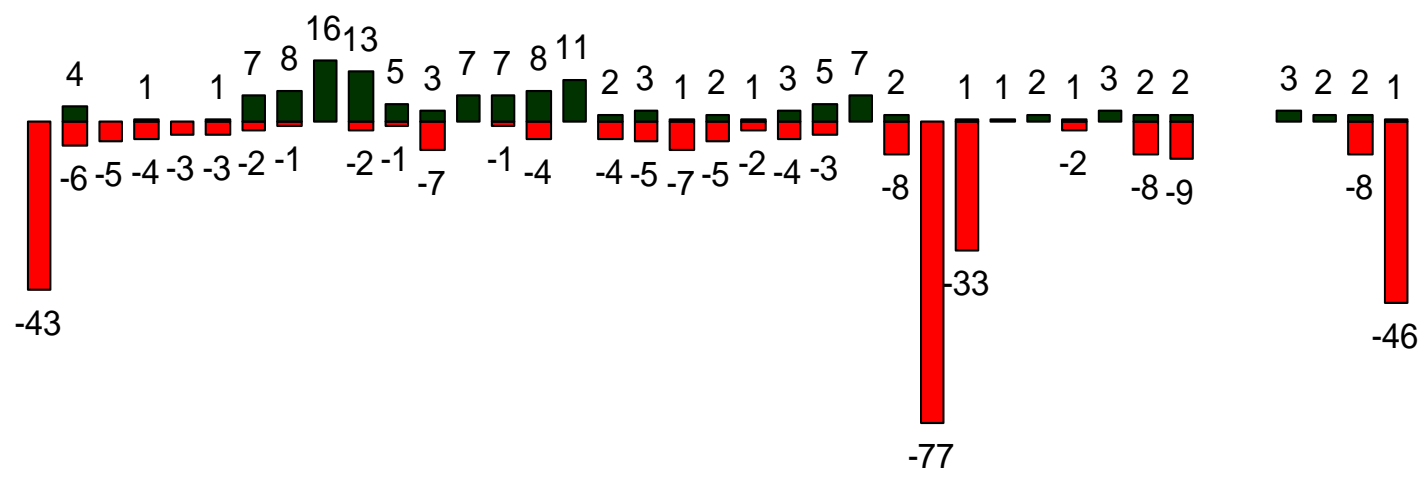

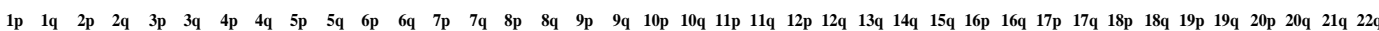

Abb. 3-12: Chromosomale Aberrationen von 100 GIST, Verluste wurden nach unten und Zugewinne nach oben dargestellt

\subsubsection{Vergleich der chromosomalen Aberrationen mit der Lokalisation}

Die 63 proximal lokalisierten GIST hatten insgesamt 216 Aberrationen und im Mittel 3,5 $( \pm 3,8)$ Aberrationen. Die 37 distal lokalisierten GIST hatten insgesamt 221 Aberrationen und im Mittel 5,9 $( \pm 4,3)$ Aberrationen. Proximale und distale GIST unterschieden sich somit signifikant in der Gesamtanzahl der chromosomalen Aberrationen (t-test für unverbundene Stichproben: $p=0,005)$. Auf dem Chromosom 14q ließ sich eine Tendenz für einen häufigeren Verlust bei den proximalen GIST erkennen, allerdings war der Unterschied statistisch nicht signifikant (Chi-Square: $\mathrm{p}=0,1$ ). Auf dem Chromosom 1p lag bei den proximalen GIST in 13 von 63 Fällen ein Verlust vor, bei den distal gelegenen Fällen in 30 von 37 Fällen. Distal gelegene GIST hatten damit signifikant häufiger einen Verlust von 1p als proximal gelegene GIST (Chi-Square: $\mathrm{p}=0,0001)$. Auf Chromosom 15q hatten distale GIST mit 
20 von 37 Fällen im Gegensatz zu proximal gelegenen GIST mit 13 von 63 Fällen signifikant häufiger einen Verlust (Chi-Square: $\mathrm{p}=0,0006$ ). Auf dem Chromosom 22q ließen sich keine signifikanten Unterschiede feststellen (Chi-Square: $\mathrm{p}=0,1)$.

Tab.3.5.1/1

Tabelle 3-7: Vergleich der Chromosomalen Aberrationen nach Lokalisation; Anzahl der Fälle in Klammern; statistischer Vergleich von Verlusten und Zugewinnen mit Chi-Square, von Aberrationen mit t-test für unverbundene Stichproben

\begin{tabular}{|l|llll|}
\hline Lokalisation & & Proximal (63) & Distal (37) & p-Wert \\
\hline Verluste & $14 \mathrm{q}$ & 46 & 21 & 0,1 \\
& $1 \mathrm{p}$ & 13 & 30 & 0,0001 \\
& $15 \mathrm{q}$ & 13 & 20 & 0,0006 \\
& $22 \mathrm{q}$ & 25 & 21 & 0,1 \\
\hline Zugewinne & $4 \mathrm{q}$ & 6 & 1 & 0,2 \\
& $8 \mathrm{p}$ & 5 & 3 & 0,98 \\
& $8 \mathrm{q}$ & 5 & 6 & 0,2 \\
\hline Gesamtaberrationen & & $3,5( \pm 3,8)$ & $5,9( \pm 4,3)$ & 0,005 \\
\hline
\end{tabular}




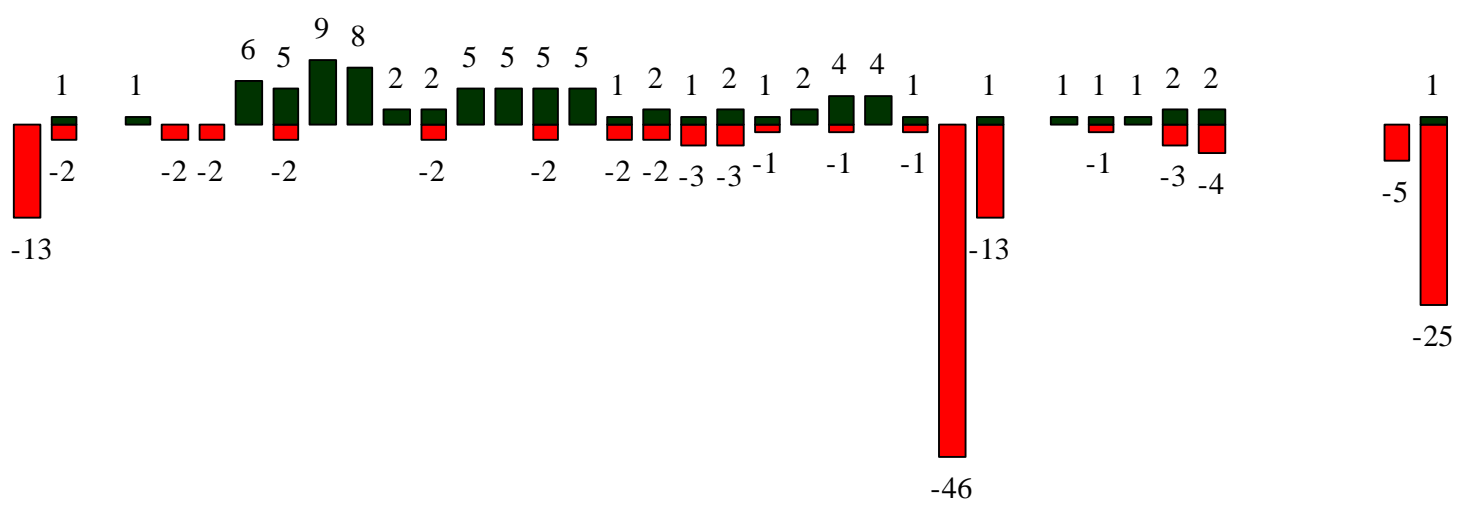

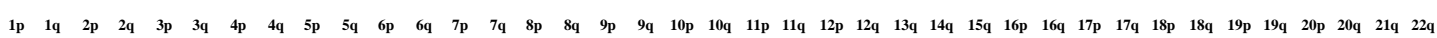

Abb. 3-13: Chromosomale Aberrationen bei 63 proximal gelegenen GIST

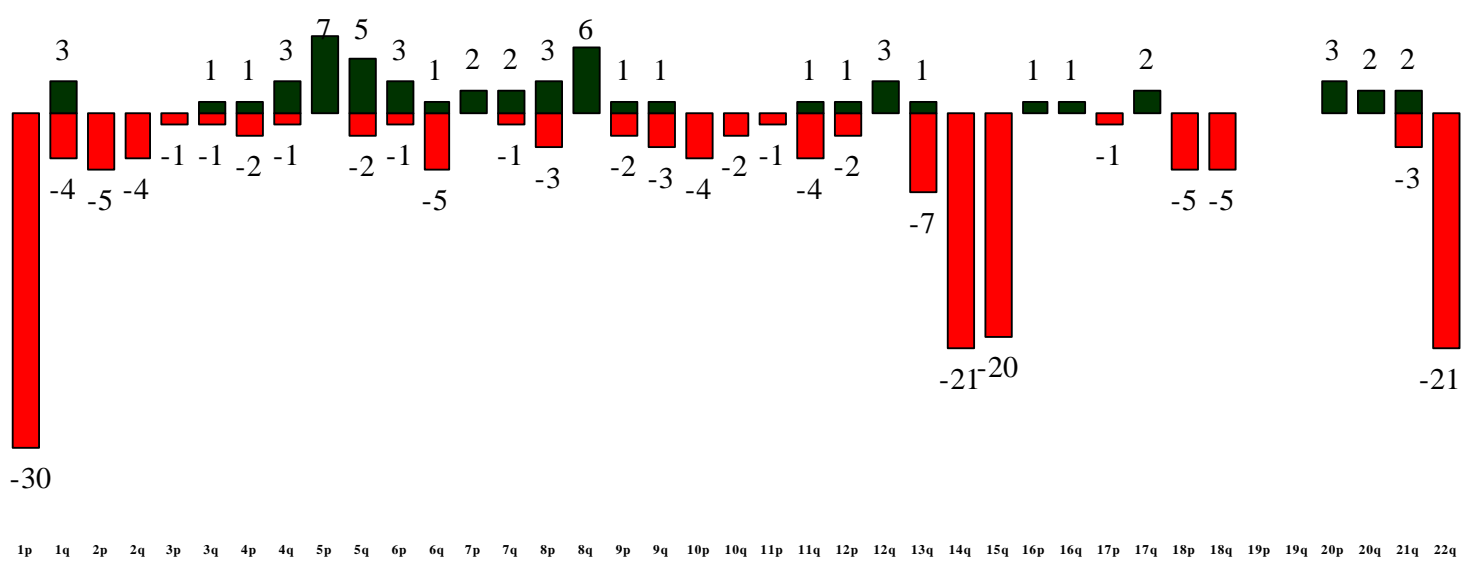

Abb. 3-14: Chromosomale Aberrationen bei 37 distal gelegenen GIST

\subsection{Vergleich der Ergebnisse der Mutationsanalyse und der CGH}

\subsubsection{Häufigkeit chromosomaler Aberrationen im Vergleich von GIST mit einer KIT-Exon-11-Punktmutation bzw. Deletion}

Die GIST mit einer Exon-11-Punktmutation hatten im Durchschnitt 4,3 ( $\pm 3,8)$ Aberrationen (Tabelle 3-8). Die GIST mit einer Exon-11-Deletion hatten im Durchschnitt 4,5 $( \pm 4,5)$ Abberationen. Es wurde kein signifikanter Unterschied in der Anzahl der Aberrationen zwischen GIST mit einer Exon-11-Punktmutation bzw. Deletion beobachtet (t-test für unverbundene Stichproben: $p=0,8)$. Im Vergleich der einzelnen Aberrationen lagen weder an 14q, 1p, 15q, noch an 22q signifikante Unterschiede in der Häufigkeit der Verlusten vor (Chi-Square: $\mathrm{p}=0,5 ; \mathrm{p}=0,6 ; \mathrm{p}=0,8 ; \mathrm{p}=0,4$ ). GIST mit einer Exon-11-Punktmutation hatten auf dem Chromosomenarm $4 q$ signifikant häufiger einen Zugewinn als GIST mit 
einer Exon-11-Deletion (Chi-Square: $\mathrm{p}=0,027)$ Zudem fanden sich signifikante Unterschiede in der Häufigkeit eines Zugewinns auf dem q-und dem p-Arm des Chromosoms 8. Auf beiden Armen hatten GIST mit einer Exon-11-Deletion signifikant häufiger einen Zugewinn als die GIST mit einer Exon-11-Punktmutation (Chi-Square: $\mathrm{p}=0,027 ; \mathrm{p}=0,023$ )

Tabelle 3-8: Vergleich chromosomaler Aberrationen zwischen Exon-11-Punktmutationen und Deletionen

\begin{tabular}{|l|llll|}
\hline Gesamt & & PM (50) & DEL (50) & p-Wert \\
\hline Verluste & $14 \mathrm{q}$ & 35 & 32 & 0,5 \\
& $1 \mathrm{p}$ & 20 & 23 & 0,6 \\
& $15 \mathrm{q}$ & 16 & 17 & 0,8 \\
& $22 \mathrm{q}$ & 21 & 25 & 0,4 \\
\hline Zugewinne & $4 \mathrm{q}$ & 7 & 1 & 0,03 \\
& $8 \mathrm{p}$ & 1 & 7 & 0,03 \\
& $8 \mathrm{q}$ & 2 & 9 & 0,02 \\
\hline Gesamtaberrationen & & $4,3( \pm 3,8)$ & $4,5( \pm 4,5)$ & 0,8 \\
\hline
\end{tabular}




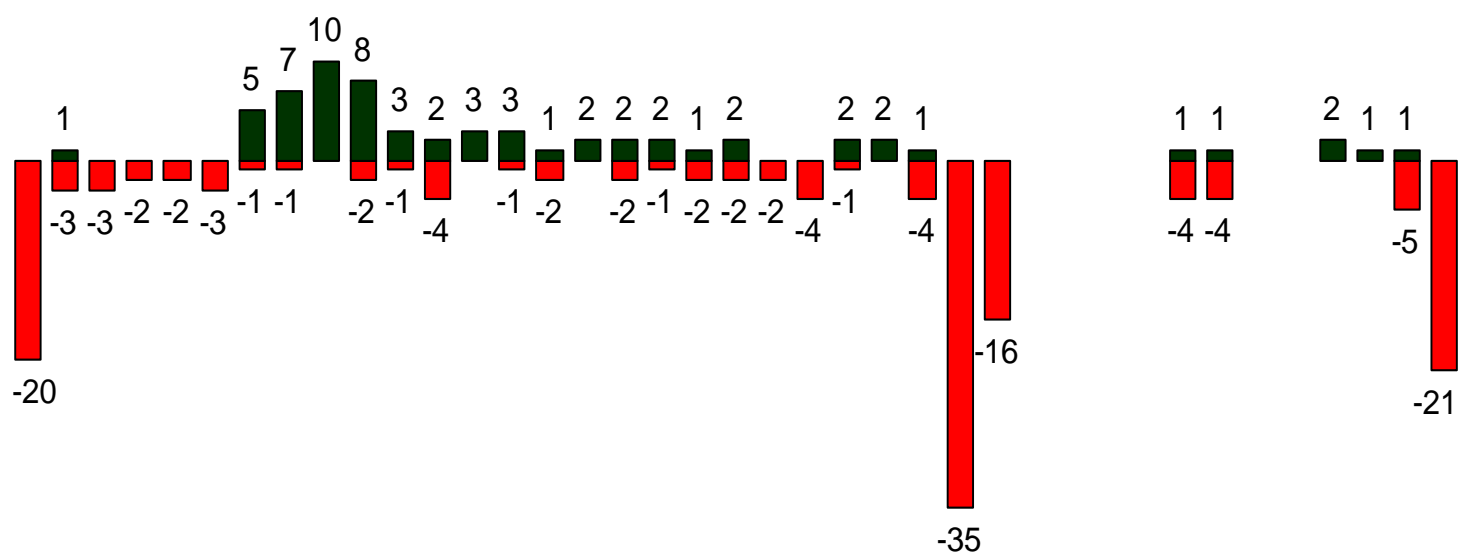

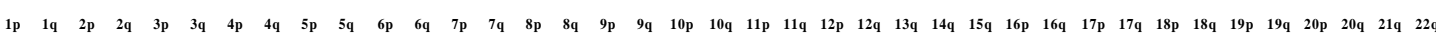

Abb. 3-15: Chromosomale Verluste und Zugewinne von 50 GIST mit einer Exon-11-Punktmutation

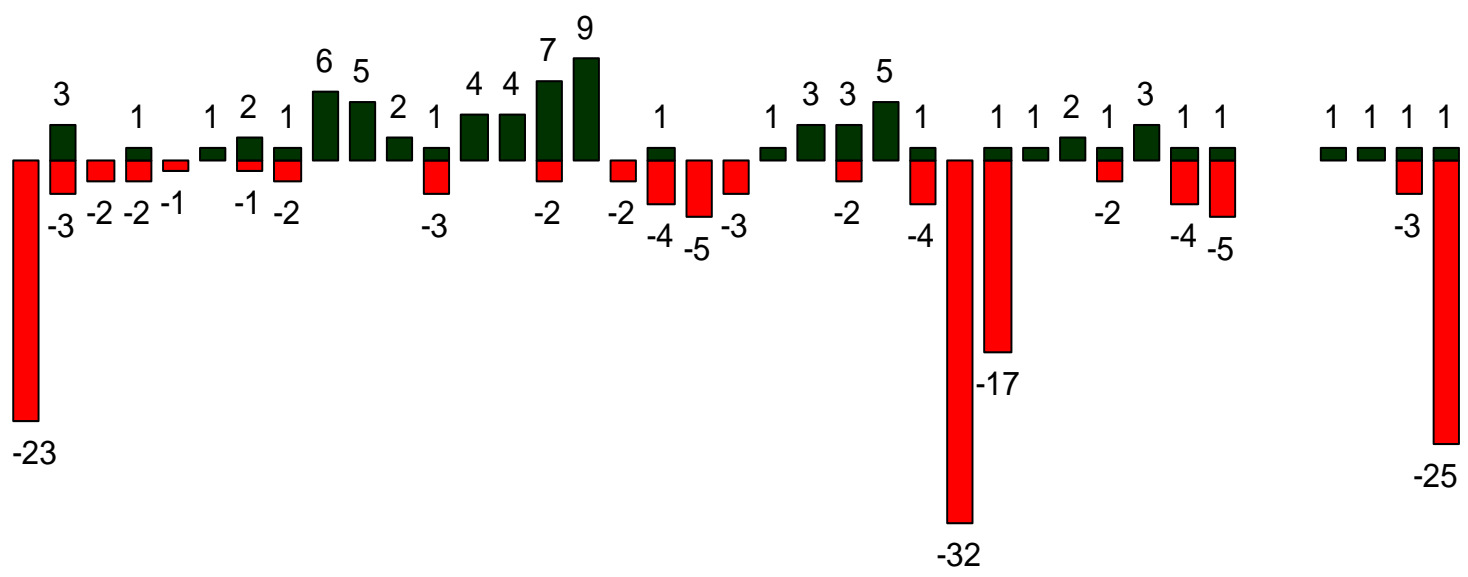

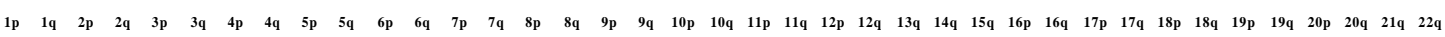

Abb. 3-16: Chromosomale Verluste und Zugewinne von 50 GIST mit einer Exon-11-Deletion

\subsubsection{Häufigkeit chromosomaler Aberrationen im Vergleich von GIST mit einer} KIT-Exon-11-Punktmutation bzw. Deletion unter Berücksichtigung der Tumorlokalisation

\section{GIST mit einer Exon-11-Punktmutation}

Vergleicht man die GIST mit einer Exon-11-Punktmutation hinsichtlich ihrer Lokalisation, so lagen proximal 3,3 $( \pm 3,4)$ Aberrationen und distal 6,2 ( \pm 4$)$ Aberrationen vor. Bei distalen GIST mit Exon-11-Punktmutation wurden signifikant mehr Aberrationen beobachtet als bei proximalen GIST (t-test für unverbundene Stichproben: $\mathrm{p}=0,008$ ). Vergleicht man die Verluste auf dem 1p Arm, so hatten proximal gelegene GIST in 5 von 30 Fällen einen Verlust. In distalen GIST mit Exon-11-Punktmutation hatten 15 von 17 Fällen einen Verlust. Damit wiesen distale GIST signifikant öfter einen Verlust im 1p Arm auf als proximal gelegene 
GIST (Chi-Square: $\mathrm{p}=0$,0001). Auf dem 15q Arm fanden sich proximal 6 Verluste und distal 10 Verluste, damit hatten distale GIST signifikant häufiger einen Verlust an 15q als proximal gelegene GIST (Chi-Square: $\mathrm{p}=0$,035). Auf den Chromosomenarmen 14q und 22q, sowie bei den Zugewinnen ließen sich keine signifikanten Unterschiede feststellen (ChiSquare: $\mathrm{p}=0,06 ; \mathrm{p}=0,3)$. In Chromosom 8q war bei distal gelegenen GIST mit Exon-11Punktmutationen signifikant häufiger ein Zugewinn zu beobachten als bei proximalen (ChiSquare: $\mathrm{p}=0,04)$. Bei den proximal oder distal gelegenen GIST mit Exon-11Punktmutationen war in $4 \mathrm{q}$ und $8 \mathrm{p}$ kein signifikanter Unterschied in der Häufigkeit eines Zugewinns festzustellen (Chi-Square: $\mathrm{p}=0,5 ; \mathrm{p}=0,2$ ).

Tabelle 3-9: Vergleich chromosomaler Aberrationen bei GIST mit einer Exon-11-Punktmutation, unterschieden nach der Lokalisation

\begin{tabular}{|l|llll|}
\hline PM & & Proximal (33) & Distal (17) & p-Wert \\
\hline Verluste & $14 \mathrm{q}$ & 26 & 9 & 0,06 \\
& $1 \mathrm{p}$ & 5 & 15 & 0,0001 \\
& $15 \mathrm{q}$ & 6 & 10 & 0,04 \\
& $22 \mathrm{q}$ & 12 & 9 & 0,3 \\
\hline Zugewinne & $4 \mathrm{q}$ & 4 & 1 & 0,5 \\
& $8 \mathrm{p}$ & 0 & 1 & 0,2 \\
& $8 \mathrm{q}$ & 0 & 2 & 0,04 \\
\hline Gesamtaberrationen & & $3,3( \pm 3,4)$ & $6,2( \pm 4)$ & 0,008 \\
\hline
\end{tabular}

GIST mit einer Exon-11-Deletion

Vergleicht man die GIST mit Exon-11-Deletion hinsichtlich ihrer Lokalisation, so fand man bei proximal gelegenem GIST im Durchschnitt 3,8 $( \pm 4,3)$ und distal 5,7 $(4,6 \pm)$ Aberrationen. Proximal oder distal gelegene GIST mit einer Exon-11-Deletion unterschieden sich damit nicht signifikant in der Anzahl der chromosomalen Aberrationen (t-test für unverbundene Stichproben: $\mathrm{p}=0,2)$. Auf dem 1p Arm lagen bei den proximalen GIST in 8 von 30 Fällen Verluste vor, bei den distalen GIST hingegen in 15 von 20 Fällen. Damit hatten distal gelegene GIST mit einer Exon-11-Deletion signifikant häufiger Verluste auf dem 1p Arm als proximal gelegene GIST (Chi-Square: $p=0,008$ ). Auf dem 15q Arm lag in 7 von 30 Fällen bei den proximalen, und in 10 von 20 bei den distalen ein Verlust vor. Damit hatten distal gelegene GIST mit einer Exon-11-Deletion häufiger Verluste auf dem 15q Arm als proximal gelegene GIST, allerdings war dieser Wert nicht signifikant (Chi-Square: $\mathrm{p}=0,051$ ). Auf den Chromosomenarmen 14q und 22q, sowie bei den Zugewinnen war kein signifikanter Unterschied festzustellen. (Chi-Square: $p=0,2 ; p=0,5 ; p=0,8$ ). 
Tabelle 3-10: Vergleich Chromosomaler Aberrationen bei GIST mit Exon-11-Deletionen nach der Lokalisation

\begin{tabular}{|l|llll|}
\hline DEL & & Proximal (30) & Distal (20) & p-Wert \\
\hline Verluste & $14 \mathrm{q}$ & 20 & 12 & 0,6 \\
& $1 \mathrm{p}$ & 8 & 15 & 0,008 \\
& $15 \mathrm{q}$ & 7 & 10 & 0,051 \\
& $22 \mathrm{q}$ & 13 & 12 & 0,3 \\
\hline Zugewinne & $4 \mathrm{q}$ & 2 & 0 & 0,2 \\
& $8 \mathrm{p}$ & 5 & 2 & 0,5 \\
& $8 \mathrm{q}$ & 5 & 4 & 0,8 \\
\hline Gesamtaberrationen & & $3,8( \pm 4,3)$ & $5,7(4,6 \pm)$ & 0,2 \\
\hline
\end{tabular}

\section{Proximale GIST}

Im Vergleich der GIST mit einer Exon-11-Punktmutation bzw. Deletion im Magen hatten GIST mit Exon-11-Punktmutation im Durchschnitt 3,3 $( \pm 3,4)$ Aberrationen, und GIST mit

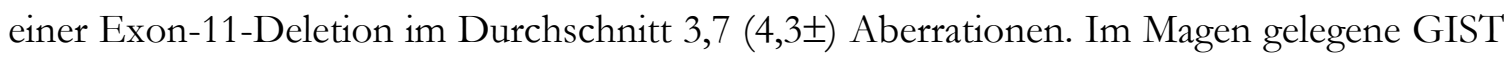
mit einer Exon-11-Punktmutation bzw. Deletion unterschieden sich damit nicht signifikant in der Anzahl der Aberrationen (t-test für unverbundene Stichproben: $\mathrm{p}=0,6$ ). Auf Chromosom 4q wurde bei den proximalen GIST mit einer Exon-11-Punktmutation signifikant häufiger ein Zugewinn verzeichnet als bei den proximalen GIST mit einer Exon-11-Deletion (Chi-Square: $p=0,0263$ ). Im Gegensatz dazu wurde bei den proximal gelegenem GIST mit einer Exon-11-Deletion signifikant häufiger ein Zugewinn auf Chromosom 8 verzeichnet als bei den proximal gelegenem GIST mit einer Exon-11-Punktmutation (Chi-Square: $\mathrm{p}$ $=0,0145)$. Bei den Chromosomenarmen 14q, 1p, 15q, und 22q gab es keine signifikanten Unterschiede (Chi-Square: $p=0,3 ; p=0,3 ; p=0,6 ; p=0,6$ ).

Tabelle 3-11: Vergleich Chromosomaler Aberrationen bei proximal gelegenen GIST mit Exon-11Punktmutation und Deletion

\begin{tabular}{|l|llll|}
\hline Proximal & & PM (33) & DEL (30) & p-Wert \\
\hline Verluste & $14 \mathrm{q}$ & 26 & 20 & 0,3 \\
& $1 \mathrm{p}$ & 5 & 8 & 0,3 \\
& $15 \mathrm{q}$ & 6 & 7 & 0,6 \\
& $22 \mathrm{q}$ & 12 & 13 & 0,6 \\
\hline Zugewinne & $4 \mathrm{q}$ & 5 & 0 & 0,0263 \\
& $8 \mathrm{p}$ & 0 & 5 & 0,0145 \\
& $8 \mathrm{q}$ & 0 & 5 & 0,0145 \\
\hline Gesamtaberrationen & & $3,3( \pm 3,4)$ & $3,7(4,3 \pm)$ & 0,6 \\
\hline
\end{tabular}




\section{Distale GIST}

Im Vergleich der distal gelegenen GIST mit Exon-11-Punktmutation bzw. Deletion hatten die Fälle mit einer Exon-11-Punktmutation im Durchschnitt 6,2 $( \pm 4)$ Aberrationen, und die Fälle mit einer Exon-11-Deletion im Durchschnitt 5,6 $( \pm 4,6)$ Aberrationen. Es lag somit kein signifikanter Unterschied in der Gesamthäufigkeit der Aberrationen vor (t-test für unverbundene Stichproben: $\mathrm{p}=0,7)$. Auch im Vergleich der einzelnen Aberrationen lag bei den distalen GIST kein signifikanter Unterschied zwischen GIST mit Exon-11Punktmutation und Exon-11-Deletion vor (Chi-Square: $p=0,7 ; p=0,3 ; p=0,6 ; p=0,7 ; p=$ $0,3 ; \mathrm{p}=0,7 ; \mathrm{p}=0,5)$.

Tabelle 3-12: Vergleich Chromosomaler Aberrationen bei distal gelegenen GIST mit Exon-11Punktmutation und Deletion

\begin{tabular}{|l|llll|}
\hline Distal & & PM $(17)$ & DEL (20) & p-Wert \\
\hline Verluste & $14 \mathrm{q}$ & 9 & 12 & 0,7 \\
& $1 \mathrm{p}$ & 15 & 15 & 0,3 \\
& $15 \mathrm{q}$ & 10 & 10 & 0,6 \\
& $22 \mathrm{q}$ & 9 & 12 & 0,7 \\
\hline Zugewinne & $4 \mathrm{q}$ & 1 & 0 & 0,3 \\
& $8 \mathrm{p}$ & 1 & 2 & 0,7 \\
& $8 \mathrm{q}$ & 2 & 4 & 0,5 \\
\hline Gesamtaberrationen & & $6,2( \pm 4)$ & $5,6( \pm 4,6)$ & 0,7 \\
\hline
\end{tabular}




\section{Diskussion}

\subsection{Kit-Exon-11-Mutationen}

\subsubsection{Kit-Exon-11-Punktmutationen}

Bei dem vorliegenden Kollektiv wurden Kit-Exon-11-Punktmutationen auf vier Codons gefunden. Am häufigsten war das Codon 559 mit 44\% der Fälle betroffen, darauf folgten Codon 560, 557 und 576 mit jeweils 25\%, 20\% und 10\%. Bei den untersuchten GIST mit Kit-Exon-11-Punktmutation fanden sich in 22\% die Mutationen Val559Asp, in 18\% die Mutation Val560Asp, in 14\% die Mutation Val559Gly, in 10\% die Mutation Val559Ala, in 8\% der Fälle die Mutation Trp557Arg und in 8\% die Mutation Leu576Pro. In 20\% wurden unterschiedliche Aminosäuren ausgetauscht, allerdings lagen diese Mutationen ebenfalls auf einem der vier Codons.

Auf Codon 557 und 559 wurde jeweils dreimal, auf 560 zweimal ein unterschiedlicher Aminosäureaustausch auf Proteinebene beobachtet. Auf Codon 576 fand immer die gleiche Mutation statt. In einem Fall gab es auf Codon 576 noch eine zusätzliche Mutation auf Codon 578 (p. [Leu576Pro (+) Tyr578Phe]). Ebenso wurde in einem der fünf GIST mit der Punktmutation p.Trp557Arg noch eine zusätzliche Punktmutation p.Glu562Lys gefunden.

Bei Lasota und Miettinen (2008) werden 198 Fälle mit Kit-Exon-11-Punktmutation beschrieben. Davon sind ausschließlich vier Codons betroffen. Am häufigsten ist das Codon 559 mit 44\% betroffen, gefolgt von Codon 560, 557 und 576 mit jeweils 27\%, 20\% und 9\%. Lasota erwähnt vereinzelt auch Mutationen, die nicht auf einem der vier Codons stattfinden, allerdings werden in dem dort beschriebenen Kollektiv keine derartigen Fälle erwähnt. Die häufigsten Punktmutationen auf diesen Codons sind Trp557Arg, Val559Asp, Val559Ala, Val559Gly, Val560Asp und Leu576 Pro. Die genaue Anzahl der einzelnen Punktmutationen werden nicht angegeben.

Die untersuchten Kollektive unterscheiden sich in ihrer Gesamtgröße, wobei das bei Lasota und Mietinnen (2008) beschriebene Kollektiv mit 198 Fällen fast viermal so groß ist wie das eigene mit insgesamt 50 Fällen. In beiden Kollektiven sind ausschließlich die vier erwähnten Codons von Kit-Exon-11-Punktmutatinoen betroffen. Trotz unterschiedlicher Fallzahl findet sich ein sehr ähnliches Verteilungsmuster. In beiden Kollektiven ist das Codon 559 mit 44\% das am häufigsten von Kit-Exon-11-Punktmutation betroffene Codon, gefolgt von Codon 560, 557 und 576. Ebenso werden die identischen Punktmutationen Trp557Arg, Val559Asp, Val559Ala, Val559Gly, Val560Asp und Leu576 Pro gefunden.

Bei GIST mit Exon-11-Punktmutationen kommen verschiedene Punktmutationen auf den vier Codons 557, 559560 und 576 vor. Grundsätzlich können die Punktmutationen in einer großen Heterogenität vorkommen, dennoch kommen einige Punktmutationen gehäuft 
vor. Im vorliegenden Kollektiv konnten sechs solcher Punktmutationen gefunden werden. Dieselben wurden bereits von Lasota und Miettinen (2008) in einer Studie als die häufig vorkommenden Punktmutationen beschrieben. Ebenso finden sich seltener vorkommende Mutationen. Es gibt Hinweise darauf, dass die unterschiedlichen Codons, sowie unterschiedliche Mutationen auf demselben Codon, eine unterschiedliche Prognose haben. Zudem werden seltene Mutationen mit schlechter Prognose beschrieben. Allerdings ist das biologische Potential solcher Mutationen bisher nicht bekannt (Lasota und Miettinen 2008).

\subsubsection{Kit-Exon-11-Deletionen}

Beim vorliegenden Kollektiv fanden sich auf Proteinebene bei 50 untersuchten GIST mit Kit-Exon-11-Deletion 64\% reine Deletionen und 36\% Deletion/Insertionen. Die Deletionen reichten vom Verlust eines einzelnen Codons bis zum Verlust von 9 Codons. Die KitExon-11-Deletion bei den untersuchten GIST variierten stark in der Länge und/oder in der genauen Lokalisation. Einzelne Deletionen wurden gehäuft beobachtet. Die am häufigsten gefunden Deletion war mit 14\% p.Trp557_Lys558, gefolgt von der Deletion p.Trp557_Glu561del, p.Val560del und p.Asp579del mit jeweils 8\%. Die übrigen 62\% der Deletionen wurden jeweils nur einmal im Kollektiv beobachtet. Trotz der großen Heterogenität traten die Deletionen vor allem im Abschnitt von Codon 550 bis 561 auf. Dort fanden insgesamt $81 \%$ aller Mutationen statt. Die Codons 557 und 558 waren mit $42 \%$ und $46 \%$ am häufigsten von unterschiedlichen Deletionen betroffen. In 38\% waren beide Codons betroffen.

Bei Lasota und Miettinen (2008) werden auf Proteinebene einfache Deletionen und Deletion/Insertionen beschrieben. In dem dortigen Kollektiv reichten die Deletionen vom Verlust eines einzelnen Codons bis zum Verlust von 10 Codons. Die beschriebenen Deletionen kamen in einer großen Heterogenität mit einer Bevorzugung des Bereiches von Codon 550 bis 561 vor. In diesem Bereich befanden sich 57\% der Mutationen.

p.Asp579del ist die häufigste beobachtete Deletion. Ebenso kommt die Deletion p.Trp557_Lys558 gehäuft vor (Lasota und Miettinen 2008). In verschiedenen anderen Studien über GIST mit Kit-Exon-11-Deletion wurde das vermehrte Vorkommen der Deletion p.Trp557_Lys558 beschrieben. Bei Martin et al. (2005) wurde ebenfalls die Deletion p.Trp557_Lys558 in 48\% der Fälle bei einer Kollektivgröße von 48 GIST mit Kit-Exon-11Deletion gefunden. Bei Andersson et al. (2006) bestand das Kollektiv aus 61 GIST mit KitExon-11-Deletion, wovon in 57\% Codon 557 und/oder Codon 558 betroffen war. In 46\% sind beide betroffen. Wardelmann et al. (2003) beschreiben bei einer Kollektivgröße von 35 GIST mit Kit-Exon-11-Deletion in 23\% die Deletion p.Trp557_Lys558.

Kit-Exon-11-Deletionen kommen in einer großen Heterogenität vor. Es gibt einzelne Mutationen, die unter anderem gehäuft beobachtet werden können. Am häufigsten in der Literatur ist die Deletion p.Trp557_Lys558 beschrieben. Im vorliegenden Kollektiv konnte 
diese Deletion ebenfalls am häufigsten beobachtet werden. Es gibt noch vereinzelt weitere Mutationen, die gehäuft beobachtet werden. Im vorliegenden Kollektiv waren dies die beiden Deletionen p.Trp557_Glu561del und p.Val560del.

GIST mit Exon-11-Deletion finden sich in einer großen Variabilität und über das gesamte Exon 11 hinweg. Jedoch treten Deletionen vor allem im Abschnitte von Codon 550 bis Codon 561 auf. Einzelne Deletionen kommen gehäuft vor, insbesondere die Deletion p.Trp557_Lys558 wurde in mehreren Studien vermehrt beobachtet. Die Involvierung der Codons 557 und 558 ist mit einer schlechteren Prognose assoziiert (Wardelmann et al. 2003). Codon 557 und/oder 558 sind in der vorliegenden Dissertation in einem Großteil der Deletionen involviert.

\subsection{Korrelation zwischen GIST mit Exon-11-Punktmutation und Deletion und klinisch-pathologischen Parametern}

Für die Prognosabschätzung von GIST werden nach Fletcher CD et al. (2002) die Mitoseanzahl und die Tumorgröße angegeben. Miettinen und Lasota (2006) ziehen zudem noch die Lokalisation im Magen-Darm-Trakt zur Risikoabschätzung hinzu. Für das in dieser Arbeit untersuchte Tumorkollektiv wurde überprüft, ob und inwiefern sich Exon-11Punktmutationen und Deletionen in den klinisch-pathologischen Parametern Mitoseanzahl auf 50 High-Power-Fields (HPFs) und Tumorgröße (Maximaler Durchmesser in $\mathrm{cm}$ ) unterscheiden. Die Risikoklassifizierung fand unter der Berücksichtigung der Lokalisation gemäß Miettinen und Lasota (2006) statt. DeMatteo et al. (2008) konnten in einer Studie die einzelne unabhängige, prognostische Bedeutung von Mitoserate, Größe und Mutationsart in GIST zeigen.

Im vorliegenden Kollektiv waren distal gelegene GIST größer und hatten mehr Mitosen als proximal gelegene GIST und waren nach der Risikoklassifikation mit einem signifikant höheren Risiko der Malignität behaftet. In mehreren Studien konnte gezeigt werden, dass distale GIST größer sind und eine höhere Mitosezahl aufweisen. Die Prognose ist dementsprechend schlechter als bei proximalen GIST ( Singer et al. 2002, Miettinen et al. 2005, Lasota und Miettinen 2008). Wahrscheinlich lässt sich im Hinblick auf die Lokalisation eine Aussage über das klinische Verhalten von GIST mit Exon-11-Mutation treffen. Distale GIST haben durchschnittlich eine höhere Mitoserate und sind tendenziell größer als proximal gelegene GIST. Distal gelegene GIST haben eine signifikant schlechtere Prognose.

Im vorliegenden Kollektiv hatten GIST mit Exon-11-Deletion eine signifikant höhere Mitoserate als GIST mit Exon-11-Punktmutation, allerdings konnte kein Unterschied zwischen beiden Mutationsarten in der maximalen Tumorgröße festgestellt werden. Bei Andersson et al. (2006) waren GIST mit Exon-11-Deletion größer und hatten eine höhere Mitoserate als GIST mit einer Exon-11-Punktmutation. Singer et al. (2002) berichten ebenfalls über eine 
im Vergleich zu GIST mit Exon-11-Punktmutationen höhere Mitoserate bei GIST mit Exon-11-Deletionen und eine kürzere rezidivfreie Überlebenszeit nach Resektion. In mehreren Studien wurde ein prognostisch ungünstigerer klinischer Verlauf von GIST mit Exon11-Deletion festgestellt (Wardelmann et al. 2003, Martin et al. 2005, Andersson et al. 2006). DeMatteo et al. (2008) konnten zeigen, dass GIST mit Exon-11-Deletion eine höhere Mitoserate als solche mit Punktmutation hatten und eine kürzere rezidivfreie Überlebenszeit. GIST mit Exon-11-Deletionen sind mit einer höheren Mitoserate und einer schlechteren Prognose assoziiert. Im vorliegenden Kollektiv konnte eine höhere Mitoserate nachgewiesen werden. Nach der Risikoabschätzung hatten die GIST mit Exon-11-Deletion zwar tendenziell eine schlechtere Prognose, allerdings war dieser Unterschied nicht signifikant, da die beiden Gruppen sich nicht deutlich in der Maximalgröße unterschieden.

Bei der Gruppe der GIST mit Exon-11-Punktmutationen waren distale GIST größer als proximale. Ebenso wurde bei den distalen GIST eine höhere Mitoserate festgestellt. Bei der Gruppe der GIST mit Exon-11-Deletionen konnte zwischen proximal und distal weder in der Tumorgröße noch in der Mitoserate ein Unterschied gefunden werden. Bei GIST mit Exon-11-Punktmutation hatten die proximalen GIST auch ein signifikant niedrigeres Risiko als die distal gelegenen. Bei den GIST mit Exon-11-Deletionen lag die gleiche Tendenz vor, allerdings keine Signifikanz. Die Ergebnisse des vorliegenden Kollektivs liefern Hinweise, dass bei GIST mit Exon-11-Punktmutation die Lokalisation einen Einfluss auf die Prognose hat. Bei GIST mit Exon-11-Deletionen scheint die Lokalisation weniger Aussagekraft zu haben.

Weiter wurden die proximalen GIST mit Exon-11-Punktmutation und Deletion miteinander verglichen. Hier stellte sich heraus, dass GIST mit Exon-11-Deletionen signifikant größer waren und eine signifikant höhere Mitoserate und damit auch eine schlechtere Prognose hatten. Beim Vergleich der distalen GIST nach Mutation konnte kein Unterschied in der Prognose festgestellt werden. Dies lag unter anderem daran, dass die distalen GIST mit Exon-11-Punktmutation im Durchschnitt größer waren als die GIST mit Exon-11-Deletion. Lasota und Miettinen (2008) beschreiben ebenfalls eine bessere Prognose für proximal gelegenen GIST mit Exon-11-Punktmutation im Gegensatz zu den Deletionen. Diese Beobachtung lässt sich ebenso wenig wie beim eigenen Kollektiv auf distalen GIST übertragen. Im vorliegenden Kollektiv konnte festgestellt werden, dass bei proximalen GIST die Mutation einen Einfluss auf die Prognose hat. Bei distalen GIST scheint die Mutation weniger Aussagekraft zu haben. 


\subsection{Beobachtete chromosomale Aberrationen bei den unter- suchten GIST}

Im vorliegenden Kollektiv fanden sich in $90 \%$ der Fälle chromosomale Aberrationen. Die häufigste Aberration war der Verlust von 14q und wurde bei $67 \%$ der Fälle gefunden, gefolgt von 22q, 1p und 15q mit jeweils 46\%, 43\% und 23\%. Der Verlust von 13q wurde in $8 \%$ der Fälle beobachtet. Zugewinne wurden speziell auf Chromosom 8p, 8q und $4 \mathrm{q}$ mit jeweils $8 \%, 11 \%$ und $8 \%$ beobachtet und ausgewertet.

In einer Studie von Wozniak et al. (2007) sind die Häufigkeiten von Verlust von 14q mit 73\%, 1p mit 62\%, 15q mit 38\% und 22q mit 59\% angegeben. El-Rifai et al. (2000) und Gunawan et al (2007) beschreiben ähnliche Häufigkeiten. In weiteren Studien wird der Verlust von $14 \mathrm{q}$ als häufigste Aberration unabhängig von der Malignität der GIST angegeben (El- Rifai et al. 1996, Sarlomo-Rikala et al. 1998, Heinrich et al. 2002, Meza-Zapeda et al. 2006, Ässämäki et al. 2007, Gunawan et al. 2007, Wozniak et al. 2007).

GIST ist stark mit den Aberrationen auf den Chromosomen 14q, 22q, 1p und 15q assoziiert. Im vorliegenden Kollektiv wurden nur GIST mit Exon-11-Punktmutation und Deletion ins Kollektiv mit einbezogen. Dennoch sind die Häufigkeiten der einzelnen Aberrationen mit anderen Studien vergleichbar. Entsprechend lässt sich die Assoziation zwischen GIST und dem Verlust von 14q, 22q, 1p, und 15q im vorliegenden Kollektiv bestehend aus GIST mit Exon-11-Punktmutation und Deletion nachvollziehen.

Wozniak et al. (2007) berichten zusätzlich über einen Verlust von 13q in einem Drittel der untersuchten Fälle. Im vorliegenden Kollektiv war diese Aberration mit 8\% ein selteneres Ereignis. Wozniak et al. (2007) beziehen allerdings neben GIST mit Exon-11-Mutationen noch andere GIST Mutationen ins Kollektiv mit ein. GIST mit entweder Exon-11Punktmutation oder Deletion ist wahrscheinlich nicht mit dem Verlust von 13q assoziiert.

\subsection{Korrelation zwischen proximal und distal gelegenen GIST hinsichtlich der Aberrationen}

Im vorliegenden Kollektiv hatten distal lokalisierte GIST signifikant mehr Aberrationen als proximale. Der Verlust von 14q und 22q kam im untersuchten Kollektiv an keiner Lokalisation signifikant gehäuft vor. Im vorliegenden Kollektiv konnte allerdings der vermehrte Verlust von 1q und 15q bei distalen GIST beobachtet werden. Bei den Zugewinnen wurden keine Unterschiede beobachtet.

El-Rifai et al. (2000) und Wozniak et al. (2007) berichten über keine Korrelation zwischen der Anzahl der Aberrationen und der Lokalisation. Bei diesen Studien wurden auch GIST mit PDGFRA Mutationen mit einbezogen. Wozniak et al. (2007) verglichen zudem GIST 
mit c-KIT-Mutationen und fanden im Durchschnitt eine höhere Anzahl von Aberrationen bei distalen GIST.

Wozniak et al. (2007) führten eine Studie an 66 GIST durch. 18 dieser GIST enthielten eine PDGFRA-Mutation. Dort kamen Chromosomenaberrationen in einem lokalisationsabhängigen Muster vor. So kommen bei GIST mit c-KIT-Mutation 14q Verluste signifikant häufiger proximal und $1 \mathrm{p}$ Verlust häufiger distal vor. $14 \mathrm{q}$ Verlust wurden in 73\% der GIST gefunden. Auch unter Ausschluss von GIST mit PDGFRA-Mutationen wurde proximal signifikant häufiger ein 14q Verlust beobachtet. Dabei hatten $87 \%$ der proximalen GIST mit KIT Mutation einen 14q Verlust, gegenüber 48\% der distalen GIST. Gunawan et al. (2004) fanden bei 55 GIST mit c-KIT-Mutation ebenfalls signifikant häufiger einen Verlust von $14 \mathrm{q}$ in proximalen GIST.

Ebenso wurde bei Wozniak et al. (2007) unter Ausschluss von GIST mit PDGFRAMutation der Verlust von 1q signifikant häufiger in distalen GIST beobachtet. Der Verlust von 22q wurde dort weder bei proximal noch bei distal gelegenen GIST vermehrt gefunden. Gunawan et al. (2004) fanden einen vermehrten Verlust von 22q in distalen GIST.

Verlust von $15 \mathrm{q}$ bei GIST mit KIT Mutation kam signifikant häufiger bei distalen als bei proximalen GIST vor und wurde insgesamt häufiger bei malignen GIST gefunden (Wozniak et al. 2007).

Distale GIST sind mit einem Verlust von 1p und 15q assoziiert, wobei beide Verluste meistens in Kombination auftreten. Der Verlust von $1 \mathrm{p} / 15 \mathrm{q}$ ist mit einer schlechten Prognose assoziiert (Wozniak et al. 2007). Wozniak et al. (2007) fanden Hinweise, dass der Verlust von 14q spät in der Entstehung von distalen GIST auftritt. Dabei wird der späte Verlust auf das akkumulierte Auftreten von 1p/15q und anderen Verluste bei distalen GIST zurückgeführt. Die vermehrte Akkumulation von frühzeitigen Chromosomenverlusten spielt wahrscheinlich eine Rolle für die Tumorgenese im frühen Stadium und trägt zu der schnelleren Progression und der schlechteren Prognose von distal gelegenen GIST bei (Wozniak et al. 2007).

Der nicht vorhandene Unterschied in der Häufigkeit von 14q Verlust kann dadurch erklärt werden, dass im vorliegenden Kollektiv nur GIST mit Exon-11-Punktmutation und Deletion mit einbezogen wurden. Hier gab es nach den vorliegenden Ergebnissen keinen Unterschied, obwohl in mehreren Studien berichtet wird, dass ein 14q Verlust häufiger in proximalen GIST gefunden wird. Der Großteil der GIST mit PDGFRA Mutationen liegt proximal und es liegen Hinweise vor, dass der 14q Verlust mit GIST mit PDGRFAMutationen assoziiert ist (Gunawan et al. 2004, Gunawan et al. 2007). Dies könnte den häufigeren Verlust von 14q bei proximalen GIST aus anderen Studien erklären, wo nicht nach Mutation unterschieden wird. In dem Kollektiv von Wozniak et al. (2007) wurde allerdings kein Unterschied zwischen GIST mit PDGFRA und KIT und dem Verlust von 14q gefunden. 
Die Beobachtung von Gunawan et al. (2004), die den Verlust von 22q häufiger bei distalen GIST beschreiben, steht den am vorliegenden Kollektiv beobachteten Ergebnissen entgegen, da der Verlust von 22q weder distal noch proximal signifikant häufiger aufgetreten ist.

\subsection{Korrelation zwischen Mutationstyp und Aberrationen}

Das vorgestellte Kollektiv wurde auf einen eventuellen Zusammenhang zwischen der Gesamtzahl der Aberrationen, einem vermehrten Zugewinn/Verlustes eines speziellen Chromosoms von GIST mit Exon-11-Punktmutation im Gegensatz zu GIST mit Exon-11Deletion untersucht. Diesbezüglich sollte folgendes untersucht werden:

1) Haben GIST mit Kit-Exon-11-Deletion generell mehr Aberrationen?

2) Werden unterschiedliche genetische Wege beschritten?

3) Unterscheiden sich einzelne Aberrationen in ihrer Anzahl?

Im vorliegenden Kollektiv unterschieden sich GIST mit Exon-11-Punktmutation und Deletion nicht in der Anzahl der Gesamtaberrationen.

Es wurde weder auf einem der häufig betroffenen Chromosomen 14q, 1p, 15q oder 22q noch auf einem anderen Chromosom ein signifikanter Unterschied in der Anzahl der Verluste beobachtet.

Unterschiede bei den Zugewinnen konnten auf zwei Chromosomen beobachtet werden. So hatten GIST mit Exon-11-Deletion signifikant mehr Hinzugewinne auf Chromosom 8, während GIST mit Exon-11-Punktmutation signifikant mehr Zugewinne auf Chromosom $4 \mathrm{q}$ verzeichneten.

In der Literatur wird die Assoziation von der Gesamtzahl von Chromosomenaberrationen mit dem klinischen Verlauf beschrieben. So haben GIST mit einer höheren Anzahl chromosomaler Aberrationen einen ungünstigeren klinischen Verlauf. Mehrere Autoren beschreiben in verschiedenen Studien die Assoziationen einzelner Chromosomenaberrationen mit einem ungünstigen klinischen Verlauf. So wird unter anderem der Verlust von 22q und 9p sowie der Zugewinn von 8q mit einem maligneren klinischen Verlauf beschrieben. Verschiedene Onkogene sind auf Chromosom 22q und 8q bereits beschrieben, weitere sind noch zu identifizieren (El-Rifai et al. 2000, Gunawan et al. 2007).

Der für GIST typische KIT-Rezeptor (CD117) ist auf dem Chromosom 4q lokalisiert. Tabone et al. (2005) stellen die Amplifizierung speziell des c-KIT-Genes bei chromosomalen Aberrationen von GIST in Frage. Es handelt sich bei dem vermehrten Zugewinn wohl eher um eine unspezifische Amplifizierung, wobei keine direkte Assoziation zwischen dem c-KIT-Gen und der Amplifizierung von 4q besteht (El-Rifai et al. 2000, Tabone et al. 2005). 
Am vorliegenden Kollektiv konnte kein Zusammenhang zwischen der Prognose und der Anzahl der Gesamtaberrationen festgestellt werden, da GIST mit Exon-11-Punktmutation und Deletion sich nicht in der Gesamtzahl der Aberrationen unterschieden. Weiter konnte kein Zusammenhang zwischen der höheren Malignität von GIST mit Exon-11-Deletion und dem Verlust von 22q und 9q erkannt werden. Der Verlust von 22q kam in beiden Gruppen ähnlich oft vor. Der Verlust von 9p wurde in nur 4 Fällen beobachtet. Hier reichte die Anzahl für eine statistische Aussage nicht aus.

In der Literatur werden Aberrationen auf Chromosom $4 q$ als seltene Ereignisse beschrieben (El-Rifai et al. 2000). Eine mögliche Erklärung dafür könnte sein, dass der Verlust eines Allels durch Duplikation des mutierten Allels maskiert wird. Ein solches molekulares Ereignis kann von der CGH nicht erfasst werden (Lasota et al. 2007).

Der Zugewinn von Chromosom 8 ist mit einem malignen klinischen Verlauf assoziiert (El-Rifai et al. 2000). Im vorliegenden Kollektiv hatte GIST mit Exon-11-Deletion signifikant mehr Zugewinne auf Chromosom 8. Der Zugewinn von 8q tritt vermehrt in primär malignen oder metastatischen GIST auf, und steht bereits in anderen Tumorentitäten für eine ungünstige Prognose (El-Rifai et al. 2000). Unter anderem korreliert der Zugewinn mit der Rezidivrate bei Brustkrebspatienten (Isola et al. 1995). Als bereits bekanntes Protoonkogen auf Chromosom 8 ist c-MYC identifiziert. Wahrscheinlich spielen noch andere Gene bei dem Zugewinn von Chromosom 8 bei der Tumorgenese von GIST eine Rolle. Der vermehrte Zugwinn von Chromosom 8 bei GIST mit Exon-11-Deletion im vorliegenden Kollektiv könnte Hinweise auf die Bedeutung für die Prognose geben.

Auffällig war im untersuchten Kollektiv speziell der Zugewinn auf Chromosom 4q. Der Zugewinn traf signifikant häufiger bei GIST mit Exon-11-Punktmutation auf. Tabone et al. (2005) postulieren, dass es sich bei diesem Zugewinn um einen unspezifischen Zugewinn handele, und nicht um den Zugewinn des KIT Gens, welches auf dem Chromosom 4q lokalisiert ist. Lasota et al. (2007) konnten durch spezifische Methoden zeigen, dass mehr Ereignisse auf Chromosom 4q auftreten, als von der CGH erfasst werde. Im vorliegenden Kollektiv konnte die CGH dennoch einen vermehrten Zugewinn auf Chromosom 4q bei GIST mit Exon-11-Punktmutation zeigen. Dies könnte von Bedeutung für die Tumorgenese bei GIST mit Exon-11-Punktmutation sein. In diesem Punkt stehen die vorliegenden Ergebnisse denen von Tabone et al. (2005) entgegen. 


\subsection{Korrelation zwischen Punktmutation/Deletion und chro- mosomalen Aberrationen unter besonderer Berücksichtigung der Lokalisation}

Unter Einbezug der Lokalisation, fanden sich bei den Fällen mit Exon-11-Punktmutation signifikant mehr Aberrationen im distalen als im proximalen Bereich. GIST mit Exon-11Punktmutation hatte distal mehr Verluste auf Chromosom 1p und 15q. Bei 14q und 22q ließ sich dieser Unterschied nicht beobachten. Bei den Zugewinnen auf 4q war keine Bevorzugung der Lokalisation zu beobachten. Zugewinn auf 8q kam häufiger in distalen GIST vor.

Bei den GIST mit Exon-11-Deletionen unterschieden sich proximale und distale GIST nicht in der Anzahl der Gesamtaberrationen. Im vorliegenden Kollektiv fanden sich bei distalen GIST mit Exon-11-Deletion signifikant mehr Verluste von Chromosom 1p als bei den proximal gelegenen GIST. Bei den GIST mit Deletion fand sich die Tendenz, dass 15q auch hier vermehrt in distalen GIST vorkommt. Es wurde kein Unterschied bei GIST bei $14 q$ oder 22q gefunden. Bei den Zugewinnen gab es ebenfalls keinen Unterschied zwischen proximal und distal.

Wozniak et al. (2007) verglichen GIST mit c-KIT-Mutationen und fand im Durchschnitt eine höhere Anzahl von Aberrationen bei distalen GIST. Zudem ist die Anzahl chromosomaler Aberrationen mit einer schlechteren Prognose assoziiert. Signifikante Unterschiede in der Anzahl der Aberrationen konnten beim vorliegenden Kollektiv nur bei GIST mit Exon11-Punktmutation gefunden werden. Dort fanden sich distal signifikant mehr chromosomale Aberrationen als proximal. Dies könnte ein Hinweis darauf geben, dass bei distalen GIST mit Exon-11-Punktmutation andere genetische Wege beschritten werden, die im Zusammenhang mit der schlechteren Prognose von distalen im Gegensatz zu proximalen GIST mit Exon-11-Punktmutation stehen könnten.

Bei den untersuchten GIST mit Exon-11-Deletion gab es proximal und distal keinen Unterschied in der Anzahl der Gesamtaberrationen. Bei GIST mit Exon-11-Punktmutation scheint die Lokalisation einen stärkeren Einfluss auf die Anzahl der chromosomalen Aberrationen zu haben, als bei GIST mit Exon-11-Deletion. Dort scheint die Mutation an sich einen größeren Einfluss auf die Anzahl chromosomaler Aberrationen zu spielen, als die Lokalisation.

Der häufigere Verlust von 1p/15q in distalen GIST lässt sich auf beide MutationsGruppen übertragen. Der Verlust von 1p/15 scheint stärker mit der Lokalisation assoziiert zu sein als mit dem Mutationstyp von GIST, denn unabhängig von der Mutation findet sich im distalen GIST der gehäufte Verlust von 1p/15q. Ebenso fanden sich keine signifikanten Unterschiede beider Gruppen nach Lokalisation auf Chromosom 14q und 22q. 
Bei GIST mit Exon-11-Punktmutation fanden sich insgesamt drei Zugewinne auf Chromosom 8. Diese fanden sich ausschließlich im distalen Bereich. Auf Chromosom 8q war der Unterschied signifikant. Generell ist der Zugewinn auf Chromosom 8 mit einer schlechteren Prognose assoziiert (Isola et al. 1995, El-Rifai et al. 2000). Dies scheint bei GIST mit Exon11-Punktmutation eine Rolle beim Risikounterschied zwischen proximal und distal zu spielen. Hier könnte der Zugewinn einen Einfluss auf die schlechtere Prognose von distalen GIST mit Exon-11-Punktmutation haben. Bei GIST mit Exon-11-Deletion trat der Zugewinn auf Chromosom 8 zwar insgesamt häufiger auf, als bei der Gruppe der GIST mit Exon-11-Punktmutation, dies aber ohne Zusammenhang mit der Lokalisation. Hier liegt ein weiterer Hinweis vor, dass bei GIST mit Exon-11-Deletion die Mutation an sich wichtiger für die Prognose ist, als die Lokalisation. Zugewinne auf Chromosom 4q zeigten bei den GIST mit Exon-11-Punktmutationen keine Bevorzugung einer Lokalisation. 


\section{Zusammenfassung}

In der vorliegenden Arbeit wurde bei 100 primären GIST mittels Mutationsanalyse KITExon-11-Punktmutationen und Deletionen identifiziert. Im Weiteren wurde dies mittels CGH auf chromosomale Aberrationen untersucht. Insgesamt wurden 50 GIST mit Exon11-Punktmutation und 50 GIST mit Exon-11-Deletion verglichen. Hauptuntersuchung der vorliegenden Arbeit war der gezielte Vergleich zwischen GIST mit Exon-11-Punktmutation und Deletion, wobei diese unter Einbezug der Lokalisation nach den klinischpathologischen Parametern Mitoserate, Tumorgröße, Risikoklassifikation nach Miettinen und Lasota (2006) und chromosomalen Aberrationen miteinander verglichen wurden.

Zunächst unterscheiden sich GIST mit Exon-11-Punktmutation und Deletion nicht in ihrem Risiko per se. Unterschiede fanden sich jedoch unter Berücksichtigung der Lokalisation. Dabei hatten GIST im proximalen Bereich mit Exon-11-Deletion eine signifikant schlechtere Prognose als GIST mit Exon-11-Punktmutation. Bei distalen GIST fand sich dieser Unterschied nicht. Zudem hatten proximal gelegene GIST mit Exon-11-Punktmutation eine bessere Prognose als distale. Die traf für GIST mit Exon-11-Deletion nicht zu. Dort unterschied sich die Prognose nicht nach Lokalisation. Nach den vorliegenden Daten kann der Rückschluss gezogen werden, dass bei der Gruppe der GIST mit Exon-11-Punktmutation die Lokalisation eine bedeutendere Rolle spielt, als bei den GIST mit Exon-11-Deletion.

Die CGH Untersuchung des untersuchten Kollektivs zeigte, dass Verluste auf den Chromosomen 14q, 22q, 1p und 15q die häufigsten Aberrationen waren. Zudem wurden vermehrt Zugewinn auf Chromosom 8p, 8q und 4q gefunden.

Insgesamt traten bei distalen GIST mehr chromosomale Aberrationen auf als bei proximalen. Dieser Unterschied konnte sich allerdings nur auf die Gruppe der GIST mit Exon11-Punktmutation übertragen. Dort wurden distal signifikant mehr Aberrationen festgestellt als bei proximalen. Bei der Gruppe der GIST mit Exon-11-Deletion fand sich dieser Unterschied interessanter Weise nicht. Die beiden Mutationsgruppen unterschieden sich jedoch nicht in der Anzahl der chromosomalen Aberrationen.

Im vorliegenden Kollektiv war der Verlust von 14q die häufigste beobachtete chromosomale Aberration, trat jedoch nicht häufiger bei proximalen als bei distalen GIST auf. Es gibt Hinweise, dass der Verlust von 14q eventuell mit GIST mit PDGFRA-Mutation im Magen assoziiert ist. Bei GIST mit Exon-11-Punktmutation bzw. Deletion scheint der 14q Verlust keine Assoziation mit der Lokalisation zu haben.

Der Verlust von 1p und 15q konnte unabhängig vom Mutationstyp gehäuft bei distalen GIST gefunden werden. Diese Beobachtung ließ sich bereits in anderen Studien machen. Der Verlust von 22q trat gehäuft auf, allerdings ohne Assoziation zu einer Mutation oder zu einer Lokalisation. 
Auffälligkeiten bei den Zugewinnen konnten auf zwei Chromosomen beobachtet werden. So hatten GIST mit Exon-11-Deletion signifikant mehr Zugewinne auf Chromosom 8, während GIST mit Exon-11-Punktmutation signifikant mehr Zugewinne auf Chromosom 4q verzeichneten. Bei der Gruppe der GIST mit Exon-11-Deletion hatte der Zugewinn auf Chromosom 8 keine Assoziation zur Lokalisation. Bei GIST mit Exon-11-Punktmutation kam der Zugewinn auf Chromosom 8 zwar verhältnismäßig seltener vor, hier allerdings signifikant gehäuft bei distalen GIST. Der Zugewinn auf Chromosom 8 ist mit einer schlechteren Prognose assoziiert und kann häufiger bei GIST mit Exon-11-Deletion gefunden werden. Seltener ist er bei GIST mit Exon-11-Punktmutation, hier dafür allerdings gehäuft in distal gelegenen GIST. Dies korreliert mit bisherigen Beobachtungen, dass GIST mit Exon11-Deletion und distale GIST mit Exon-11-Punktmutation mit einer ungünstigeren Prognose assoziiert sind. Dies spricht für das vorliegen noch zu identifizierender Gene auf Chromosom 8, die eventuell mit der Tumorgenes bzw. Tumorprogression von GIST im Zusammenhang stehen.

Das gehäufte Auftreten von Zugewinnen auf Chromosom 4q bei GIST ist ein seltenes Ereignis. Beim untersuchten Kollektiv konnte allerdings speziell bei GIST mit Exon-11Punktmutation ein gehäuftes Auftreten beobachtet werden. Eine Assoziation zur Lokalisation wurde allerdings nicht gefunden. 


\section{Literaturverzeichnis}

Andersson J, Sjogren H, Meis-Kindblom JM, Stenman G, Aman P, Kindblom LG (2002):

"The complexity of KIT gene mutations and chromosome rearrangements and their clinical correlation in gastrointestinal stromal (pacemaker cell) tumors." Am J Pathol $\underline{160}(1): 15-22$.

Andersson J, Sihto H, Meis-Kindblom JM, Joensuu H, Nupponen N, Kindblom LG (2005): "NF1-associated gastrointestinal stromal tumors have unique clinical, phenotypic, and genotypic characteristics." Am J Surg Pathol 29(9): 1170-1176.

Andersson J, Bumming P, Meis-Kindblom JM, Sihto H, Nupponen N, Joensuu H, Oden A, Gustavsson B, Kindblom LG, Nilsson B (2006): "Gastrointestinal stromal tumors with KIT exon 11 deletions are associated with poor prognosis." Gastroenterology 130(6): 1573-1581.

Antonescu CR (2006): "Gastrointestinal stromal tumor (GIST) pathogenesis, familial GIST, and animal models." Semin Diagn Pathol 23(2): 63-69.

Antonescu CR, Besmer P, Guo T, Arkun K, Hom G, Koryotowski B, Leversha MA, Jeffrey PD, Desantis D, Singer S, et al. (2005): Acquired resistance to imatinib in gastrointestinal stromal tumor occurs through secondary gene mutation. Clin Cancer Res $\underline{11}$, $4182-4190$

Appelman HD (1986): "Smooth muscle tumors of the gastrointestinal tract. What we know now that Stout didn't know." Am J Surg Pathol 10 Suppl 1: 83-99.

Ässämäki R, Sarlomo-Rikala M, Lopez-Guerrero JA, Lasota J, Andersson LC, LlombartBosch A, Miettinen M, Knuutila S (2007): "Array comparative genomic hybridization analysis of chromosomal imbalances and their target genes in gastrointestinal stromal tumors." Genes Chromosomes Cancer 46(6): 564-576.

Cajal SR (1893). Sur les ganglions et plexus nerveux de lìntestin. C R Soc Biol (Paris) $\underline{45}, 217$ $-223$.

Carney JA (1983): "The triad of gastric epithelioid leiomyosarcoma, pulmonary chondroma, and functioning extra-adrenal paraganglioma: a five-year review." Medicine (Baltimore) 62(3): 159-169.

Chan PM, Ilangumaran S, La Rose J, Chakrabartty A, Rottapel R (2003): "Autoinhibition of the kit receptor tyrosine kinase by the cytosolic juxtamembrane region." Mol Cell Biol 23(9): 3067-3078. 
Chen Y, Tzeng CC, Liou CP, Chang MY, Li CF, Lin CN (2004): Biological significance of chromosomal imbalance aberrations in gastrointestinal stromal tumors. J Biomed Sci $\underline{11}, 65-71$

Chetty R (2008): "Small and microscopically detected gastrointestinal stromal tumours: an overview." Pathology $\underline{40(1): ~ 9-12 . ~}$

Coindre JM, Terrier P, Bui NB, Bonichon F, Collin F, Le Doussal V, Mandard AM, Vilain MO, Jacquemier J, Duplay H, et al. (1996): "Prognostic factors in adult patients with locally controlled soft tissue sarcoma. A study of 546 patients from the French Federation of Cancer Centers Sarcoma Group." J Clin Oncol 14(3): 869-877.

Connolly EM, Gaffney E, Reynolds JV (2003): Gastrointestinal stromal tumours. Br J Surg 90, $1178-1186$

Corless CL, McGreevey L, Haley A, Town A, Heinrich MC (2002): "KIT mutations are common in incidental gastrointestinal stromal tumors one centimeter or less in size." Am J Pathol 160(5): 1567-1572.

Corless CL, Fletcher JA Heinrich MC (2004): "Biology of gastrointestinal stromal tumors." J Clin Oncol 22(18): 3813-3825.

Corless CL, Schroeder A, Griffith D, Town A, McGreevey L, Harrell P, Shiraga S, Bainbridge T, Morich J Heinrich MC (2005): "PDGFRA mutations in gastrointestinal stromal tumors: frequency, spectrum and in vitro sensitivity to imatinib." J Clin On$\operatorname{col} 2 \underline{23}(23): 5357-5364$.

Dei Tos AP (2003): "The reappraisal of gastrointestinal stromal tumors: from Stout to the KIT revolution." Virchows Arch 442(5): 421-428.

DeMatteo RP, Lewis JJ, Leung D, Mudan SS, Woodruff JM, Brennan MF (2000): "Two hundred gastrointestinal stromal tumors: recurrence patterns and prognostic factors for survival." Ann Surg 231(1): 51-58.

DeMatteo RP, Gold JS, Saran L, Gonen M, Liau KH, Maki RG, Singer S, Besmer P, Brennan MF, Antonescu CR (2008): "Tumor mitotic rate, size, and location independently predict recurrence after resection of primary gastrointestinal stromal tumor (GIST)." Cancer 112(3): 608-615.

Duensing A, Medeiros F, McConarty B, Joseph NE, Panigrahy D, Singer S, Fletcher CD, Demetri GD, Fletcher JA (2004): "Mechanisms of oncogenic KIT signal transduction in primary gastrointestinal stromal tumors (GISTs)." Oncogene 23(22): 39994006. 
El-Rifai W, Sarlomo-Rikala M, Miettinen M, Knuutila S, Andersson LC (1996): "DNA copy number losses in chromosome 14: an early change in gastrointestinal stromal tumors." Cancer Res $\underline{56}(14): 3230-3233$.

El-Rifai W, Sarlomo-Rikala M, Andersson LC, Knuutila S, Miettinen M (2000): "DNA sequence copy number changes in gastrointestinal stromal tumors: tumor progression and prognostic significance." Cancer Res 60(14): 3899-3903.

Erlandson RA, Klimstra DS, Woodruff JM (1996): "Subclassification of gastrointestinal stromal tumors based on evaluation by electron microscopy and immunohistochemistry." Ultrastruct Pathol 20(4): 373-393.

Faussone-Pellegrini MS, Thuneberg L (1999): "Guide to the identification of interstitial cells of Cajal." Microsc Res Tech $\underline{47(4): 248-266 .}$

Fletcher CD, Berman JJ, Corless C, Gorstein F, Lasota J, Longley BJ, Miettinen M, O'Leary TJ, Remotti H, Rubin BP, et al. (2002): "Diagnosis of gastrointestinal stromal tumors: A consensus approach." Hum Pathol 33 (5): 459-465.

Fletcher JA, Rubin BP (2007): "KIT mutations in GIST." Curr Opin Genet Dev 17(1): 3-7.

Franquemont DW, Frierson HF Jr. (1992): "Muscle differentiation and clinicopathologic features of gastrointestinal stromal tumors." Am J Surg Pathol 16(10): 947-954.

Füzesi L (2003). Gastrointestinal Stromal Tumour (GIST): Review of Pathology. Viszeralchirurgie $\underline{38}, 358-362$.

Golden T, Stout AP (1941). Smooth muscle tumors of the gastrointestinal tract and retroperitoneal tissues. Surg Gynecol Obstet $\underline{73}, 784$ - 810.

Gunawan B, Schulten HJ, von Heydebreck A, Schmidt B, Enders C, Hoer J, Langer C, Schuler P, Schindler CG, Kuhlgatz J, et al. (2004): Site-independent prognostic value of chromosome 9q loss in primary gastrointestinal stromal tumours. J Pathol 202, $421-429$

Gunawan B, von Heydebreck A, Sander B, Schulten HJ, Haller F, Langer C, Armbrust T, Bollmann M, Gasparov S, Kovac D, et al. (2007): "An oncogenetic tree model in gastrointestinal stromal tumours (GISTs) identifies different pathways of cytogenetic evolution with prognostic implications." J Pathol 211(4): 463-470.

Haller F: Molekularbiologische Evaluation prognostischer Parameter in Gastrointestinalen Stromatumoren (GIST). Med. Habil.-Schr. Göttingen 2008

Haller F, Lobke C, Ruschhaupt M, Schulten HJ, Schwager S, Gunawan B, Armbrust T, Langer C, Ramadori G, Sultmann H, et al. (2008): "Increased KIT signalling with up- 
regulation of cyclin D correlates to accelerated proliferation and shorter disease-free survival in gastrointestinal stromal tumours (GISTs) with KIT exon 11 deletions." J Pathol 216(2): 225-235.

Heinrich MC, Rubin BP, Longley BJ, Fletcher JA (2002): "Biology and genetic aspects of gastrointestinal stromal tumors: KIT activation and cytogenetic alterations." Hum Pathol $\underline{33}(5):$ 484-495.

Heinrich MC, Corless CL, Duensing A, McGreevey L, Chen CJ, Joseph N, Singer S, Griffith DJ, Haley A, Town A, et al. (2003a): "PDGFRA activating mutations in gastrointestinal stromal tumors." Science 299(5607): 708-710.

Heinrich MC, Corless CL, Demetri GD, Blanke CD, von Mehren M, Joensuu H, McGreevey LS, Chen CJ, Van den Abbeele AD, Druker BJ, et al. (2003b): "Kinase mutations and imatinib response in patients with metastatic gastrointestinal stromal tumor." J Clin Oncol 21(23): 4342-4349.

Hillemanns M, Hofler H (2000): "[Current classification of gastrointestinal stromal tumors]." Chirurg 71(11): 1327-1334.

Hirota S, Isozaki K, Moriyama Y, Hashimoto K, Nishida T, Ishiguro S, Kawano K, Hanada M, Kurata A, Takeda M, et al. (1998): "Gain-of-function mutations of c-kit in human gastrointestinal stromal tumors." Science 279(5350): 577-580.

Hirota S, Nishida T, Isozaki K, Taniguchi M, Nakamura J, Okazaki T, Kitamura Y (2001): "Gain-of-function mutation at the extracellular domain of KIT in gastrointestinal stromal tumours." J Pathol 193(4): 505-510.

Huizinga JD, Thuneberg L, Klüppel M, Malysz J, Mikkelsen HB, Bernstein A (1995). W/kit gene required for interstitial cells of Cajal and for intestinal pacemaker activity. Nature $\underline{373}, 347-349$.

Isola JJ, Kallioniemi OP, Chu LW, Fuqua SA, Hilsenbeck SG, Osborne CK, Waldman FM (1995): "Genetic aberrations detected by comparative genomic hybridization predict outcome in node-negative breast cancer." Am J Pathol 147(4): 905-911.

Isozaki K, Hirota S, Nakama A, Miyagawa J, Shinomura Y, Xu Z, Nomura S Kitamura Y (1995): "Disturbed intestinal movement, bile reflux to the stomach, and deficiency of c-kit-expressing cells in Ws/Ws mutant rats." Gastroenterology 109(2): 456-464.

Kallioniemi OP, Kallioniemi A, Piper J, Isola J, Waldman FM, Gray JW, Pinkel D (1994): Optimizing comparative genomic hybridization for analysis of DNA sequence copy number changes in solid tumors. Genes Chromosomes Cancer 10, 231-243 
Kawanowa K, Sakuma Y, Sakurai S, Hishima T, Iwasaki Y, Saito K, Hosoya Y, Nakajima T Funata N (2006): "High incidence of microscopic gastrointestinal stromal tumors in the stomach." Hum Pathol 37(12): 1527-1535.

Kay S, Still WJS (1969). A comparative electron microscopy study of a leiomyosarcoma and bizarre leiomyoma (leiomyoblastoma) of the stomach. Am J Clin Pathol 2, 403 413.

Kim NG, Kim JJ, Ahn JY, Seong CM, Noh SH, Kim CB, Min JS, Kim H (2000): "Putative chromosomal deletions on 9P, 9Q and 22Q occur preferentially in malignant gastro-

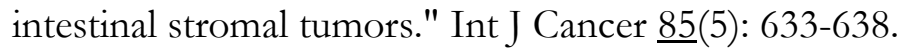

Kindblom LG, Remotti HE, Aldenborg F, Meis-Kindblom JM (1998): "Gastrointestinal pacemaker cell tumor (GIPACT): gastrointestinal stromal tumors show phenotypic characteristics of the interstitial cells of Cajal." Am J Pathol 152(5): 1259-1269.

Lasota J, Miettinen M (2008): "Clinical significance of oncogenic KIT and PDGFRA mutations in gastrointestinal stromal tumours." Histopathology $\underline{53}$ (3): 245-266.

Lasota J, Jasinski M, Sarlomo-Rikala M Miettinen M (1999): "Mutations in exon 11 of c-Kit occur preferentially in malignant versus benign gastrointestinal stromal tumors and do not occur in leiomyomas or leiomyosarcomas." Am J Pathol 154(1): 53-60.

Lasota J, Wozniak A, Kopczynski J, Dansonka-Mieszkowska A, Wasag B, Mitsuhashi T, Sarlomo-Rikala M, Lee JR, Schneider-Stock R, Stachura J, Limon J, Miettinen M (2005). Loss of heterozygosity on chromosome 22q in gastrointestinal stromal tumors (GISTs): a study on 50 cases. Lab Invest $\underline{\text { 85, }} 237$ - 247.

Lasota J, vel Dobosz AJ, Wasag B, Wozniak A, Kraszewska E, Michej W, Ptaszynski K, Rutkowski P, Sarlomo-Rikala M, Steigen SE, Schneider-Stock R, Stachura J, Chosia M, Ogun G, Ruka W, Siedlecki JA, Miettinen M(2007): "Presence of homozygous KIT exon 11 mutations is strongly associated with malignant clinical behavior in gas-

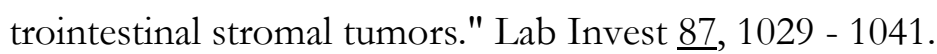

Lennartsson J, Jelacic T, Linnekin D, Shivakrupa R (2005): "Normal and oncogenic forms of the receptor tyrosine kinase kit." Stem Cells $\underline{23}(1): 16-43$.

Ma Y, Cunningham ME, Wang X, Ghosh I, Regan L, Longley BJ (1999). Inhibition of spontaneous receptor phosphorylation by residues in a putative alpha-helix in the KIT intracellular juxtamembrane region. J Biol Chem 274, 13399 - 13402. 
Maeda H, Yamagata A, Nishikawa S, Yoshinaga K, Kobayashi S, Nishi K, Nishikawa S (1992). Requirement of c-kit for development of intestinal pacemaker system. Development $\underline{116}, 369$ - 375 .

Martin J, Poveda A, Llombart-Bosch A, Ramos R, Lopez-Guerrero JA, Garcia del Muro J, Maurel J, Calabuig S, Gutierrez A, Gonzalez de Sande JL, et al. (2005): "Deletions affecting codons 557-558 of the c-KIT gene indicate a poor prognosis in patients with completely resected gastrointestinal stromal tumors: a study by the Spanish Group for Sarcoma Research (GEIS)." J Clin Oncol 23 (25): 6190-6198.

Mazur MT, Clark HB (1983): "Gastric stromal tumors. Reappraisal of histogenesis." Am J Surg Pathol 7(6): 507-519.

Mechtersheimer G, Lehnert T, Penzel R, Joos S, Egerer G Otto HF (2003): "[Gastrointestinal stromal tumors. A morphologic and molecular genetic independent tumor entity with new therapeutic perspectives]." Pathologe 24(3): 182-191.

Medeiros F, Corless CL, Duensing A, Hornick JL, Oliveira AM, Heinrich MC, Fletcher JA, Fletcher CD (2004): KIT-negative gastrointestinal stromal tumors: proof of concept and therapeutic implications. Am J Surg Pathol 28, 889-894

Melnick PJ (1932). Metastasizing leiomyoma of the stomach. Am J Cancer 16, 890 - 902.

Meza-Zepeda LA, Kresse SH, Barragan-Polania AH, Bjerkehagen B, Ohnstad HO, Namlos HM, Wang J, Kristiansen BE, Myklebost O (2006): "Array comparative genomic hybridization reveals distinct DNA copy number differences between gastrointestinal stromal tumors and leiomyosarcomas." Cancer Res $\underline{66}$ (18): 8984-8993.

Miettinen M, Lasota J (2006): "Gastrointestinal stromal tumors: review on morphology, molecular pathology, prognosis, and differential diagnosis." Arch Pathol Lab Med 130(10): 1466-1478.

Miettinen M, Virolainen M Maarit Sarlomo R (1995): "Gastrointestinal stromal tumors-value of CD34 antigen in their identification and separation from true leiomyomas and schwannomas." Am J Surg Pathol 19(2): 207-216.

Miettinen M, El-Rifai W, L HLS, Lasota J (2002): "Evaluation of malignancy and prognosis of gastrointestinal stromal tumors: a review." Hum Pathol 33(5): 478-483.

Miettinen M, Sobin LH, Lasota J (2005): "Gastrointestinal stromal tumors of the stomach: a clinicopathologic, immunohistochemical, and molecular genetic study of 1765 cases with long-term follow-up." Am J Surg Pathol 29(1): 52-68. 
Miettinen M, Makhlouf H, Sobin LH Lasota J (2006): "Gastrointestinal stromal tumors of the jejunum and ileum: a clinicopathologic, immunohistochemical, and molecular genetic study of 906 cases before imatinib with long-term follow-up." Am J Surg Pathol $\underline{30(4): ~ 477-489 . ~}$

Mitelman F (ed) (1995): ISCN (1995): An Inernational System for Human Cytogenetic Nomenclature. S.Karger, Basel

Mol CD, Dougan DR, Schneider TR, Skene RJ, Kraus ML, Scheibe DN, Snell GP, Zou H, Sang BC, Wilson KP (2004): "Structural basis for the autoinhibition and STI-571 inhibition of c-Kit tyrosine kinase." J Biol Chem 279(30): 31655-31663.

Ng EH, Pollock RE, Munsell MF, Atkinson EN, Romsdahl MM (1992): "Prognostic factors influencing survival in gastrointestinal leiomyosarcomas. Implications for surgical management and staging." Ann Surg 215(1): 68-77.

Nilsson B, Bumming P, Meis-Kindblom JM, Oden A, Dortok A, Gustavsson B, Sablinska K, Kindblom LG (2005): "Gastrointestinal stromal tumors: the incidence, prevalence, clinical course, and prognostication in the preimatinib mesylate era--a population-based study in western Sweden." Cancer 103(4): 821-829.

Prakash S, Sarran L, Socci N, DeMatteo RP, Eisenstat J, Greco AM, Maki RG, Wexler LH, LaQuaglia MP, Besmer P, et al. (2005): "Gastrointestinal stromal tumors in children and young adults: a clinicopathologic, molecular, and genomic study of 15 cases and review of the literature." J Pediatr Hematol Oncol 27(4): 179-187.

Robinson TL, Sircar K, Hewlett BR, Chorneyko K, Riddell RH, Huizinga JD (2000). Gastrointestinal stromal tumors may originate from a subset of CD34-positive interstitial cells of Cajal. Am J Pathol 156, 1157 - 1163.

Roskoski R, Jr. (2005a): "Signaling by Kit protein-tyrosine kinase--the stem cell factor receptor." Biochem Biophys Res Commun 337(1): 1-13.

Roskoski R, Jr. (2005b): "Structure and regulation of Kit protein-tyrosine kinase--the stem cell factor receptor." Biochem Biophys Res Commun 338(3): 1307-1315.

Rubin BP, Singer S, Tsao C, Duensing A, Lux ML, Ruiz R, Hibbard MK, Chen CJ, Xiao S, Tuveson DA, Demetri GD, Fletcher CD, Fletcher JA (2001). KIT activation is a ubiquitous feature of gastrointestinal stromal tumors. Cancer Res 61, 8118 8121.tumors. Cancer Res 61, 8118 - 8121. 
Rudolph P, Gloeckner K, Parwaresch R, Harms D Schmidt D (1998a): "Immunophenotype, proliferation, DNA ploidy, and biological behavior of gastrointestinal stromal tumors: a multivariate clinicopathologic study." Hum Pathol 29 (8): 791-800.

Rudolph P, Bonichon F, Gloeckner K, Collin F, Chassevent A, Schmidt D, Coindre JM, Parwaresch R Kloppel G (1998b): "Comparative analysis of prognostic indicators for sarcomas of the soft parts and the viscerae." Verh Dtsch Ges Pathol 2: 246-252.

Rutkowski P, Nowecki ZI, Michej W, Debiec-Rychter M, Wozniak A, Limon J, Siedlecki J, Grzesiakowska U, Kakol M, Osuch C, et al. (2007): "Risk criteria and prognostic factors for predicting recurrences after resection of primary gastrointestinal stromal tumor." Ann Surg Oncol 14(7): 2018-2027.

Sabah M, Cummins R, Leader M, Kay E (2004): "Loss of heterozygosity of chromosome 9p and loss of p16INK4A expression are associated with malignant gastrointestinal stromal tumors." Mod Pathol 17(11): 1364-1371.

Sarlomo-Rikala M, El-Rifai W, Lahtinen T, Andersson LC, Miettinen M, Knuutila S (1998): "Different patterns of DNA copy number changes in gastrointestinal stromal tumors, leiomyomas, and schwannomas." Hum Pathol 29 (5): 476-481.

Saul SH, Rast ML, Brooks JJ (1987): "The immunohistochemistry of gastrointestinal stromal tumors. Evidence supporting an origin from smooth muscle." Am J Surg Pathol 11(6): 464-473.

Singer S, Rubin BP, Lux ML, Chen CJ, Demetri GD, Fletcher CD, Fletcher JA (2002): "Prognostic value of KIT mutation type, mitotic activity, and histologic subtype in gastrointestinal stromal tumors." J Clin Oncol 20(18): 3898-3905.

Sircar K, Hewlett BR, Huizinga JD, Chorneyko K, Berezin I, Riddell RH (1999): Interstitial cells of Cajal as precursors of gastrointestinal stromal tumors. Am J Surg Pathol $\underline{23}$, $377-389$.

Stout AP (1962): "Bizarre smooth muscle tumors of the stomach." Cancer 15: 400-409.

Tabone S, Theou N, Wozniak A, Saffroy R, Deville L, Julie C, Callard P, Lavergne-Slove A, Debiec-Rychter M, Lemoine A, et al. (2005): "KIT overexpression and amplification in gastrointestinal stromal tumors (GISTs)." Biochim Biophys Acta 1741(1-2): 165172.

Tran T, Davila JA, El-Serag HB (2005): "The epidemiology of malignant gastrointestinal stromal tumors: an analysis of 1,458 cases from 1992 to 2000." Am J Gastroenterol $\underline{100}(1): 162-168$. 
Tryggvason G, Gislason HG, Magnusson MK, Jonasson JG (2005): "Gastrointestinal stromal tumors in Iceland, 1990-2003: the icelandic GIST study, a population-based incidence and pathologic risk stratification study." Int J Cancer 117(2): 289-293.

Wardelmann E, Losen I, Hans V, Neidt I, Speidel N, Bierhoff E, Heinicke T, Pietsch T, Buttner R Merkelbach-Bruse S (2003): "Deletion of Trp-557 and Lys-558 in the juxtamembrane domain of the c-kit protooncogene is associated with metastatic behavior of gastrointestinal stromal tumors." Int J Cancer 106(6): 887-895.

Wardelmann E, Buttner R, Merkelbach-Bruse S, Schildhaus HU (2007): "Mutation analysis of gastrointestinal stromal tumors: increasing significance for risk assessment and effective targeted therapy." Virchows Arch 451(4): 743-749.

Welsh RA, Meyer AT (1969): "Ultrastructure of gastric leiomyoma." Arch Pathol 87(1): 71 81.

Wozniak A, Sciot R, Guillou L, Pauwels P, Wasag B, Stul M, Vermeesch JR, Vandenberghe P, Limon J, Debiec-Rychter M (2007): "Array CGH analysis in primary gastrointestinal stromal tumors: cytogenetic profile correlates with anatomic site and tumor aggressiveness, irrespective of mutational status." Genes Chromosomes Cancer $\underline{46}(3)$ : 261-276. 